\title{
Dust Storm Satellite Images
}

\author{
Meshari Al-Obed, Sief Uddin, and Ashraf Ramadhan
}

\section{Abstract}

- DATA of Aerosol Robotic Network (Aeronet) stations and Ozone Monitoring Instrument (OMI) were obtained to get valuable and reliable information about the occurrence of dust events. In addition to Total Ozone Mapping Spectrometer (TOMS) provide informative and long dust events record.

- To analyze the dust time series, monthly, annual and seasonal linear trends are applied to the dust time series. This is achieved by summing the total number of dusty hours for each month and then the total number of dusty days for the month is calculated.

- Dust trend analysis includes; annual, winter, spring, summer and autumn with the rate of change.

- Dust frequency of seasons in days/season before and after sorting in a descending manner from 1984 to 2013.

- Satellite images use for PM2.5 Estimation and concentrations

- Remote sensing-based measurements

- Calibration of Field and Laboratory Equipment.

- Particle concentrations in different size ranges and the total suspended particulate matter in the air in Kuwait.

- Dust deposition rates were monitored and analyzed in Kuwait at the northern Arabian Gulf to estimate quantities of fallen dust within major eight dust trajectories in the Arabian Gulf.

- Kuwait is surrounded by five major sources of dust rather than intermediate dust source areas that are listed.

M. Al-Obed ( $\square)$

Meteorological Unit, Kuwait National Guard, P.O. Box: 17010

72451 Khaldiya, Kuwait

e-mail: Dr.Aeolian@gmail.com

S. Uddin · A. Ramadhan

Environmental Pollution and Climate Program (EPCP),

Environment and Life Sciences Research Center (ELSRC),

Kuwait Institute for Scientific Research (KISR), P.O. Box: 24885

13109 Safat, Kuwait
- Satellite images from 2000 to 2010 were used to identify major dust trajectories within seven major deserts in the world.

\section{Introduction}

Dust is a common phenomenon in Kuwait. Therefore, understanding dust is a significant step toward adapting control measures in the area to minimize its adverse socioeconomic effects. Dust, traveling long distances, is commonly very fine, with the predominant sizes being between $0.068 \mathrm{~mm}$ and $0.02 \mathrm{~mm}$ (Walker and Costin 1971). Significant quantities of dust may be blown thousands of kilometers from their source (Meng and Lu 2007; Al-Dabbas et al. 2011; Awadh 2012; Al-Awadhi and Al-Dousari 2013; Al-Dousari and Al-Hazza 2013), and it has been estimated that windblown dust derived from soil erosion contributes approximately $500 \times 106$ tons of particulate matter to the atmosphere each year (Peterson and Junge 1971). Northwesterly winds are prevalent in Kuwait, with $18 \mathrm{~km} / \mathrm{h}$ as the average wind speed (Al-Ghadban et al. 2008; Al-Dousari et al. 2017). Al-Dousari (2009) listed Kuwait as having one of the highest dust precipitation rates in the world. Safar (1980) states that the annual average number of dusty days of dust storms, or rising dust, or suspended dust in Kuwait is 255.4. Al-Dousari and Al-Awadhi (2012) identified five major sources of dust: (1) southwestern desert of Iraq; (2) the Mesopotamian Floodplain in Iraq; (3) the northeastern desert of Saudi Arabia; (4) the drained marshes (Ahwar) area in southern Iraq; and (5) sabkhas, dry marshes, and abandoned farms in Iran, especially in the northern coastal area of the Arabian Gulf (Fig. 1.1). This atlas covers the physical (particle size, particle surface area) and chemical (mineralogy, trace element percentages, and radionuclide contents) characteristics, as well as the pollen contents within 
deposited dust to identify its origin and to adapt to such common phenomena in the area, as well as to determine the distribution pattern of the dust fallout.

The dust fallout in Kuwait was monitored continuously to attain the following objectives:

- To assess the physical (morphometry of the grains) and chemical (trace elements percentages) characteristics of dust fallout to identify its origin.

- To identify the potential local sources and distribution pattern of the dust fallout in Kuwait.

- To test and environmentally evaluate many varieties of effective control measures.

- To identify the pollen distribution in dust samples.

- To establish a geographical information system (GIS) database on dust and pollen in Kuwait.
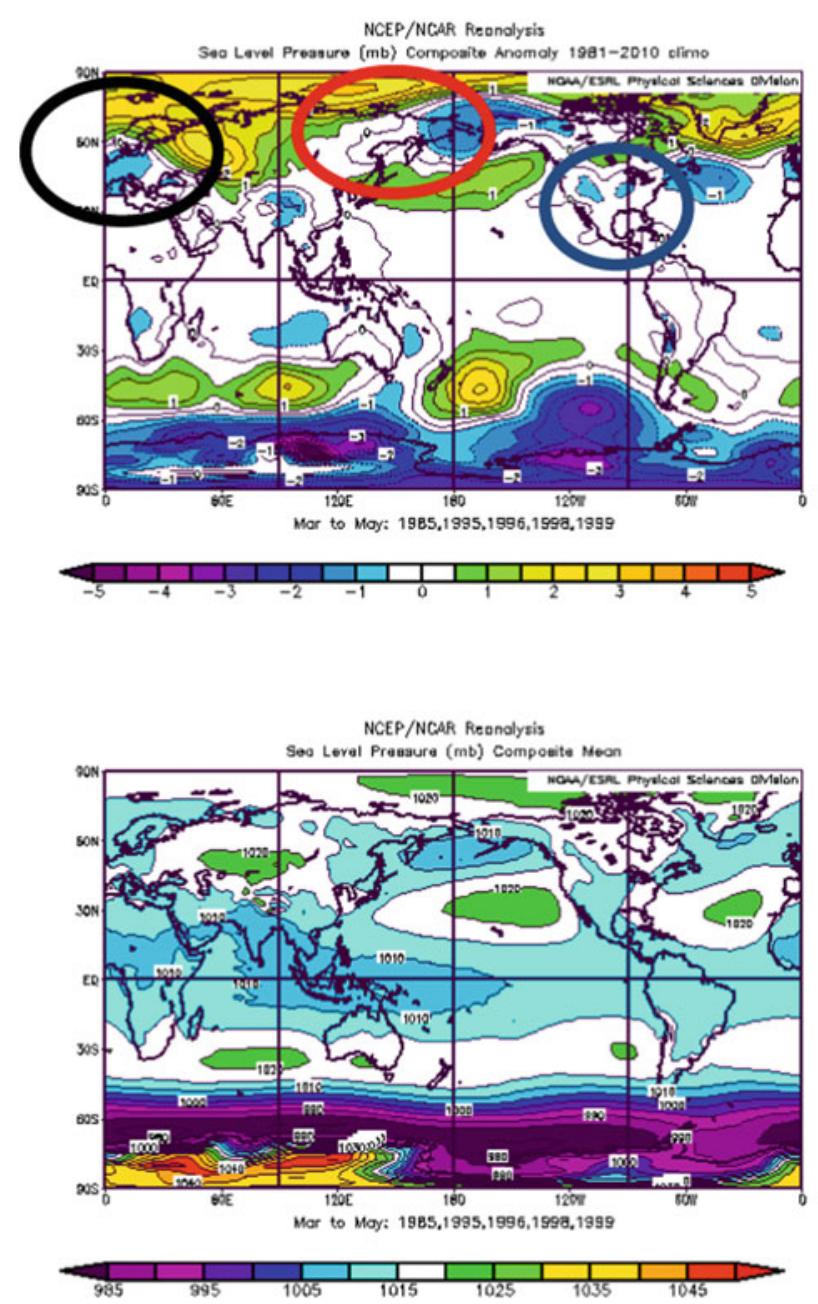

Fig. 1.1 Top left (bottom left) anomalies (mean) of sea level pressure during the minimum spring frequency; top right (bottom left) anomalies (mean) of sea level pressure during the maximum spring frequency.
The dust fallout in Kuwait was monitored, and the monthly dust fallout data were recorded. Then, samples were analyzed to study the fallout. Maps were generated to understand the dust fallout distribution, statistical parameters, mineralogy, etc.

\section{Data}

State-of-the-art instruments such as Aerosol Robotic Network (AERONET) stations and the Ozone Monitoring Instrument (OMI) can provide valuable and reliable information about the occurrence of dust events (Al-Dousari et al. 2018a). However, such instruments do not offer lengthy records as monitoring AERONET stations and OMIs have been installed and operational only since 2000. Other
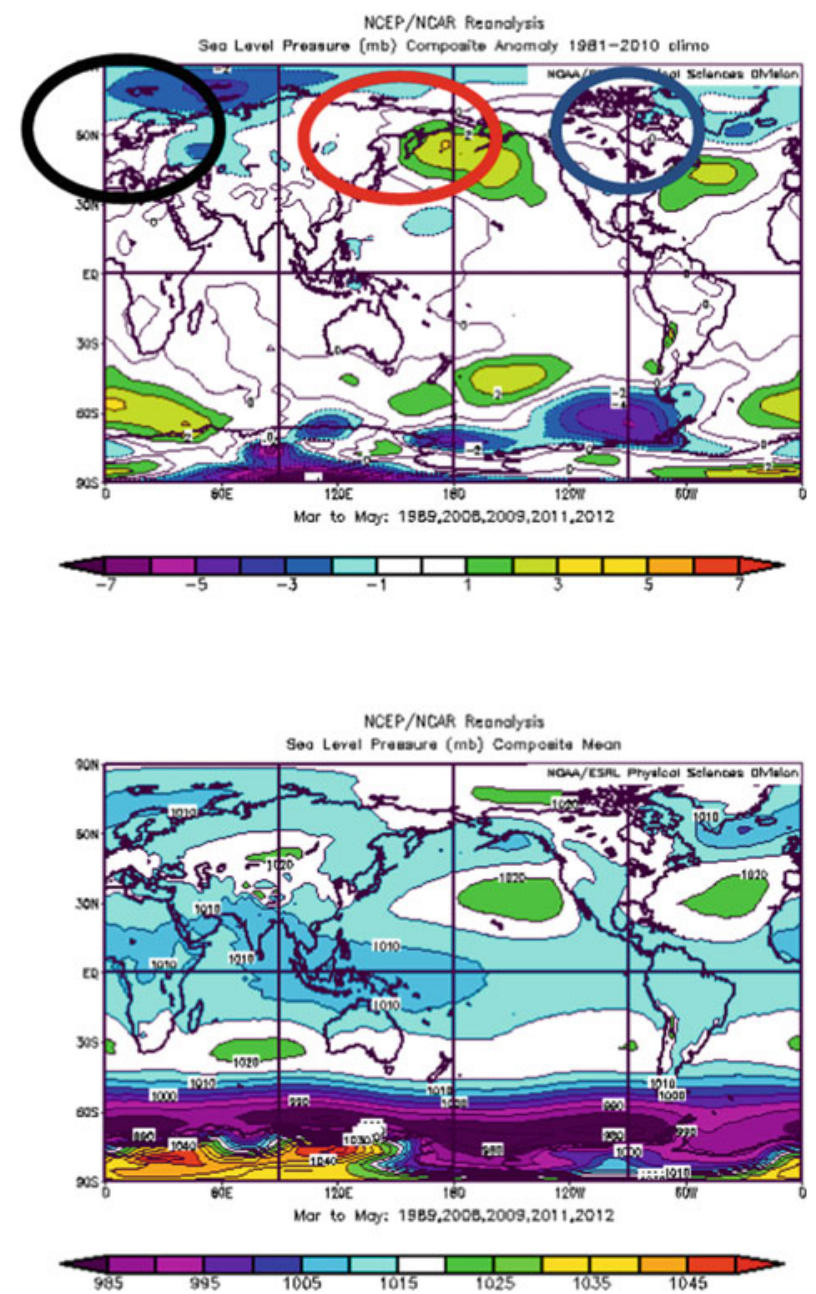

The images show also the areas of Aleutian low pressure, Azores high pressure, and the western flank of the Siberian high pressure, which are encircled in red, blue, and black, respectively 
Aerosol Optical Depth recorders, such as the Total Ozone Mapping Spectrometer (TOMS), provide informative and long dust-event records. Nevertheless, due to the limitations of remote sensing instruments, dust events within the planetary boundary layer cannot be easily detected (Prospero et al. 2002). In addition, the presence of cloud can obscure low-level dust detection. Therefore, 30 years of hourly climate data (recorded between 1983 and 2013) from the Kuwait International Airport weather station (WMO\# 40,582 located at $29.22 \mathrm{~N}, 047.96 \mathrm{E}$ ) were used to determine dust-event outbreaks in Kuwait. Within the climate data, a report summarizing the daily weather is included. This summary provides additional information about the occurrence of any weather phenomena, such as dust, haze, or fog. However, most of the daily reports are missing or inaccurate, especially prior to 2004 .

Therefore, in this study, dusty conditions are extrapolated from other climate variables, such as visibility, wind speed, and relative humidity $(\mathrm{RH})$. Certain criteria were selected to filter out hourly dust conditions: in Kuwait, the minimum wind speed required to lift dust is between 5.5 and $6 \mathrm{~m} / \mathrm{s}$ (Wilkerson 1991; Al-Dousari et al. 2018b). In this study, $7.7 \mathrm{~m} / \mathrm{s}$ is the minimum threshold for wind speeds. This wind speed is the minimum threshold for initiating sandstorms (Wilkerson 1991). Furthermore, RH during dust events ranges from 5 to $45 \%$ in the summer and winter, respectively (Al-Dousari et al. 2008). While there is no specific research for this region that states at what particular visibility range dust substantially influences life patterns, the authors, who have local knowledge of the area, conclude that dust events that reduce visibility ranges to less than $4 \mathrm{~km}$ affect life patterns. This distance is due to the local deposition of dust in the area, which can cause severe consequences for life patterns. Thus, only hours that recorded visibility less than and equal to $4 \mathrm{~km}, \mathrm{RH}$ less than and equal to $45 \%$, and wind speeds greater than $7.7 \mathrm{~m} / \mathrm{s}$ were selected for Kuwait dust storm frequency analysis.

\section{Methodology}

At least one dust event occurs every month in Kuwait. To analyze the dust time series, monthly, annual, and seasonal linear trends are applied. This approach is achieved by summing the total number of dusty hours for each month, and then the total number of dusty days for the month is calculated. For example, if the number of dusty hours in December 1990 is 240 , then $240 / 24=10$ dusty days for December. Then, the monthly, annual, and seasonal total numbers of dusty days are calculated. Subsequently, linear trends are fitted to each of the mentioned time series above to investigate any increase in Kuwait dust frequency. However, this research considers only slopes of linear trends that have $95 \%$ confidence interval and above. Boyles and Raman (2003) used the same method when analyzing climate trends in North Carolina.

After obtaining the time scales at which dust conditions have significantly changed over the period of study, the data from only significant time series were sorted in a descending manner. Subsequently, the top and bottom 15 th percentile of the selected time scale were chosen. Plots of global pressure anomalies for the selected period of maximum and minimum frequency were produced, which assisted with the investigation of any possible effect caused by the change in global pressure systems on Kuwait dust frequency. For example, if dust-event frequency has significantly increased in the spring season, then the top and bottom five years for the 30-year record of spring are selected. Then, the reanalysis plots of global pressure anomalies of the same years and season are obtained from NCEP/NCAR. The reanalysis plots of the five years that experienced the highest frequency and the five years that experienced the lowest frequency are compared and carefully examined to determine whether there is a possible relationship between any of the global climate indices and the dust frequency. After that, if a potential relationship is detected in the anomaly plots, the correlation between the Kuwait dust index and the selected pressure index is investigated (Table 1.1).

\section{Results and Discussion}

As is evident in the table above, only the spring dust trend is significant for the period of study (significant at 95\%). Other than that, dust frequency appears not to have changed in the past 30 years. Therefore, only the spring season data are sorted in a descending manner, and the top and bottom 15th percentiles were selected. The maximum and minimum
Table 1.1 Dust trend analysis results

\begin{tabular}{l|l|l|l}
\hline Timescale & Dust trends & Significance & Rate of change \\
\hline Annual & 9.77 & Not Significant & 0.039 days/years \\
\hline Winter & 0.68 & Not Significant & 0.007 days/season \\
\hline Spring & 1.1 & Significant at 95\% Confidence Interval & 0.075 days/season \\
\hline Summer & 0.69 & Not Significant & 0.0078 days/season \\
\hline Autumn & 1.1 & Not Significant & 0.075 days/season \\
\hline
\end{tabular}


Table 1.2 Dust frequency of the spring season in days/season before and after sorting in a descending manner

\begin{tabular}{|c|c|c|c|}
\hline Years & Days in spring season & Years & Days in spring season \\
\hline 1984 & 2.63 & 2012 & 6.71 \\
\hline 1985 & 0.38 & 1989 & 5.58 \\
\hline 1986 & 0.96 & 2008 & 5.29 \\
\hline 1987 & 2.67 & 2011 & 4.42 \\
\hline 1988 & 2.79 & 2009 & 3.92 \\
\hline 1989 & 5.58 & 2000 & 3.50 \\
\hline 1990 & 1.38 & 2003 & 3.50 \\
\hline 1991 & 1.25 & 2010 & 3.13 \\
\hline 1992 & 1.50 & 1988 & 2.79 \\
\hline 1993 & 1.50 & 2013 & 2.71 \\
\hline 1994 & 2.00 & 1987 & 2.67 \\
\hline 1995 & 0.29 & 1984 & 2.63 \\
\hline 1996 & 0.33 & 2007 & 2.33 \\
\hline 1997 & 0.96 & 1994 & 2.00 \\
\hline 1998 & 0.17 & 2006 & 1.54 \\
\hline 1999 & 0.92 & 1992 & 1.50 \\
\hline 2000 & 3.50 & 1993 & 1.50 \\
\hline 2001 & 1.08 & 1990 & 1.38 \\
\hline 2002 & 1.25 & 2005 & 1.38 \\
\hline 2003 & 3.50 & 1991 & 1.25 \\
\hline 2004 & 1.17 & 2002 & 1.25 \\
\hline 2005 & 1.38 & 2004 & 1.17 \\
\hline 2006 & 1.54 & 2001 & 1.08 \\
\hline 2007 & 2.33 & 1986 & 0.96 \\
\hline 2008 & 5.29 & 1997 & 0.96 \\
\hline 2009 & 3.92 & 1999 & 0.92 \\
\hline 2010 & 3.13 & 1985 & 0.38 \\
\hline 2011 & 4.42 & 1996 & 0.33 \\
\hline 2012 & 6.71 & 1995 & 0.29 \\
\hline 2013 & 2.71 & 1998 & 0.17 \\
\hline
\end{tabular}

frequencies of the spring season occurred in 1989, 2008, 2009, 2011, and 2012, and 1985, 1995, 1996, 1998, and 1999, respectively, as displayed in Table 1.2. A plot of global pressure anomalies for 1989, 2008, 2009, 2011, and 2012 is shown in the bottom left (mean pressure for the same period below it), and the plot of global pressure anomalies 1985, 1995, 1996, 1998, and 1999 is shown in the bottom right (mean pressure for the same period below it).

The global pressure anomaly plots reveal that the Azores high-pressure, Siberian high-pressure, and the Aleutian and Icelandic low-pressure systems behave in the opposite mode between the years of maximum and minimum spring season dust frequencies. During the peaks, positive anomalies are observed for the Aleutian low-pressure and Azores high-pressure areas. Meanwhile, negative anomalies were found for the western flank of the Siberian high-pressure and the Icelandic low-pressure areas. During the minimum, the anomalies of the previously mentioned systems are the opposite.

The spring dust frequency is correlated with the Azores high-pressure index, the Icelandic and Aleutian low-pressure indices, and the western flank of the Siberian high-pressure index. These correlation scores are not significant at lag $(0$, 1, 2, and 3) (not shown). Since the area between the latitudes of $30 *$ and $65^{*} \mathrm{~N}$ seems to be displaying different modes between the maximum and minimum spring dust frequencies, the NPI*, which covers the same area, is correlated with the dust index on different time scales. The NPI is significantly correlated (at $95 \%$ confidence interval) with dust frequency on an annual time scale, and the spring dust 
frequency is significantly correlated (at 95\% confidence interval) with the winter means NPI (see Table 1.3 for the correlations results).

As there is a possible influence of the NPI on Kuwait dust frequency, further investigation of this factor and regional dust frequency is needed. In addition, Trenberth and Hurrell, James and the National Center for Atmospheric Research Staff postulated that Pacific sea surface temperatures (SSTs), which govern the NPI area, are influenced by tropical SSTs. Thus, the relationship between Kuwait and regional dust frequency and the tropical SST and El Niño Southern Oscillation (ENSO) should be explored.

*As mentioned by Trenberth and Hurrell (1994), the NPI is the area-weighted sea level pressure over the region $30^{\circ} \mathrm{N}-$ $65^{\circ} \mathrm{N}, 160^{\circ} \mathrm{E}-140^{\circ} \mathrm{W}$. The NPI measures interannual to decadal variations in the atmospheric circulation. The dominant atmosphere-ocean relation in the North Pacific is one in which atmospheric changes lead to changes in SSTs by one to two months. However, strong ties exist with events in the tropical Pacific, with changes in tropical Pacific SSTs leading SSTs in the North Pacific by three months.

(https://climatedataguide.ucar.edu/climate-data/northpacific-np-index-trenberth-and-hurrell-monthly-and-winter).

\section{Satellite Images Use for $\mathbf{P M}_{2.5}$ Estimation}

Dust storm episodes are among the most critical weather phenomena in arid countries worldwide (Al-Awadhi 2005; Chi et al. 2008; Garrison et al. 2006). These episodes are caused by high-energy winds eroding the topsoil in regions with minimal vegetation cover. Kuwait and other countries
Table 1.3 On the left is the annual mean values of dust frequency in days and the North Pacific Index (NPI) with the correlation and t-test value; on the right is the correlation between winter mean NPI values and spring dust frequency values in days

\begin{tabular}{|c|c|c|c|c|c|}
\hline Year & NPI annual means & Annual dust freq. & Year & NPI winter means & Spring dust freq. \\
\hline 1984 & 1011.6 & 20.3 & 1984 & 1007.12 & 2.63 \\
\hline 1985 & 1014.2 & 13.1 & 1985 & 1008.33 & 0.38 \\
\hline 1986 & 1010.8 & 11.2 & 1986 & 1001.25 & 0.96 \\
\hline 1987 & 1010.9 & 17.0 & 1987 & 1003.22 & 2.67 \\
\hline 1988 & 1011.9 & 11.2 & 1988 & 1006.36 & 2.79 \\
\hline 1989 & 1014.6 & 23.0 & 1989 & 1011.80 & 5.58 \\
\hline 1990 & 1013.8 & 7.0 & 1990 & 1010.11 & 1.38 \\
\hline 1991 & 1012.3 & 6.0 & 1991 & 1007.45 & 1.25 \\
\hline 1992 & 1011.4 & 5.7 & 1992 & 1004.54 & 1.50 \\
\hline 1993 & 1012.2 & 5.6 & 1993 & 1008.79 & 1.50 \\
\hline 1994 & 1013.4 & 9.7 & 1994 & 1008.51 & 2.00 \\
\hline 1995 & 1011.5 & 3.6 & 1995 & 1004.73 & 0.29 \\
\hline 1996 & 1012.2 & 1.6 & 1996 & 1005.32 & 0.33 \\
\hline 1997 & 1011.5 & 9.5 & 1997 & 1005.36 & 0.96 \\
\hline 1998 & 1011.7 & 0.6 & 1998 & 1003.10 & 0.17 \\
\hline 1999 & 1013.2 & 4.1 & 1999 & 1008.74 & 0.92 \\
\hline 2000 & 1012.4 & 12.6 & 2000 & 1008.33 & 3.50 \\
\hline 2001 & 1011.9 & 4.2 & 2001 & 1004.90 & 1.08 \\
\hline 2002 & 1012.3 & 4.5 & 2002 & 1008.24 & 1.25 \\
\hline 2003 & 1011.9 & 11.8 & 2003 & 1003.45 & 3.50 \\
\hline 2004 & 1011.4 & 6.0 & 2004 & 1003.56 & 1.17 \\
\hline 2005 & 1012.1 & 9.2 & 2005 & 1007.10 & 1.38 \\
\hline 2006 & 1013.6 & 8.2 & 2006 & 1007.29 & 1.54 \\
\hline 2007 & 1011.8 & 7.9 & 2007 & 1007.21 & 2.33 \\
\hline 2008 & 1013.3 & 22.8 & 2008 & 1008.58 & 5.29 \\
\hline 2009 & 1014.2 & 16.6 & 2009 & 1013.04 & 3.92 \\
\hline 2010 & 1011.9 & 9.6 & 2010 & 1003.13 & 3.13 \\
\hline 2011 & 1013.2 & 18.7 & 2011 & 1010.83 & 4.42 \\
\hline 2012 & 1013.3 & 18.7 & 2012 & 1007.75 & 6.71 \\
\hline \multirow[t]{2}{*}{2013} & 1013.4 & 11.5 & 2013 & 1008.45 & 2.71 \\
\hline & $\mathrm{C}=0.38$ & 2.15 & & $\mathrm{C}=0.423$ & 2.475 \\
\hline
\end{tabular}


in the Middle East experience some of the worst dust storm episodes in the world. Kuwait is particularly susceptible to dust storms because of its low topography, scant vegetative cover, and strong, turbulent winds that occur mainly in the summer months (Al-Awadhi 2005; Ahmed and Al-Dousari 2013; Al-Awadhi et al. 2014). The rates of dust fallout in Kuwait have been reported as being among the highest in the world (Foda et al. 1985), with mean monthly concentrations as high as $1400 \mu \mathrm{g} \mathrm{m}^{-3}$.

It is possible to trace the origin of dust and its transport pathway from the nature of the particulate matter (PM). The frequency of dust activity can be related to long- and short-term climate changes (Prasad and Singh 2007). Climatic processes can also be affected by dust events (Boucher and Haywood 2001). Air temperatures, for example, may be altered by dust as a result of the scattering and absorption of solar radiation (Li et al. 1996; Moulin et al. 1997; Alpert et al. 1998; Miller and Tegen 1998; Goudie and Middleton 2001). Suspended dust modifies the short-wave solar radiation transmitted through to the earth and long-wave infrared radiation emitted into space (Goudie and Middleton 2001). Moreover, the size and type of aerosol have a major influence on radiation, in addition to cloud cover and surface albedo. Massive dust storms have been reported to result in the lowering of ocean temperatures, which may affect the primary productivity of seas and oceans (Pierson et al. 2003) and impact carbon dioxide sequestration (Ridgwell 2002). This study utilized satellite data to estimate atmospheric aerosol, especially $\mathrm{PM}_{2.5}$, which has been reported to have a significant effect on human health (Dockery et al. 1993; Pope and Dockery 2006; Pope et al. 2002) and on the regional and global climatic changes (Hansen et al. 1998; Hurtado et al. 1996; Ramanathan et al. 2007; Hu et al. 2010). Several reports have indicated that dust serves as a vehicle for the long-range transport of associated contaminants, including viruses (Griffin 2007; Reynolds and Pepper 2000; Williamson et al. 2003; Yates and Yates 1988), pathogens (Garrison et al. 2006; Griffin 2007; Griffin et al. 2002), trace metals (Di-Lella et al. 2006), and organic pollutants (Di-Lella et al. 2006; Gevao et al. 2011).

\section{Remote Sensing-Based Measurements}

Remote sensing measurements, by virtue of their synoptic monitoring capabilities, can be used to quantify dust on a large spatiotemporal scale. Currently, the Multiangle Imaging Spectro Radio Meter (MISR), which can determine AERONET's observations in desert regions (AOD) over land and ocean surfaces through observing visible and infrared wavelengths (King et al. 1992, 1999; Kaufman et al. 1997; Diner et al. 1998, 2002; Kahn et al. 1998, 2005a, b; Liu et al. 2004, 2005, 2007, 2009; Hu et al. 2010), was used. Images over
Kuwait and adjacent areas were procured from the National Aeronautics and Space Administration (NASA). The relationship between MISR AOD and surface $\mathrm{PM}_{2.5}$ was established. The $\mathrm{PM}_{2.5}$ data were correlated using in situ measurements at two calibration sites: one in Abdalli and the other at the KISR Shuwaikh. A high degree of correlation was observed between the MISR AOD and the $\mathrm{PM}_{2.5}$ estimates. However, the relationship is empirical due to the complicated dependence on multiple factors, including aerosol chemistry, particulate size distribution, aerosol profile, and, most importantly, the atmospheric conditions. The Moderate Resolution Imaging Spectroradiometer (MODIS) has fewer and poorer retrievals over Kuwait because of high surface albedo. However, with the Collection 6 data, the problem was solved, and now MODIS is a more useful sensor for PM retrieval. The satellite-based measurements used AOD as a quantitative measure of PM abundance in the atmospheric column. AOD is dominated by near-surface emission sources and can be used to track long-range dust transport pathways caused by a storm event (Seinfeld and Pandis 1998). AOD retrieved at visible wavelengths is sensitive to $0.1-2 \mu \mathrm{m}$ particle sizes (Kahn and Braverman 1998) and is not affected by gaseous co-pollutants, providing a noisy measurement of fine PM loading over large spatial areas.

The methodology proposed by Liu et al. (2004) for PM estimation using MISR data was used. The method demonstrates the validity of the MISR AOT with standard ground-level aerosol optical thickness (AOT) measurement from the AERONET. The sensitivity of the MISR AOT measurements from 0.05 to $2.0 \mu \mathrm{m}$ has also been reported (Kahn et al. 2001; Liu et al. 2005; Hu et al. 2010). Field validation of the $\mathrm{PM}_{2.5}$ retrievals from the satellite datasets was carried out at Abdalli and KISR's Shuwaikh campus on a weekly basis over the past 36 months. The samples were collected using a high-volume air sampler (HVAS) fitted with a six-stage cascade impactor. The metrological parameters, such as mixing height, RH, air temperature, and wind speed, which could affect $\mathrm{PM}_{2.5}$ retrievals using AOD, were also accounted for. The rapid update cycle (RUC) model of the Earth System Research (ERS) group was used to integrate the various metrological data sources.

The MISR's aerosol retrieval algorithms do not depend on explicit radiometric surface properties (Martonchik et al. 2004, 16,102-pp. 1-4, American Geophysical Union). Therefore, the MISR can retrieve aerosol properties over a variety of terrain conditions, including highly reflective surfaces such as found in Kuwait. Observing continuously at nine distinct zenith angles and in four narrow spectral bands centered at 446, 558, 672, and $866 \mathrm{~nm}$ The MISR repeats its measurements every 16 days in a tropical region. Version 22 MISR aerosol data were used, which have a spatial resolution of $17.6 \mathrm{~km}$. "In this dataset, there are 74 different aerosol mixtures that are constructed from up to three of the eight 


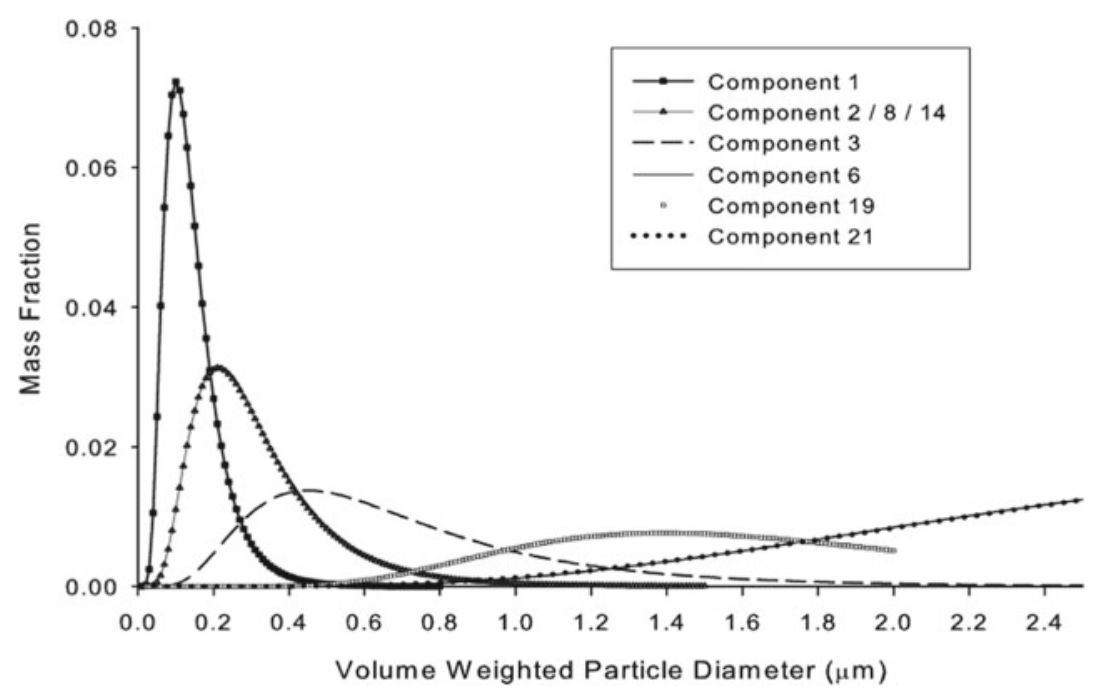

Note that Components 8 and 14 have the same mass distributions by size as Component 2, and the distributions of Components 6 and 21 are nearly identical in the plotted size range (Fig. 1.2).

Fig. 1.2 Mass size distribution for the MISR aerosol components ( source https://edg.larc.nasa.gov/)

pre-defined aerosol components (i.e., Components 1, 2, 3, 6, 8, 14, 19, and 21)" (Liu et al. 2009, IEEE, p. 177) (Fig. 1.2).

Each MISR aerosol component is defined by size distribution, shape, and single scattering albedo, of which two (Components 19 and 21) are designed for dust particles. "A detailed discussion of MISR data structure, the aerosol components used to construct the aerosol models and the percentage contribution of each component to total AOD as given elsewhere" (Liu et al. 2009, IEEE, 177). The MISR aerosol data covering Kuwait and the surrounding areas from 2008 to 2014 were processed. The data were downloaded from the NASA Langley Research Center (LARC) Atmospheric Sciences Data Center.

MISR AOD Validation in the Gulf Region. It has been demonstrated that MISR AOD compares well with AERONET's observations in desert regions (Martonchik et al. 2004). We conducted a more comprehensive validation of MISR AOD in the region. The following AERONET sites (Abu Al Bukhoosh, Bahrain, Abu Dhabi, Dhadnah, Hamim, Kuwait University, Mezaira, Mussafa, Solar Village) were identified in the study region with at least one year of operation time. These AERONET data were downloaded from the NASA Goddard Space Flight Center (https:// aeronet.gsfc.nasa.gov/). MISR AOD maps were generated for the area (Figs. 1.3 and 1.4).

\section{Sampling and Particulate Quantification}

The sampling campaign was initiated in April 2012. Sizesegregated aerosol samples were collected using a six-stage high-volume cascade impactor (Tisch Environmental, Inc) on the premises of the KISR $\left(29^{\circ} 20.227 \mathrm{~N} ; 47^{\circ} 54.208 \mathrm{E}\right)$ and Abdalli $\left(30^{\circ} 02.312 \mathrm{~N} ; 47^{\circ} 49.589 \mathrm{E}\right)$. The sampler was located about $2 \mathrm{~m}$ above the ground. Over each $24 \mathrm{~h}$ sampling period, approximately $815 \pm 5 \mathrm{~m}^{3}$ of air was drawn through the cascade impactor at a constant flow rate of 0.855 $\mathrm{m}^{3} / \mathrm{min}$ to trap various aerodynamic particles on different filters. The particles were separated into the aerodynamic diameter ( $\mathrm{Dp}$ ) size ranges, such as the following: $<0.39$ (backup high-volume filter), 0.39 to $0.69,0.69$ to $1.3,1.3$ to $2.1,2.1$ to $4.2,4.2$ to 10.2 , and $>10.2 \mu \mathrm{m}$. In addition to the weekly sampling, the samples were also collected on all dusty days to capture the spatiotemporal variations in the PM concentrations.

In addition to the in situ HVAS sampling, a noninvasive infrared (IR)-based measurement was conducted for both the particulate count and the particulate mass determination using a Metone AEROCET 531 particle mass profiler and counter, which takes hourly measurements and logs the data in the built-in data logger. 
Fig. 1.3 AOD map for the study area corresponding to 01 April 2008

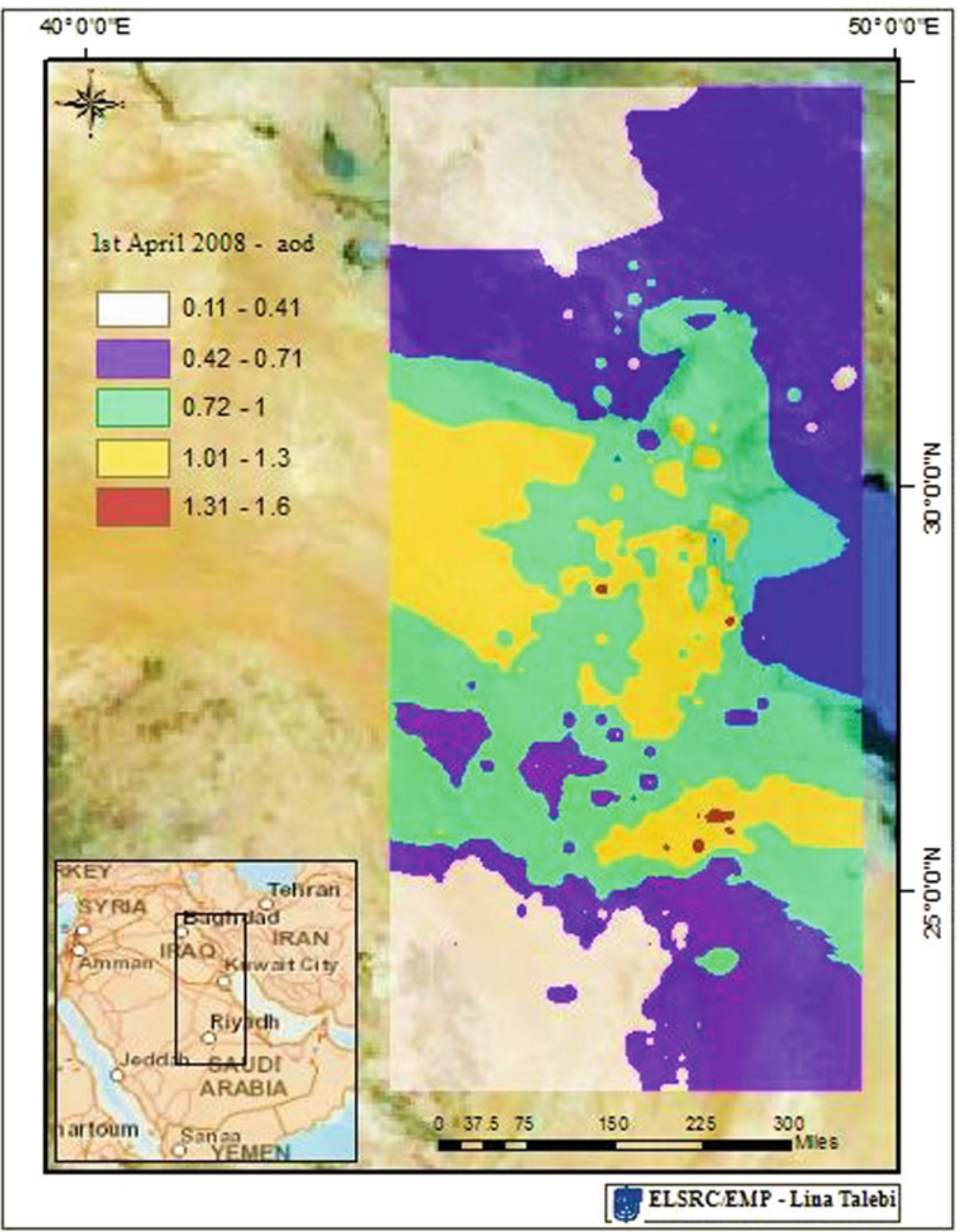

\section{Calibration of Field and Laboratory Equipment}

Air volumes for each sample collected were determined using a flowmeter with a flow tantalizer, in addition to a Magnehelic gauge (Tisch Environmental, Inc.). Calibrations were done in accordance with the manufacturer's guidelines. The calibrations were performed upon the installation of the sampler, and at least once every quarter.

\section{Model Development for $\mathrm{PM}_{2.5}$ Estimation}

Given the scarcity of ground-level $\mathrm{PM}_{2.5}$ measurements in the study region, a technique that can estimate regional $\mathrm{PM}_{2.5}$ concentrations without ground data support becomes an important tool. The MISR has eight aerosol components that are indicative of different contributions to ground-level $\mathrm{PM}_{2.5}$ concentrations: total MISR column AOD was 
Fig. 1.4 AOD map for the study area corresponding to 01 September 2008

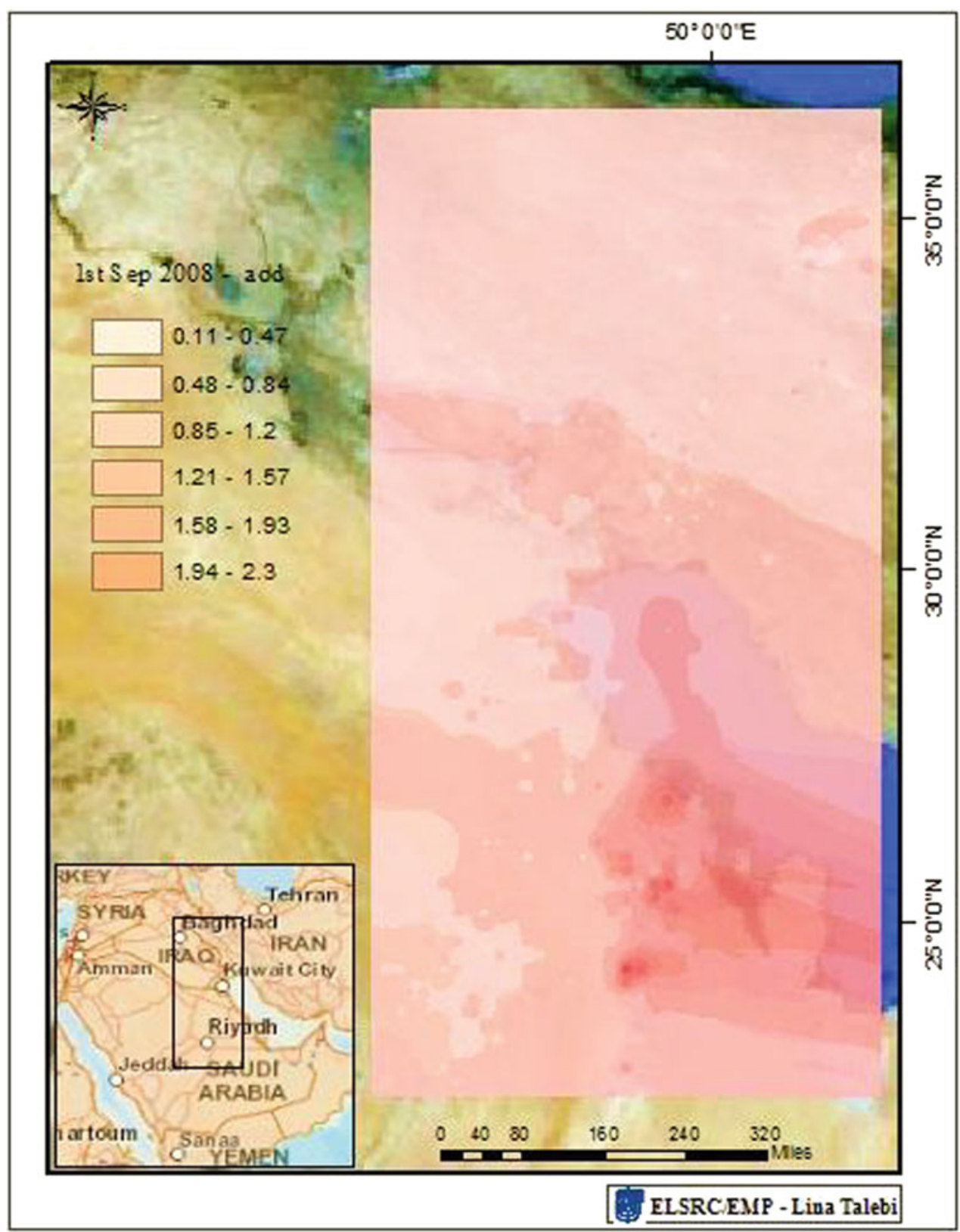

deconstructed into species-related fractions using the AOD value associated with, and the three aerosol components defined by, each of the 74 aerosol mixtures (Eq. 1.1). The fractional AOD of an MISR aerosol component is defined as the average contribution of this component to total AOD. For example, if the MISR does not observe the presence of any dust particles in a 17.6-km pixel, the fractional AODs for dust components (i.e., 19 and 21) would be zero. By definition, the sum of all the significant fractional AODs is equal to the total column AOD.
Fractional $\operatorname{AOD}_{i(i=1,8)}=\frac{\sum_{j=1}^{74} \mathrm{AOD}_{\text {mixture } \_j} \times \text { Fraction }_{\text {component i in mixture } \_j}}{\text { No. of Successful Mixtures }}$

Then, the simulated AOD and $\mathrm{PM}_{2.5}$ concentrations from the GEOS-Chem model were used to define a physically consistent relationship between AOD and surface level $\mathrm{PM}_{2.5}$ concentrations (Eq. 1.2). GC surface $\left[\mathrm{PM}_{2.5}\right]$ in Eq. 1.2 refers to the sum of GEOS-Chem fine particle species concentrations within $1 \mathrm{~km}$ from the surface, and GC 
column dust AOD refers to the sum of GEOS-Chem total AOD in all 35 layers. A similar analysis for dust particles was performed.

$$
\begin{array}{r}
{[\mathrm{PM} 2.5]=\frac{\text { GC Surface }[\mathrm{PM} 2.5]}{\text { GC Column AOD }} \times \text { MISR AOD }} \\
{[\text { Dust }]=\frac{\text { GC Surface }[\text { Dust }]}{\text { GC Column Dust AOD }} \times \text { MISR dust AOD }}
\end{array}
$$

This technique has been demonstrated previously using the early-version MISR and GEOS-Chem data in the United States (US) (Liu et al. 2004) and was successfully utilized in this present study. The annual MISR PM $_{2.5}$ concentrations exhibited an improved agreement with the ground measurements regarding the spatial pattern when compared with simulated $\mathrm{PM}_{2.5}$ concentrations. The annual average MISR $\mathrm{PM}_{2.5}$ concentrations had a good linear relationship with ground measurements $(r=0.69$, linear regression slope $=0.87)$, and the estimated intercept was insignificant $(p=0.81)$.

High-resolution spatial statistical models were developed using ground $\mathrm{PM}_{2.5}$ measurements from the two sites in the study region and Collection 6 MODIS 10-km AOD data. Given the limited ground data support (one site in Abdalli, KISR, and Wafra each), a linear mixed effects model was developed similar to, but more advanced. This random intercept, random slope model is expressed as follows:

$$
\begin{aligned}
{[\mathrm{PM} 2.5]_{i, j}=} & \left(\alpha+u_{j}\right)+\left(\beta_{1}+v_{j}\right) \\
& \times \operatorname{MODIS~AOD~}_{i, j}+\left(\beta_{2}+\omega_{j}\right) \\
& \times \operatorname{MODIS~AOD~}_{i, j-1}+\varepsilon_{i, j}
\end{aligned}
$$

where $[\mathrm{PM} 2.5]_{i, j}$ is the daily PM2.5 concentration at monitoring site $i$ on day $j$; MODIS $\operatorname{AOD}_{i, j}$ is the average of Collection 6 Terra and Aqua MODIS AOD in the $10 \mathrm{~km}$

$10 \mathrm{~km}$ grid cell corresponding to monitoring site $i$ on day $j$; $\alpha$ and $u_{j}$ are the fixed and random intercepts, respectively; $\beta_{1}$ and $v_{j}$ are the fixed and random slopes on same day AOD, respectively; $\beta_{2}$ and $\omega_{j}$ are the fixed and random slopes on previous day AOD, respectively; $\varepsilon_{i, j} \sim N\left(0, \sigma^{2}\right)$ is the error term at site $i$ and on day $j$. In this statistical model, the AOD fixed effect represents the average effect of AOD on PM2.5 for all study days. The AOD random effects explain the daily variability in the PM2.5-AOD relationship. Given the limited number of monitoring sites, a random intercept was not included for the site.

Since no previous studies have been conducted on desert regions, another statistical model format was explored. A generalized additive model (Liu et al. 2009) was tried also (Eq. 1.4):

$$
\mathrm{PM}_{2.5}=\mathrm{N}\left(\begin{array}{c}
\mu+f_{\mathrm{AOD}}(\mathrm{AOD})+f_{\mathrm{AOD} 2}\left(\mathrm{AOD}_{\mathrm{lag}}\right)+f_{\mathrm{RH}}(\mathrm{RH})+f_{\mathrm{TEMP}}(\mathrm{TEMP}) \\
+\beta_{1} \times \text { precip }+\beta_{2} \times \text { precip }_{\text {lag }}+\beta_{3} \times \text { weekend }
\end{array}\right)
$$

where all the covariates on the right-hand side of Eq. (1.3) are averaged spatially and, therefore, only vary with time; $\mu$ is the model intercept; $f_{\mathrm{AOD}}(\mathrm{AOD})$ is the smooth regression term describing the association between $\mathrm{AOD}$ and $\mathrm{PM}_{2.5}$; $f_{\mathrm{AOD} 2}\left(\mathrm{AOD} \_l a g\right)$ is the smooth regression term describing the association between mean AOD of the previous two days and $\mathrm{PM}_{2.5} ; \mathrm{f}_{\mathrm{RH}}(\mathrm{RH})$ and $f_{\mathrm{TEMP}}(\mathrm{TEMP})$ are smooth regression terms describing the impact of domain-averaged $\mathrm{RH}$ and surface air temperature (TEMP) on the AOD-PM 2.5 association, respectively. The inclusion of the lag AOD term reflects the fact that urban aerosol has a general lifetime of a few days without major scavenging events. Precipitation on a given day (precip) and precipitation on the previous day (precip_lag) are both modeled as a binary variable $(0=$ no rain, $1=$ rain). The weekend effect is reflected here as a binary variable (weekend $=1$ if Friday and Saturday, $=0$ otherwise).

The $\mathrm{PM}_{2.5}$ concentrations were estimated using the models developed (Fig. 1.5), which indicated a high correlation with the point measurements. The total suspended PM in each size fraction measured at the sampling site at the KISR between April and October 2012 are displayed in Fig. 1.6, whereas the time series plot of the total suspended particulate matter (TSP) over the same period is expressed in Fig. 1.7. A summary of the particle-size distribution for the entire study period, expressed as the average particle concentration in each size range, is in Fig. 1.8. The mean (and range) in TSP concentrations for the entire study period was $1400(140-8500) \mu \mathrm{g} / \mathrm{m}^{3}$. If the concentrations measured on the 6th of March are excluded, as this sample was collected during a major dust storm episode in Kuwait, the mean (and range) in TSP that is typical for this site would be 1040 (140-2750) $\mu \mathrm{g} / \mathrm{m}^{3}$. The TSP concentrations in this study were higher than those reported in Chicago $\left(27.7 \mu \mathrm{g} / \mathrm{m}^{3}\right)$ and Lake Michigan in the USA (Offenberg and Baker 1999); Mumbai (119-216 $\left.\mu \mathrm{g} / \mathrm{m}^{3}\right)$, (Venkataraman et al. 1999); rural Taiwan $\left(182-238 \mu \mathrm{g} / \mathrm{m}^{3}\right)$ (Wu et al. 2006); Thessaloniki in Greece $\left(243 \mu \mathrm{g} / \mathrm{m}^{3}\right)$ (Chrysikou et al. 2009); and in Hamilton, Ontario Canada $\left(58-121 \mu \mathrm{g} / \mathrm{m}^{3}\right.$ ) (Katz and Chan 1980). These high TSP values measured in Kuwait may be due, in part, to the fact that Kuwait is a desert country where high-energy winds often result in localized or regional dust storms. The rates of dust fallout in Kuwait have been reported as one of the highest in the world (Foda et al. 1985). The particle-size distribution was bimodal, with the major peak located in the $<0.63-\mu \mathrm{m}$ fraction, constituting about $85 \%$ (range 44-94\%) of the PM in the air. Another small but distinct peak occurred in the particle-size fraction $>10 \mu \mathrm{m}$. Particles smaller than $3.0 \mu \mathrm{m}$ are easily transported through the respiratory tract into the bronchioles and alveoli of the lungs and are, thus, a human health risk. 
Fig. 1.5 $\mathrm{PM}_{2.5}$ concentrations using satellite datasets

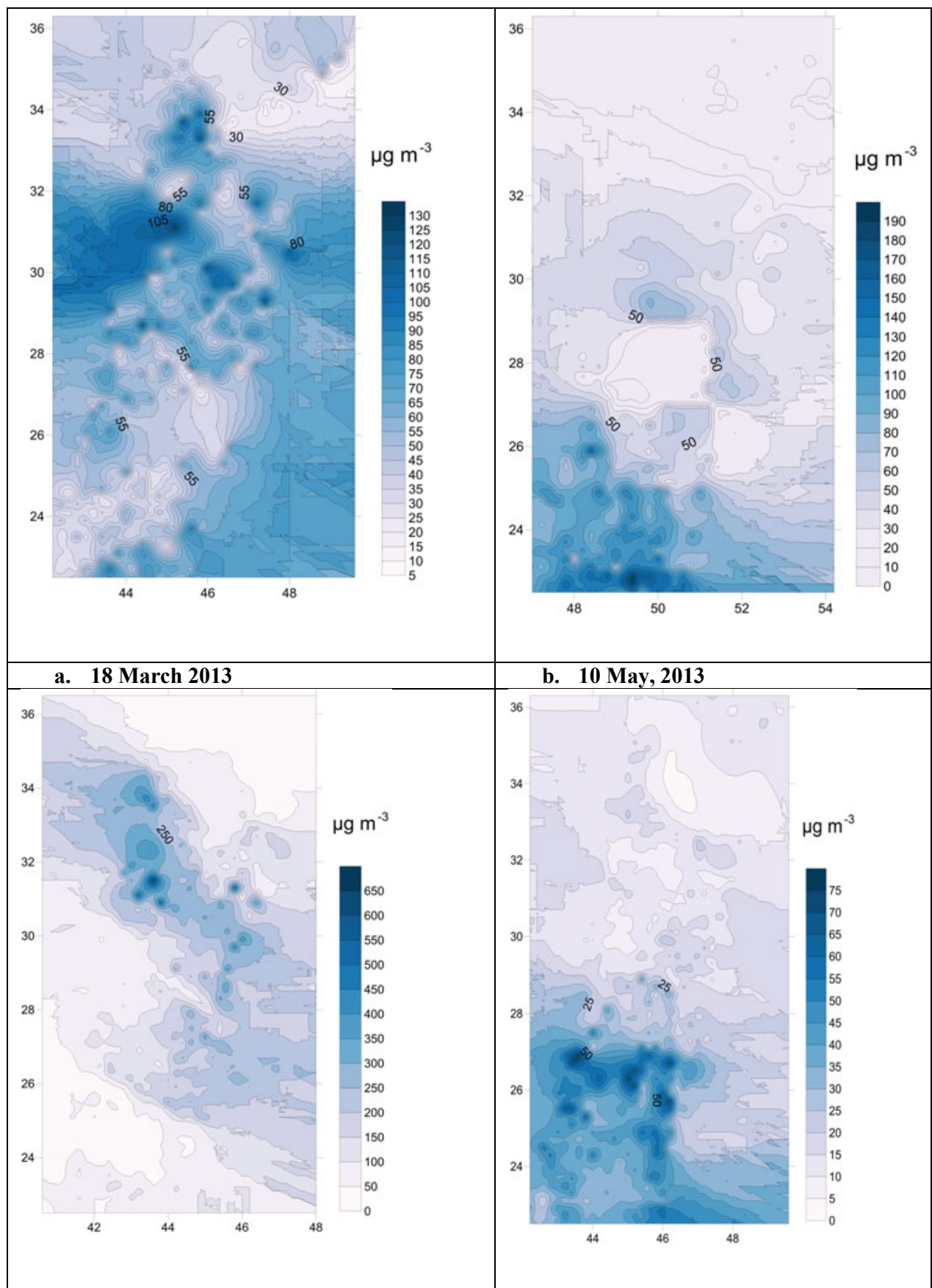

c. 18 June 2013

d. 18 November 2013
One of the most important indicators of air quality in most industrialized countries in the world, according to the World Health Organization (WHO), is the concentration of PM in the air (WHO 2005). These standards, however, often ignore the concentrations of toxic compounds, such as polycyclic aromatic hydrocarbons (PAHs), trace metals, and other contaminants, some of which are carcinogens, that are associated with these particles. This ignoring may be due to inadequate information on the concentrations of the associated contaminants that are required for risk assessments. Several studies have found that an inverse relationship exists between particle size and pollutant concentration (Lewis et al. 1999). The inhalable $(<10 \mu \mathrm{m})$ and respirable $(<2.5 \mu \mathrm{m})$ fractions of PM, which remain suspended in the air the longest, are thought to be the most essential fractions associated with respiratory illnesses. Many studies have linked long-term exposure to PM with adverse health effects, such as cardiovascular disease, chronic respiratory illnesses, 
Fig. 1.6 Atmospheric concentrations of particles in different impactor size range in the air at the KISR in Kuwait City between April and August 2012
Fig. 1.7 Total suspended particle concentrations in different impactor size ranges in the air at the KISR in Kuwait City between April and August 2012
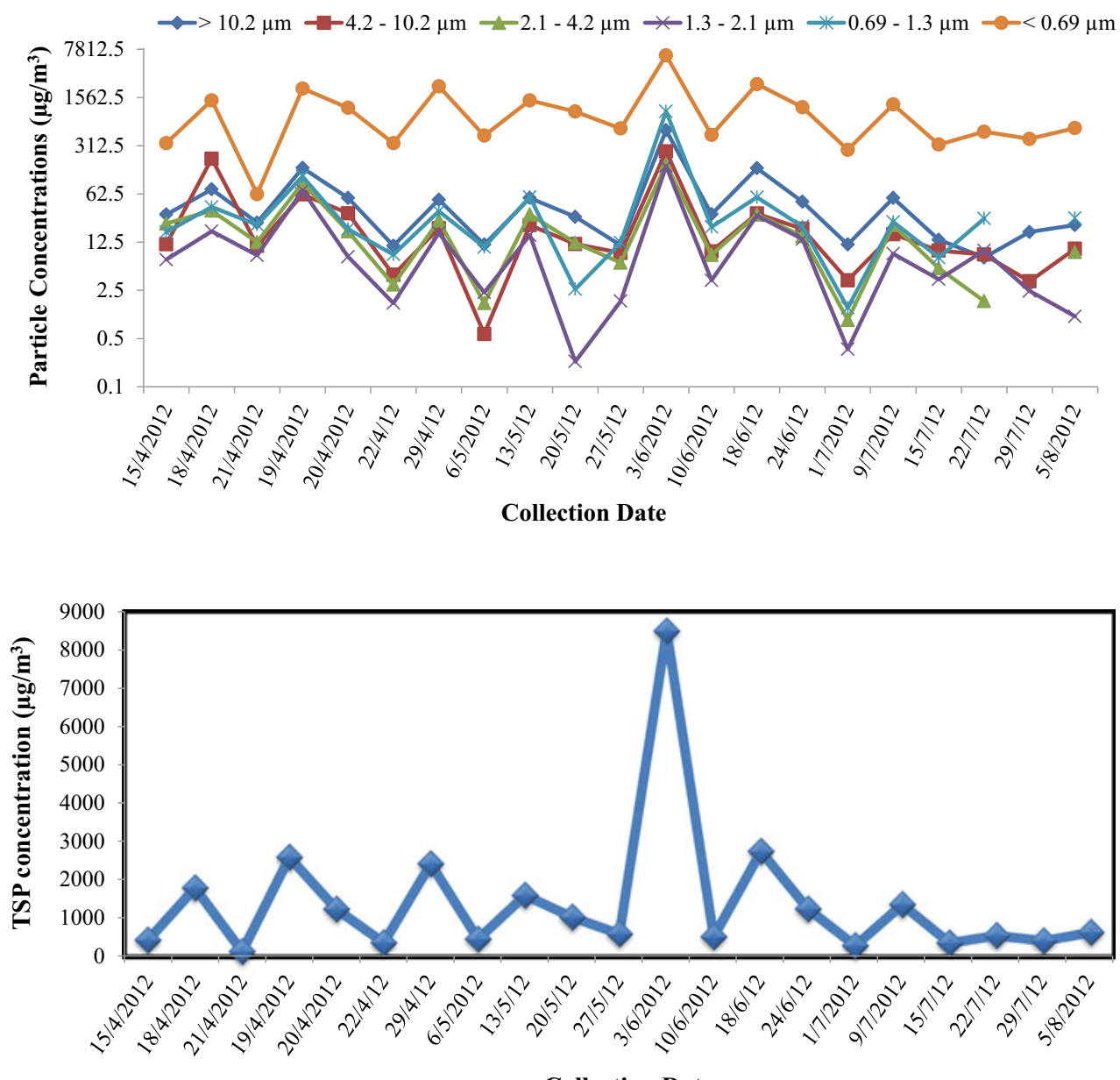

Collection Date

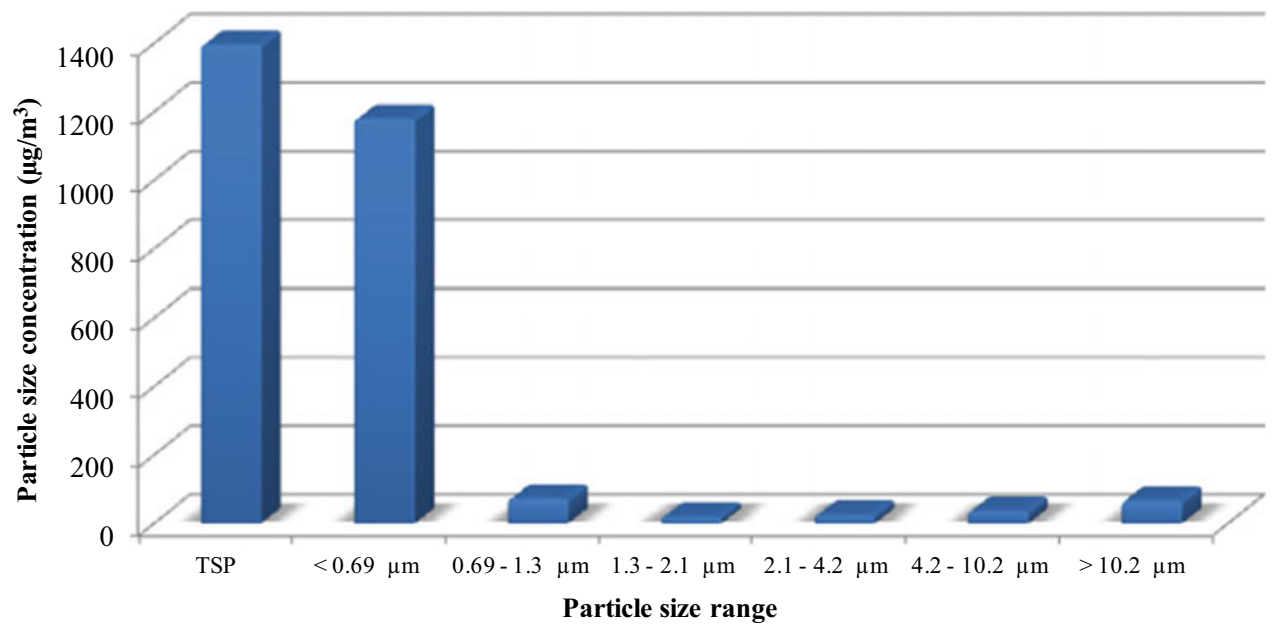

Fig. 1.8 Average particle concentrations in different size ranges and the TSP matter in the air at the KISR in Kuwait City between April and August 2012 and cancer. To comprehend better the risks posed by particle inhalation, it is important to understand the distribution of pollutants in various size fractions.

This study developed a basic model framework and setup that can be populated by continuous data collection using both an HVAS and an AEROCET particle counter. The accuracy of the MISR revealed a systematic underestimate, which, using additional data, can be integrated into the model. The calibration of Collection 6 for MODIS also provides an additional opportunity to use MODIS as a reliable satellite for PM estimation. The $\mathrm{PM}_{2.5}$ concentrations from the satellite images correlated well with the measured 
data, both from the IR mass and particle counter and the HVAS. The accuracy of the MISR determination was close to 68 and $62 \%$ for MODIS. There is currently a systematic underestimation of PM using both the MISR and the MODIS data, possibly due to very high backscatter. Nevertheless, these sensors provide a very reasonable estimate of $\mathrm{PM}_{2.5}$ concentrations on a large spatiotemporal scale.

\section{Dust Storm Trajectories}

Dust deposition rates were monitored and analyzed in Kuwait in the northern Arabian Gulf to estimate quantities of fallen dust within major dust trajectories in the Gulf. Eight major dust storm trajectories around the Gulf were detected using satellite images (2000-2010) and weather data. The Arabian Gulf receives about 120 tons. $\mathrm{km}^{2}$ annually of fallen dust. The amount of fallen dust from these major trajectories into the Gulf is estimated at 30 million tons. $\mathrm{yr}^{-1}$, by water volume. There are 4886 tons in each cubic kilometer. In comparison with other seas and oceans, the amount of dust deposited in the Gulf in reference to water body volume is the highest. The particle-size distribution of coastal dust is trimodal, with a dominance of coarse silt (19\%), medium silt $(18 \%)$, fine silt (16\%), and clay (21\%), with a minor amount of very coarse silt (9\%), very fine silt $(6 \%)$, and sand $(11 \%)$. Mineralogically, the dust is composed mainly of carbonates (41\%) and quartz (29\%), with an appreciable amount of feldspars (11\%). The mineralogical composition and particle surface area illustrate slight physical and mineralogical variations between dust fallout samples in the Arabian Gulf (Fig. 1.9).

\section{Dust Storms}

Kuwait is surrounded by major, rather than intermediate, dust source areas. In this study, these regional sources of dust were identified, and satellite-derived data were used to identify temporal and spatial variations in their emission intensities. These five major sources of dust are1.10:

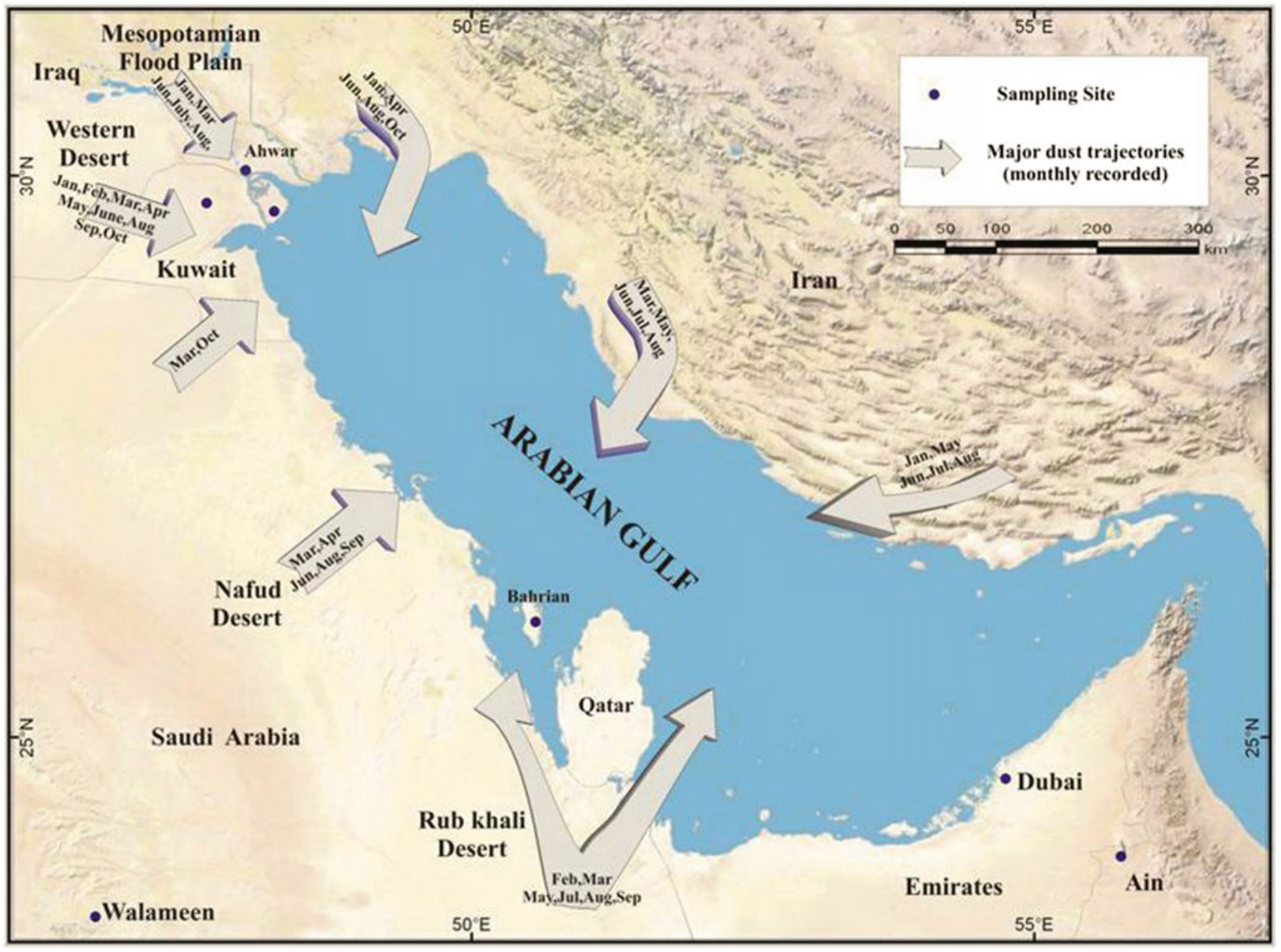

Fig. 1.9 Directions and timing of major dust trajectories with sampling sites in the Arabian Gulf 
Fig. 1.10 Major and intermediate source areas of dust storms and trajectories for the northwestern areas of the Arabian Gulf, including the study area in reference to dust storm days in Kuwait and satellite images from 2000 to 2010

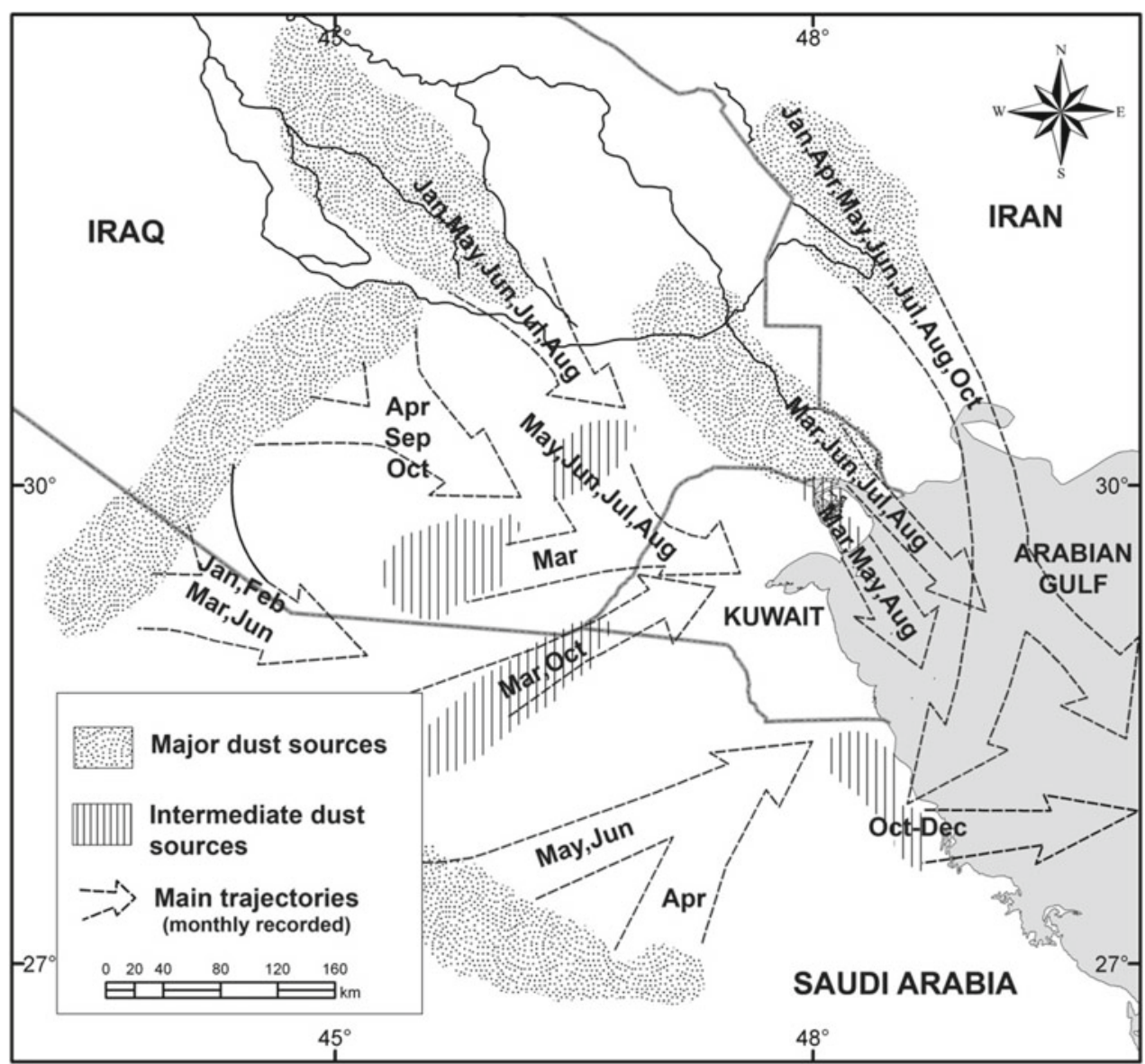

1. Southwestern desert of Iraq;

2. The Mesopotamian Floodplain in Iraq;

3. Northeastern desert of Saudi Arabia;

4. Drained marshes (Ahwar) area in southern Iraq;

5. Sabkhas, dry marshes, and abandoned farms in Iran at the northern coastal area of Arabian Gulf .

Furthermore, four intermediate sources of dust storm trajectories (covering areas of less than $3000 \mathrm{~km}^{2}$ ) were identified as follows:

1. Bubiyan and Warba islands (sabkhas) in Kuwait;

2. The drainage systems in the tri-border area between Kuwait, Saudi Arabia, and Iraq;

3. The playas and drainage basins in the southwestern desert of Iraq close to Kuwait;

4. The coastal sabkha in Saudi Arabia, near southern Kuwaiti borders.

\section{Dust Zone Areas}

Satellite images from 2000 to 2010 were used to identify major dust trajectories in seven major deserts worldwide. The fallen dust from these trajectories was collected and analyzed. Fallen dust rates tend to be lower downwind. The average samples of the world's fallen dust are negatively skewed, trimodal, and with a dominance of silt size fractions $(61 \%)$. Most of the fallen dust within major dust trajectories is fining downwind. The fallen dust from the eastern zones (Taklimakan, Gobi, and Australian deserts) are characterized by higher percentages of feldspars and clay minerals, and low carbonate content and grain surface area in comparison with the western zones (Sahara and Arabian deserts). The Western Sahara Desert dust has the highest depositional rates and average quartz percentage $(66 \%)$. The dust samples in this zone contain low carbonates and grain surface area 


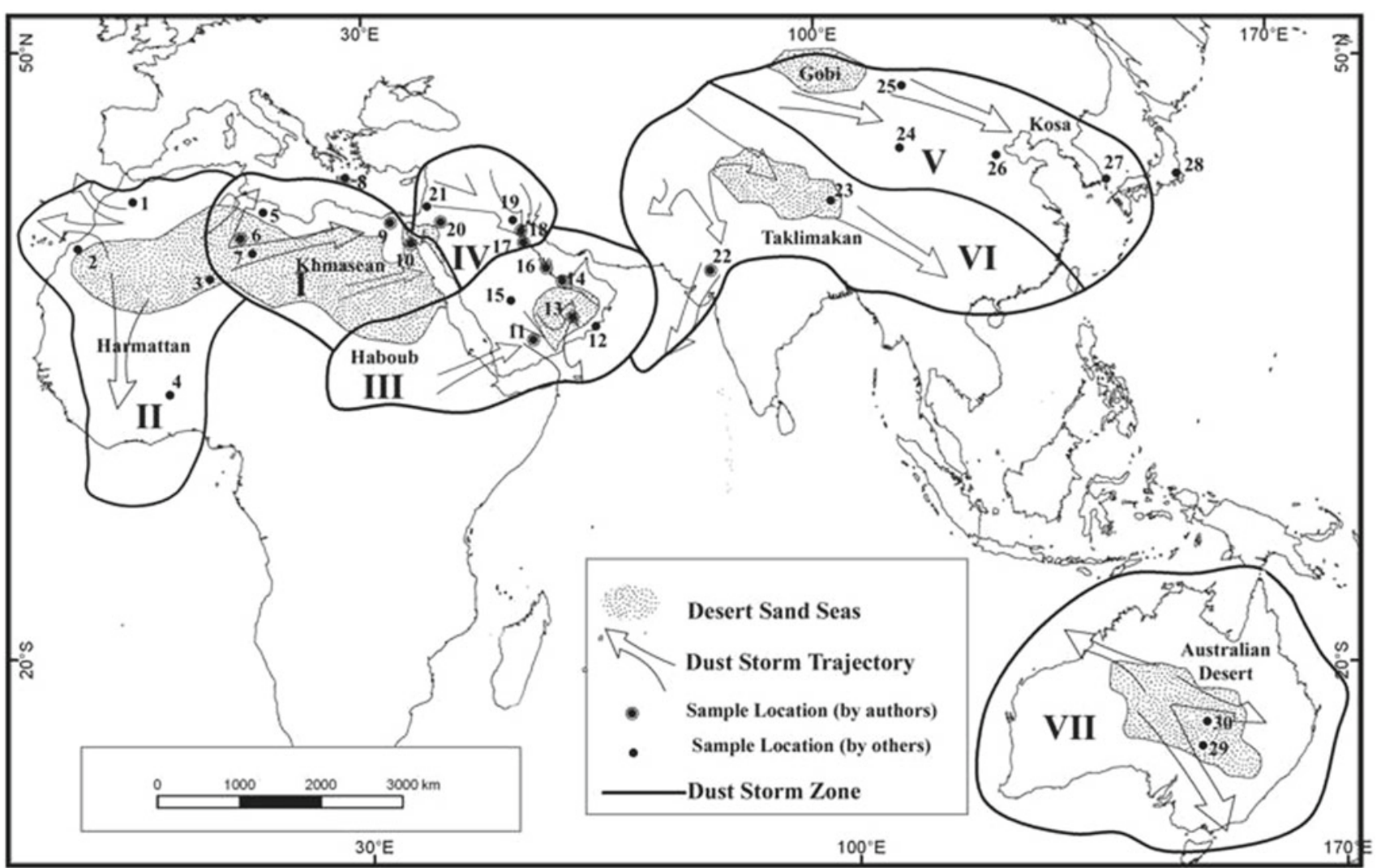

Fig. 1.11 Major dust storm trajectories within the seven zones, showing the desert sand seas, major dust trajectories, and sample locations. (1: Sous Masa, 2: Biougra, 3: Diarnena, 4: Bawku, 5: Tripoli, 6 \& 7 south Tripoli, 8: Crete, 9: Cairo, 10: Hurghada, 11: Wadi

when compared with dust from the Eastern Sahara Desert. The dust samples within the Northern Arabia and the Ethiopian-South Arabia zones contain the highest average amounts of carbonate and grain surface area (Fig. 1.11).

\section{Satellite Images}

An exotic occasion of the coalition of two dust storms to form a bidirectional dust storm, one blowing from northern Arabia and the Western Desert of Iraq toward Kuwait, and the second from the southern Mesopotamian Floodplain toward the Arabian Gulf on the 11th of February 2009. These types of dust storm trajectories take a wider form, with the area covered by the storm being more than $3000 \mathrm{~km}^{2}$. The northwestern dust storm has large trajectories that normally blow in January, February, March, April, June, September, and October. Furthermore, moderate dust storm trajectories that cover an area less than $3000 \mathrm{~km}^{2}$ are familiar in March, May, June, July, and August. In the northwesterly trajectories, fallen dust is brighter in color,
Dawasir, 12: Fahal, 13: Ain, 14: Dubai, 15: Riyadh, 16: Manama, 17 and 18: Kuwait, 19: Um Qasr, 20: Amman, 21: Dead Sea, 22: Lahore, 23: Taklimakan, 24: Ejin, 25: Shapotou, 26: Beijing, 27: Andong, 28: Tokyo, 29 and 30: Bald Hill)

coarser in size fraction, with more sand particles (diameter ranges between 0.063 and $2 \mathrm{~mm}$ ), contains more quartz and feldspars, but has fewer carbonates and clay minerals, lower particle surface area, and less iron and organic matter in comparison with trajectories from the Iranian side and the Mesopotamian Floodplain. On the other hand, dust from the northern and northeastern trajectories is finer, darker in color, contains less quartz and feldspars, is higher content in carbonates, heavy and clay minerals, is lower in surface area, and provides more organic matter compared with other trajectories around Kuwait. These dust storm trajectories normally occur in January, April, May, June, July, August, and, rarely, in February. The following weather data were recorded for 11th February 2009 (Fig. 1.12):

- Heavy cloud covers obscured the area of concern.

- The prevailing wind direction: northwest, west-northwest, west.

- The northwest, west-northwest, and west wind directions represent $21.4 \%, 41.7 \%$, and $22.4 \%$, respectively, of the total hourly wind count for that day. 


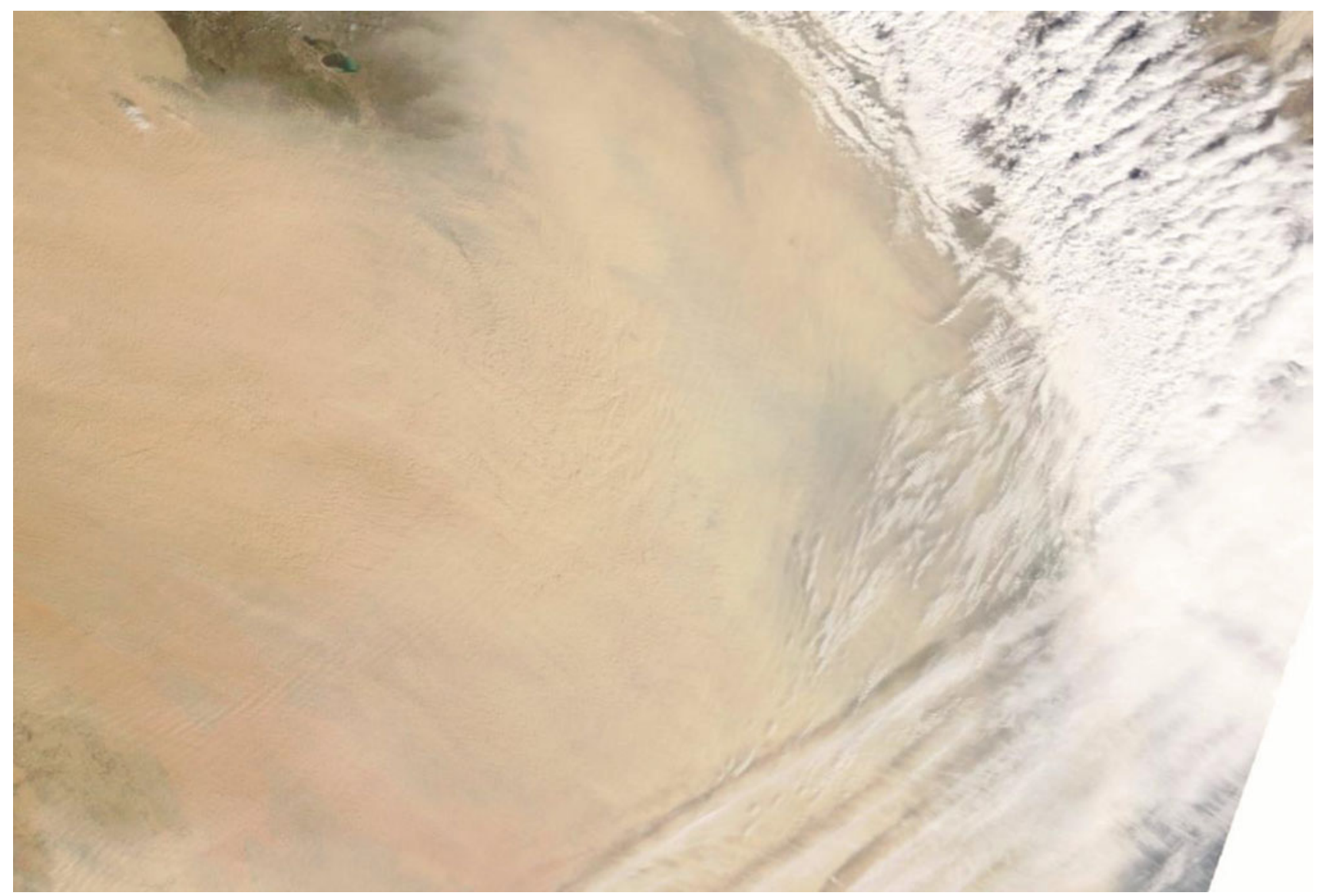

Fig. 1.12 MODIS image of dust storm that originated from the Western Desert of Iraq, covering southern Iraq, Kuwait, and northern Arabian Gulf on 11th February 2009

\section{Satellite Images}

The southeast, east-southeast, and east wind directions unidirectional dust storm blowing toward northeastern Arabia, including Kuwait and the northern Arabian Gulf on the 17th February 2009 from intermediate dust sources. This type of dust storm trajectory has moderate wind speed and forms in source areas with a short distance, is covered by a trajectory that is less than $3000 \mathrm{~km}^{2}$ in size, and the level of suspended dust particles is not as dense as in storms from the Arabian deserts. This type of dust storm trajectory normally blows in March, April, May, June, and October. The fallen dust from this type of trajectory is deposited more quickly than normal as it contains more quartz and feldspars but fewer carbonates and clay minerals, has a lower particle surface area, and lower iron and organic matter content that is brighter and coarser in size fraction, and sand particles are more than in trajectories from the Mesopotamian Floodplain. The following weather data were recorded for 17th February 2009 (Fig. 1.13):
- Heavy cloud cover obscured the area of concern.

- Prevailing wind direction: southeast, east-southeast, east, with a strong northwest component.

- The southeast, east-southeast, east wind directions represent $15.6 \%, 13.5 \%$, and $12.0 \%$, respectively, of the total hourly wind count for that day. The northwest component represented $16.7 \%$.

\section{Satellite Images}

Tridirectional dust storm: northwest, west-northwest, and west wind directions toward Kuwait from Western Desert of Iraq on 28th February 2009 toward the Arabian Gulf. This type of storm takes the broad form of dust storm trajectories in which the area covered is more than $3000 \mathrm{~km}^{2}$. This form is also associated with storm clouds. The northwest, northwest-west, and west dust storm large trajectories normally blow in January, February, March, April, June, September, and October. Furthermore, intermediate dust 


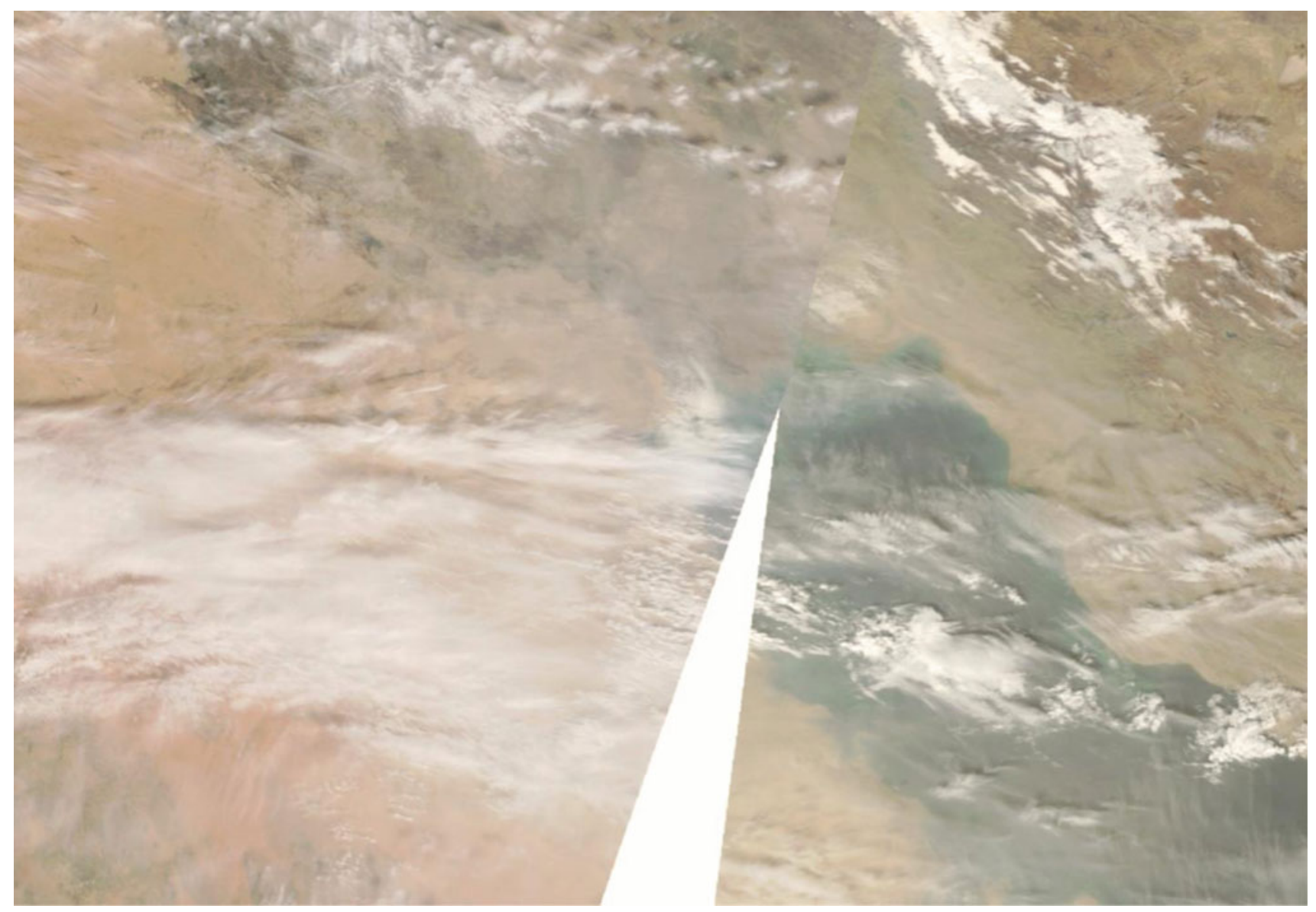

Fig. 1.13 MODIS image of dust storm that originated from the Western Desert of Iraq, covering southern Iraq, Kuwait and northern Arabian Gulf on 17th February 2009

storm trajectories are familiar in March, May, June, July, and August. With the northwesterly trajectories, fallen dust is brighter in color, coarser in mean size fraction sand particles (diameter more than $0.063 \mathrm{~mm}$ ), and contains more quartz and feldspars, but has fewer carbonates and clay minerals, a lower particle surface area, and less iron and organic matter than trajectories from the Mesopotamian Floodplain. The following weather data were recorded on 28th February 2009 (Fig. 1.14):

- Heavy cloud cover obscured the area of concern.

- The local prevailing wind direction: northwest, west-northwest, west.

- The northwest, west-northwest, and west wind directions represent $32.1 \%, 35.1 \%$, and $14.9 \%$, respectively, of the total hourly wind count for that day.

\section{Satellite Images}

A unidirectional dust storm blew from northern Arabia and the Western Desert of Iraq toward Kuwait on 2nd March 2009. This type of dust storm trajectory takes a wider form, covering an area of $3000 \mathrm{~km}^{2}$, but sometimes it occurs on a smaller scale and is seasonally known as Subag Sarayat, which extends from early March until the 28th April. The large trajectories of the northwestern dust storm normally blow in January, February, March, April, June, September, and October. Furthermore, moderate dust storm trajectories that cover an area of less than $3000 \mathrm{~km}^{2}$ are familiar in March, May, June, July, and August. Fallen dust of the northwesterly trajectories is brighter in color and coarser in size fraction, with more sand particles, more quartz and 


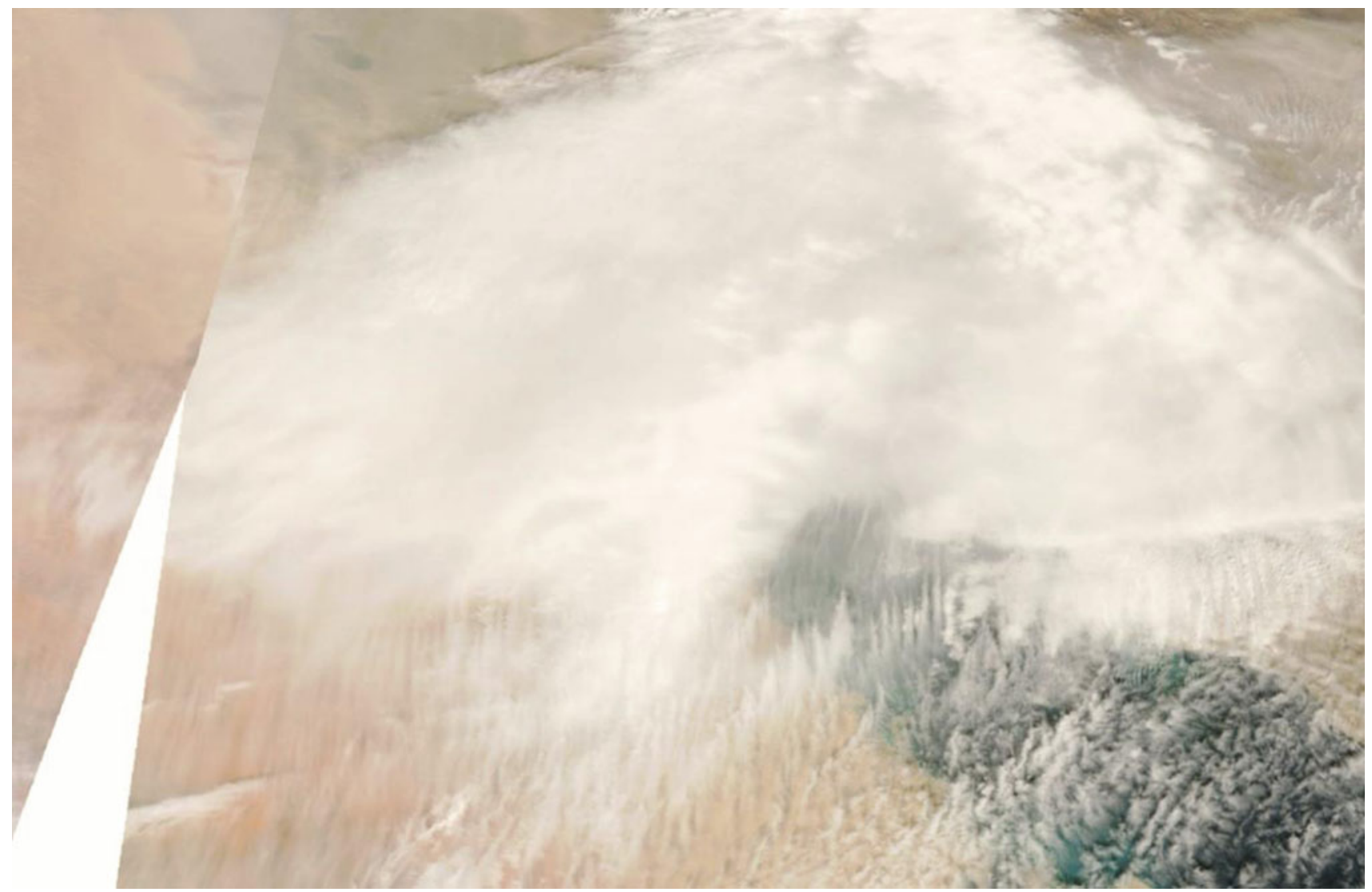

Fig. 1.14 MODIS image of dust storm that originated from the Western Desert of Iraq covering southern Iraq, Kuwait, and northern Arabian Gulf on 28th February 2009

feldspars, but fewer carbonates and clay minerals, lower particle surface area, and less iron and organic matter than trajectories from the Mesopotamian Floodplain or those coming from marches in Iraq and Iran. This trajectory is also expected to have fewer microorganisms. The following weather data were recorded for 2nd March 2009 (Fig. 1.15):

- Heavy cloud cover obscured the area of concern.

- The local prevailing wind direction: west-northwest, west.

- The west-northwest and west wind directions represent $49.4 \%$ and $22.6 \%$, respectively, of the total hourly wind count for that day.

\section{Satellite Images}

Bidirectional dust storms: one blowing from southern Iraq toward the Arabian Gulf in an arrow-shaped dust storm trajectory on 10th March 2009, while the second is blowing from the northeast. The trajectory diverted its direction from above the Arabian Gulf toward Arabia. This type of dust storm trajectory takes the wider form and is part of the Subag Sarayat season that extends from early March until 28th April. The northwestern dust storm large trajectories usually blow in January, February, March, April, May, June, July, August, September, and October. The northeastern trajectories' fallen dust is darker in color, finer in size fraction, with fewer sand particles, and contains more clay and carbonates but has fewer quartz and feldspar minerals, as well as larger values of particle surface area, and higher percentages of iron and organic matter than other trajectories. Weather data collected on 10th March 2009 were as follows (Fig. 1.16):

- The local prevailing wind direction (northwest, west-northwest) agrees with that deduced from the image. Note that there is a huge south-southeast wind component.

- The northwest and west-northwest wind directions represent $29.2 \%$ and $23.4 \%$, respectively, of the total hourly wind count for that day. The south-southeast component represents $22.4 \%$. 


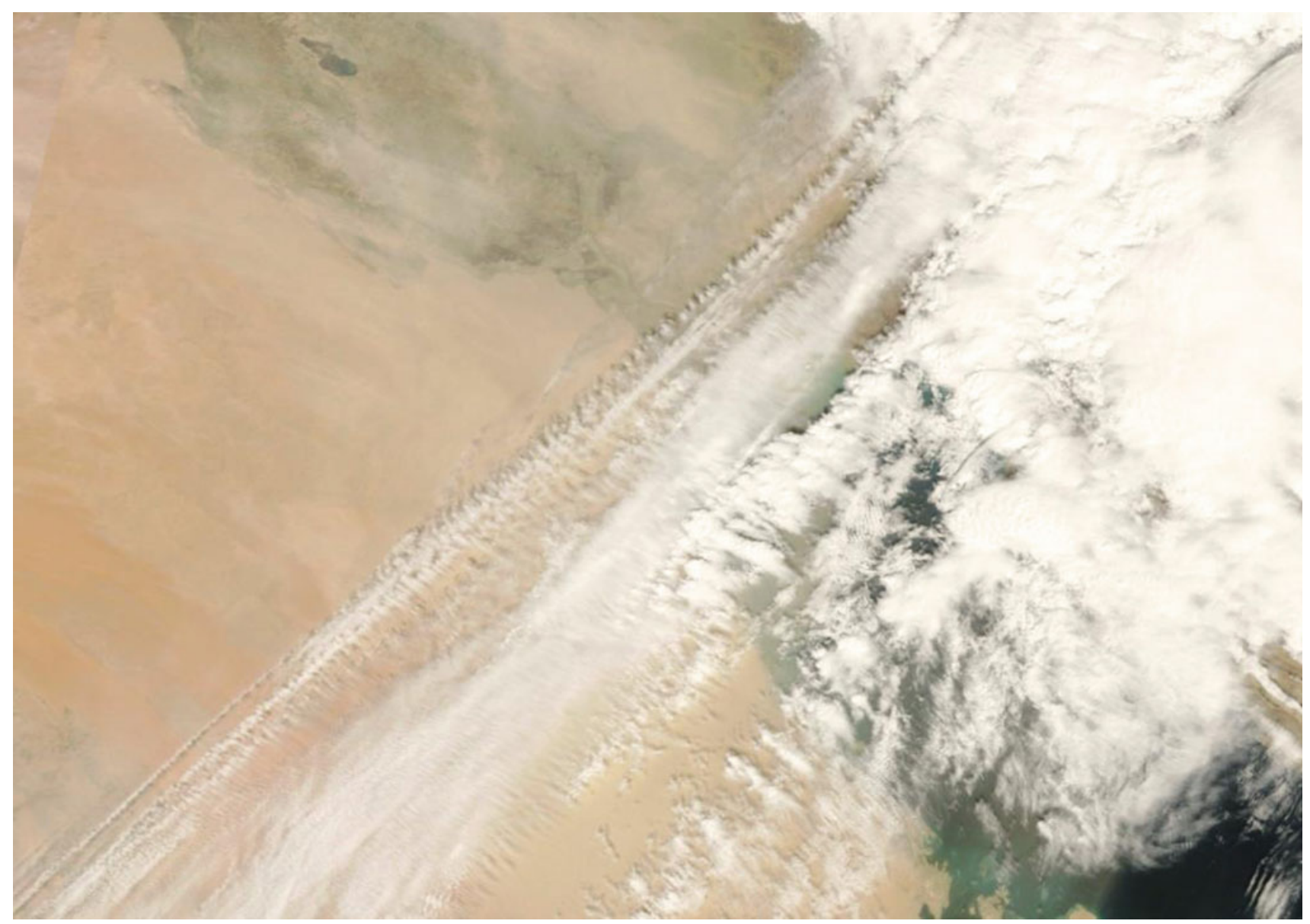

Fig. 1.15 MODIS image of dust storm that originated from the Western Desert of Iraq covering southern Iraq, Kuwait, and northern Arabian Gulf on 2 March 2009

\section{Satellite Images}

This unidirectional dust storm blew from the northern Arabian Gulf toward Kuwait on the 13th March 2009. This type of dust storm trajectory takes the wider form with a low wind speed. These northern dust storm large trajectories blow normally in January, March, April, May, June, July, August, and October. The northern trajectories' fallen dust contains higher percentages of iron and organic matter than other trajectories. Weather data collected on 13th March 2009 were as follows (Fig. 1.17):

- The local prevailing wind direction (west-northwest, northwest, north) agrees with that deduced from the image.

- The west-northwest, northwest, and north wind directions represent $19.4 \%, 21.1 \%$, and $15.4 \%$, respectively, of the total hourly wind count for that day.

\section{Satellite Images}

This unidirectional dust storm blew from northern Arabia and the Western Desert of Iraq toward Kuwait on 14th May 2009. This type of dust storm trajectory takes the wider form and blows normally in January, February, March, April, June, September, and October. Furthermore, moderate dust storm trajectories are familiar in March, May, June, July, and August. The northwesterly trajectories' fallen dust is coarser in size fraction, with sand particles (diameter more than $0.063 \mathrm{~mm}$ ) containing more quartz and feldspars minerals, a smaller particle surface area, and less iron and organic matter than trajectories from the Mesopotamian Floodplain. Weather data collected on 14th May 2009 were as follows (Fig. 1.18):

- Heavy cloud cover obscured the area of concern.

- The prevailing wind direction: northwest, west-northwest, west. 


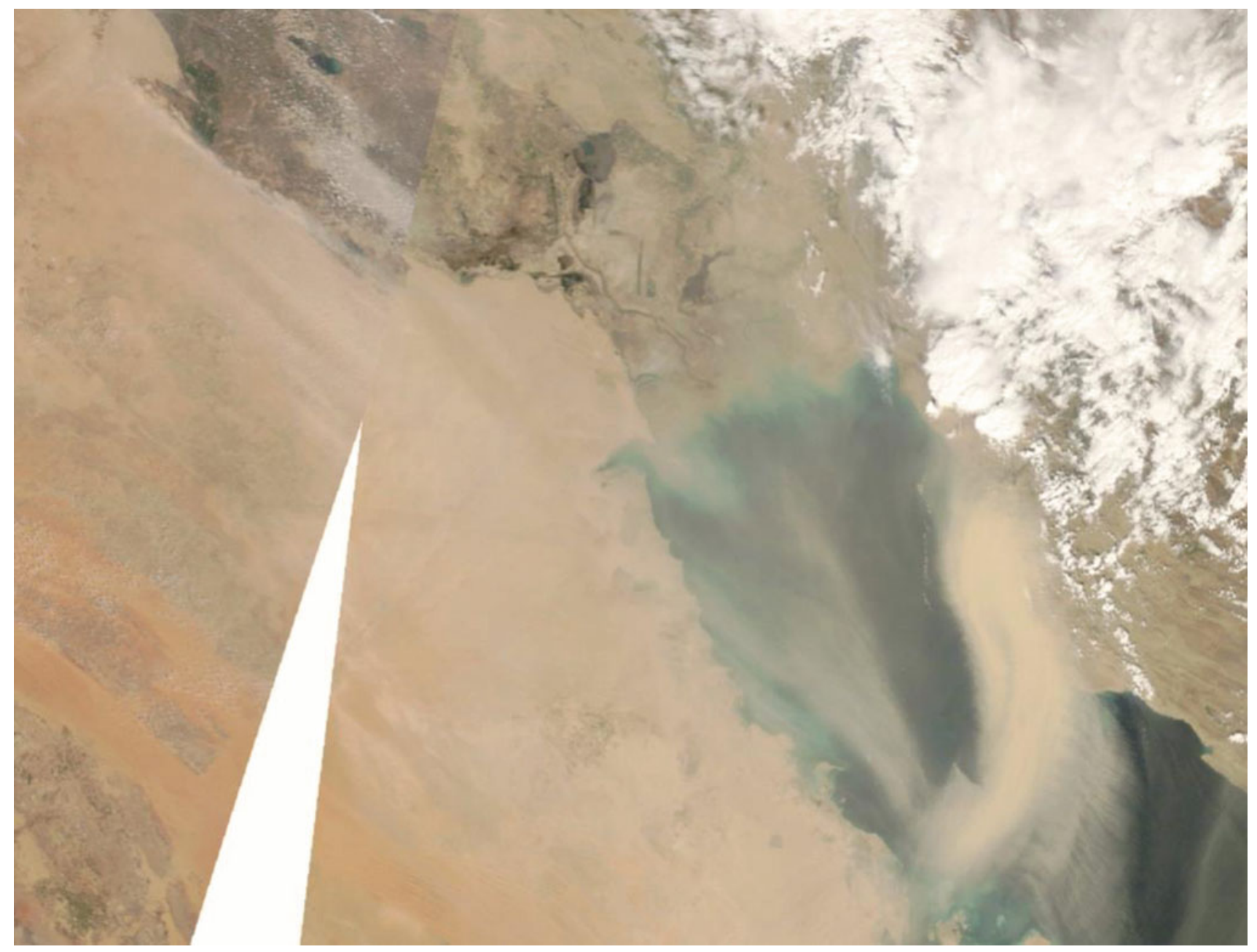

Fig. 1.16 MODIS image of dust storm that originated from the Western desert of Iraq, covering southern Iraq, Kuwait, and northern Arabian Gulf on 10th March 2009

- The northwest, west-northwest, and west wind directions represent $17.3 \%, 31.5 \%$, and $15.5 \%$, respectively, of the total hourly wind count for that day.

\section{Satellite Images}

Moderate wind speed caused a unidirectional dust storm blowing from northern Arabia and the Western Desert of Iraq toward Kuwait on 15th May 2009. The northwestern dust storm large trajectories are affected by wind from the southwest. Moderate dust storm trajectories that cover less than $3000 \mathrm{~km}^{2}$ of the area are most likely in March, May, June, July, and August. The northwesterly trajectories' fallen dust is brighter in color, coarser in size fraction, with sand particles (diameter more than $0.063 \mathrm{~mm}$ ) containing more quartz and feldspars but fewer carbonates and clay minerals, with a lower particle surface area, and less iron and organic matter than north and northeastern trajectories. The associated pollen with these types of dust trajectories originates mainly from Haloxylon $s p$. and Cyperus $s p$., native plants that were transferred a short distance from regional source areas. Weather data collected on the 15th May 2009 were as follows (Fig. 1.19):

- Cloud cover obscured the area of concern.

- Prevailing wind direction (west-southwest, west, west-northwest, with strong north-northwest component) agrees with that deduced from the image.

- The west-southwest, west, and west-northwest wind directions represent $14.3 \%, 23.8 \%$, and $16.7 \%$, respectively, of the total hourly wind count for that day. 


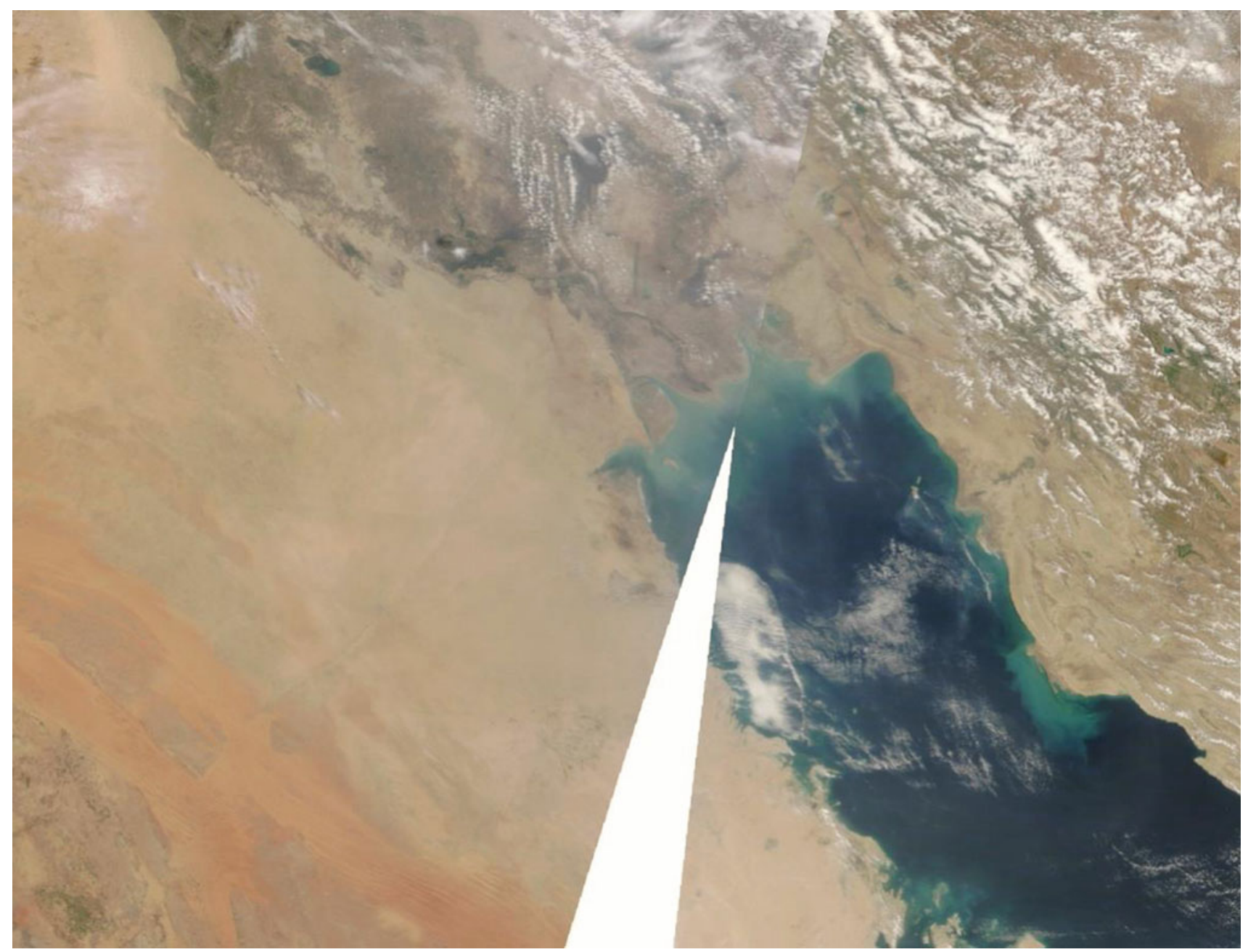

Fig. 1.17 MODIS image of dust storm that originated from the Western Desert of Iraq, covering southern Iraq, Kuwait and northern Arabian Gulf on 13th March 2009

\section{Satellite Images}

This unidirectional dust storm blew from the southwest toward Kuwait in the on 16th May 2009. This type of dust storm trajectory takes the wider form and normally blows in March, April, May, June, and October. Fallen dust from the southwesterly trajectories is brighter in color, coarser in size fraction, with more sand particles, causing dust deposits to accumulate quickly. Such dust contains more quartz and feldspars but fewer carbonates and clay minerals, a lower particle surface area, and a smaller percentage of iron and organic matter than other trajectories. Weather data collected on 16th May 2009 were as follows (Fig. 1.20):

- Heavy cloud cover obscured the area of concern.

- The prevailing wind direction was southwest, west-southwest, and west.
- The southwest, west-southwest, and west wind directions represent $12.1 \%, 19.1 \%$, and $31.8 \%$, respectively, of the total hourly wind count for that day.

\section{Satellite Images}

A small unidirectional dust storm with an arrow shape blowing from the Mesopotamian Floodplain, particularly from the Samawa region in Iraq, toward Kuwait on 2nd July 2009. This type of dust storm trajectory has a moderate size form that covers an area less than $3000 \mathrm{~km}^{2}$ and is familiar in March, May, June, July, and August. The northwesterly trajectories' fallen dust is darker in color, smaller in size fraction, with fewer sand particles that contain more carbonates and clay minerals but less quartz and feldspars, has a larger the particle surface area, and higher percentages of 


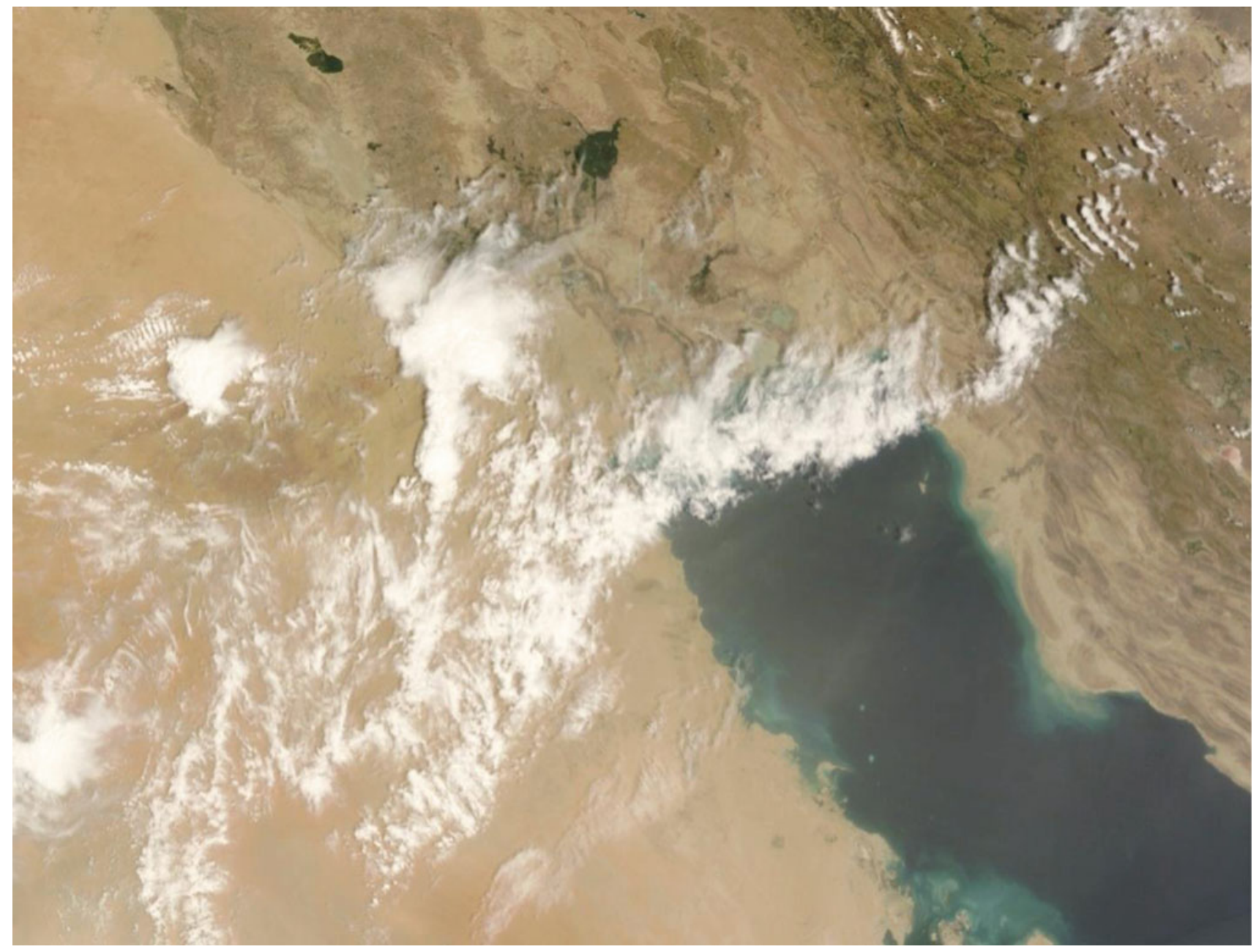

Fig. 1.18 MODIS image of dust storm that originated from the Western Desert of Iraq, covering southern Iraq, Kuwait, and the northern Arabian Gulf on 14th May 2009

iron and organic matter than other trajectories. Weather data obtained on 2nd July 2009 were as follows (Fig. 1.21):

- The local prevailing wind direction (northwest, west-northwest) agreed with that deduced from the image over the area of the State of Kuwait;

- The northwest and west-northwest wind directions represent $30.4 \%$ and $47.3 \%$, respectively, of the total hourly wind count for that day.

\section{Satellite Images}

The same dust storm that blew on 2nd July continued for a second day but at a higher wind speed. The storm took the form of an arrow shape, was unidirectional, and covered small areas. It blew from the Mesopotamian Floodplain, particularly from the Samawa region in Iraq, Bubiyan Island, and Sabiya in Kuwait, toward the Arabian Gulf on 3rd July 2009. This type of dust storm trajectory has a moderate size, covers an area of less than $3000 \mathrm{~km}^{2}$, and is familiar in March, May, June, July, and August. The northwesterly trajectories' fallen dust is darker in color, smaller in size fraction, with fewer sand particles, contains more carbonates and clay minerals, has a larger particle surface area, and high percentages of iron and organic matter compared with the other trajectories. The weather data collected on 3rd July 2009 were as follows (Fig. 1.22):

- The local prevailing wind direction (northwest, west-northwest, west) agreed with that deduced from the image over the area in Kuwait;

- The northwest, west-northwest, and west wind directions represent $33.3 \%, 36.9 \%$, and $20.8 \%$, respectively, of the total hourly wind count for that day. 


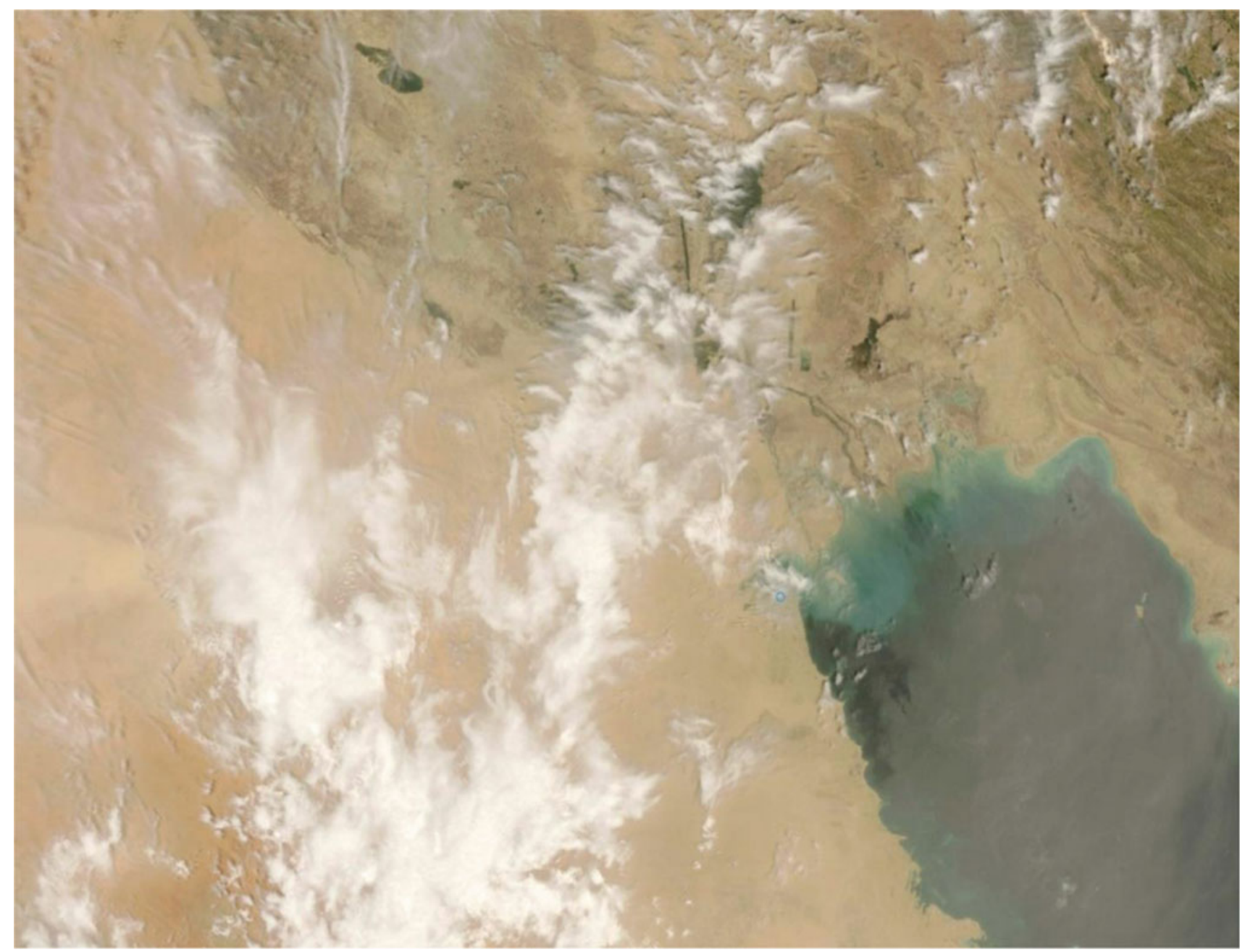

Fig. 1.19 MODIS image of dust storm that originated from the Western Desert of Iraq, covering southern Iraq, Kuwait, and the northern Arabian Gulf on 15th May 2009

\section{Satellite Images}

A transition zone of an intermediate dust storm into a wide dust storm form that covers an area of more than $3000 \mathrm{~km}^{2}$ blowing from the Mesopotamian Floodplain, mainly from the Samawa and Ahwar regions in Iraq, toward Kuwait and the Arabian Gulf on 29th July 2009. This type of dust storm trajectory is familiar in March, May, June, July, and August. The northwesterly trajectories' fallen dust is darker in color, smaller in size fraction, with fewer sand particles, contains more carbonates and clay minerals, has a larger particle surface area, and a high percentage of iron and organic matter when compared with other trajectories. The following weather data were recorded for 29th July 2009 (Fig. 1.23):

- The local prevailing wind direction (northwest, west-northwest, west) agreed with that deduced from the image over the area of the State of Kuwait;
- The northwest, west-northwest, and west wind directions represent $22.9 \%, 37.5 \%$, and $27.1 \%$, respectively, of the total hourly wind count for that day.

\section{Satellite Images}

Two dust storm trajectories taking the form of arrow-shapes, indicating high wind speed. This form is a moderate size that covers an area of less than $3000 \mathrm{~km}^{2}$ and predominantly occurs in July but is familiar in March, May, June, and August. It is a unidirectional form blowing from the Mesopotamian Floodplain, particularly from the Samawa and Hur Suwaiga regions in Iraq, Bubiyan Island, and Subiyah in Kuwait, toward the Arabian Gulf on 15th August 2009. The northwesterly trajectories' fallen dust is characterized by more carbonates and higher clay mineral percentages, is 


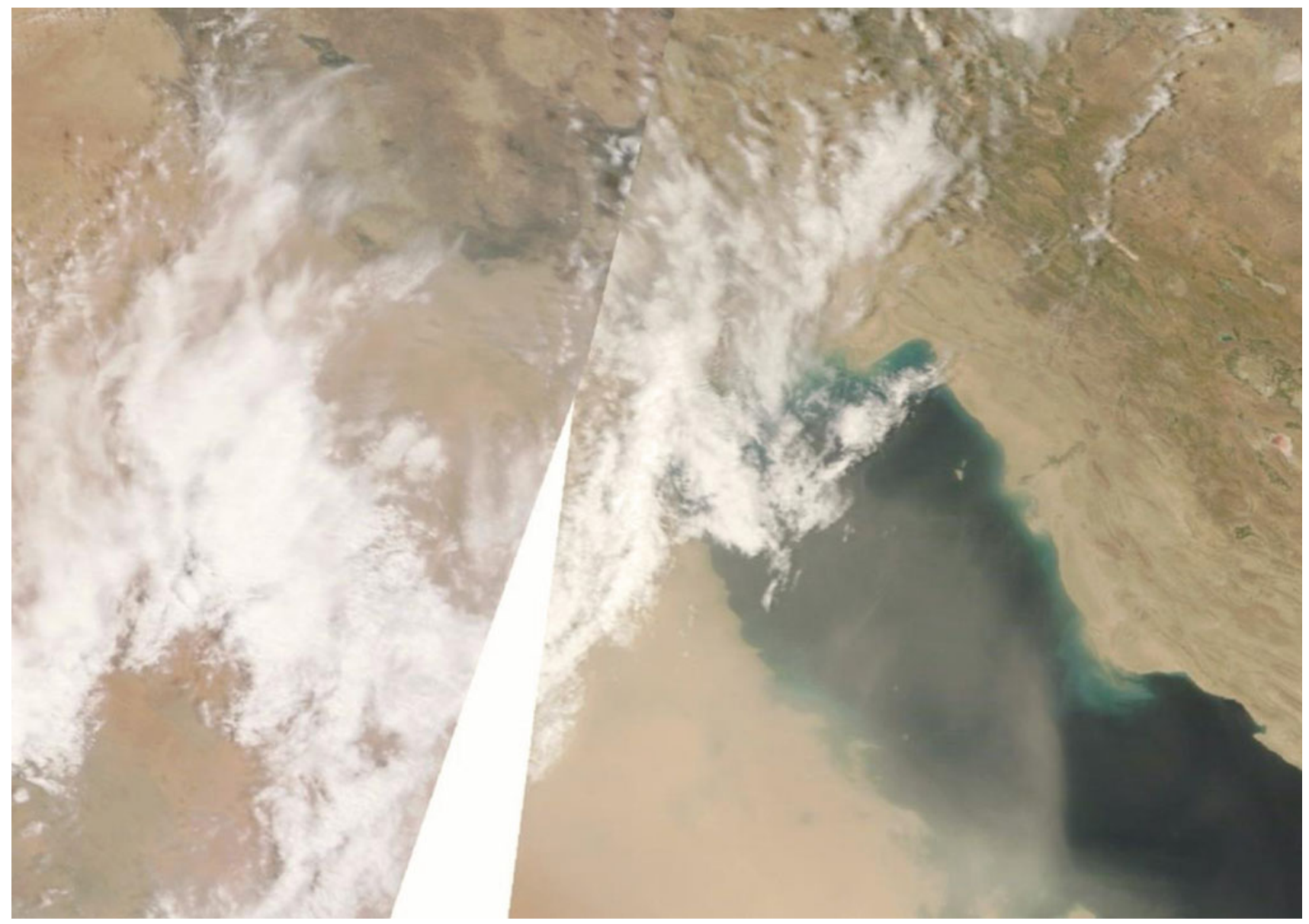

Fig. 1.20 MODIS image of dust storm that originated from the Western Desert of Iraq, covering southern Iraq, Kuwait, and the northern Arabian Gulf on 16th May 2009

darker in color, smaller in size fraction, with more mud particles, larger in particle surface area, and has high percentages of iron and organic matter in comparison with other trajectories. The following weather data were recorded on 15th August 2009 (Fig. 1.24):

- The local prevailing wind directions (west-northwest, northwest) over the entire Kuwait agreed with that deduced from the image.

- The west-northwest and northwest wind directions represent $45.9 \%$ and $43.8 \%$, respectively, of the total hourly wind count for that day.

\section{Satellite Images}

This image shows that no dust storm has occurred, which indicates that visibility is not a good indicator for dust storms, as visibility can be low due to fog, rain, smog, and humidity, rather than dust. Ordinarily, when visibility is less than $1000 \mathrm{~m}$, it is considered a clear indicator of dust storms. This day showed low visibility (less than $1000 \mathrm{~m}$ ) despite the non-occurrence of dust, which indicates that depending only on visibility as an indicator of dust storms is incorrect. The following weather data were recorded on 6th January 2010 (Fig. 1.25):

- The local prevailing wind direction was west-northwest, northwest, north-northwest over the whole area of Kuwait.

- The west-northwest, northwest, and north-northwest wind directions represent $49.0 \%, 31.8 \%$, and $12.0 \%$, respectively, of the total hourly wind count for that day.

\section{Satellite Images}

A massive dust storm blowing from the Sahara Desert in northern Africa, passing through Palestine, Jordan, northern Arabia, and the Western Desert of Iraq toward western 


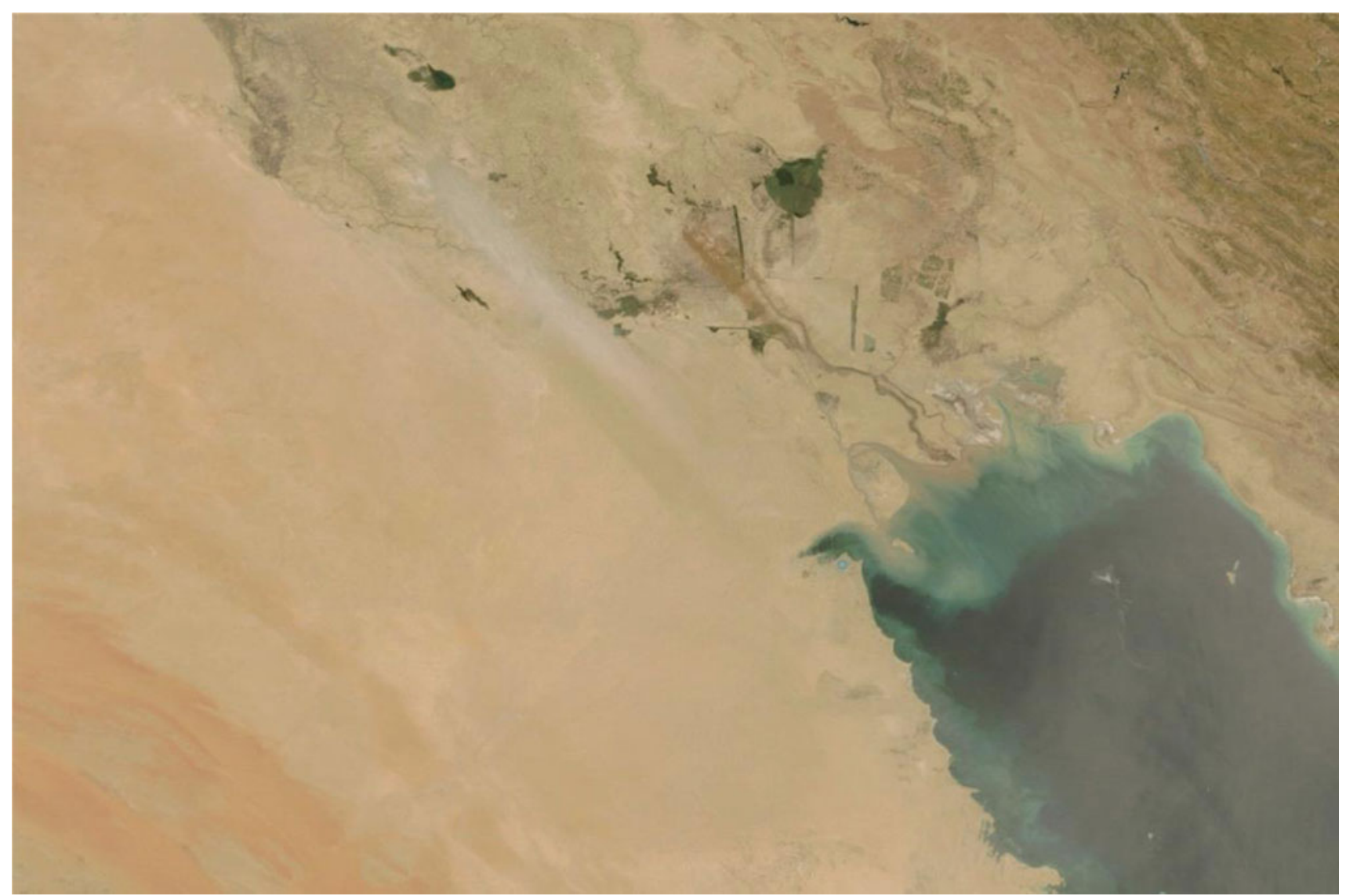

Fig. 1.21 MODIS image of dust storm that originated from the Western Desert of Iraq, covering southern Iraq, Kuwait, and the northern Arabian Gulf on 2nd July 2009

Kuwait on 25th January 2010. These types of unidirectional dust storm trajectories take the wider form of covering the Western Desert of Iraq, where the Mesopotamian Floodplain is not affected. These northwestern dust storms' large trajectories blow normally in January, February, March, April, June, September, and October. The northwesterly trajectories' fallen dust that passes only through the Western Desert of Iraq is brighter in color, coarser in size fraction, with more sand particles, and contains more quartz and feldspars but fewer carbonates and clay minerals, with a lower particle surface area, and less iron and organic matter in comparison with the trajectories from the Mesopotamian Floodplain. The following weather data were recorded on 25th January 2010 (Fig. 1.26):

- The local prevailing wind directions (west, west-northwest, northwest, and some southeast, south-southeast components) agree with those deduced from the image.

- The northwest, west-northwest, and west wind directions represent $12.5 \%, 22.9 \%$, and $14.1 \%$, respectively, of the total hourly wind count for that day

\section{Satellite Images}

A small and unidirectional dust storm blowing from the southeast toward Kuwait on 31st January 2010. The southeastern dust storms' small trajectories normally blow in October and December, and rarely in January and February. The southeastern trajectories' fallen dust is brighter in color, coarser in size fraction, with more sand particles, and contains more quartz and feldspars but fewer carbonates and clay minerals, with a lower particle surface area, and less content of iron and organic matter when compared with the trajectories from the north and northwest. On the other hand, the dust deposited from this trajectory is characterized by smaller particle size, less quartz, and contains more organic matter than trajectories from the southwest. The following weather data were recorded on 31st January 2010 (Fig. 1.27):

- Heavy cloud cover obscured the area of concern.

- Prevailing wind direction: east, east-southeast. The wind passing over the Arabian Sea became laden with water vapor, explaining the clouds. 


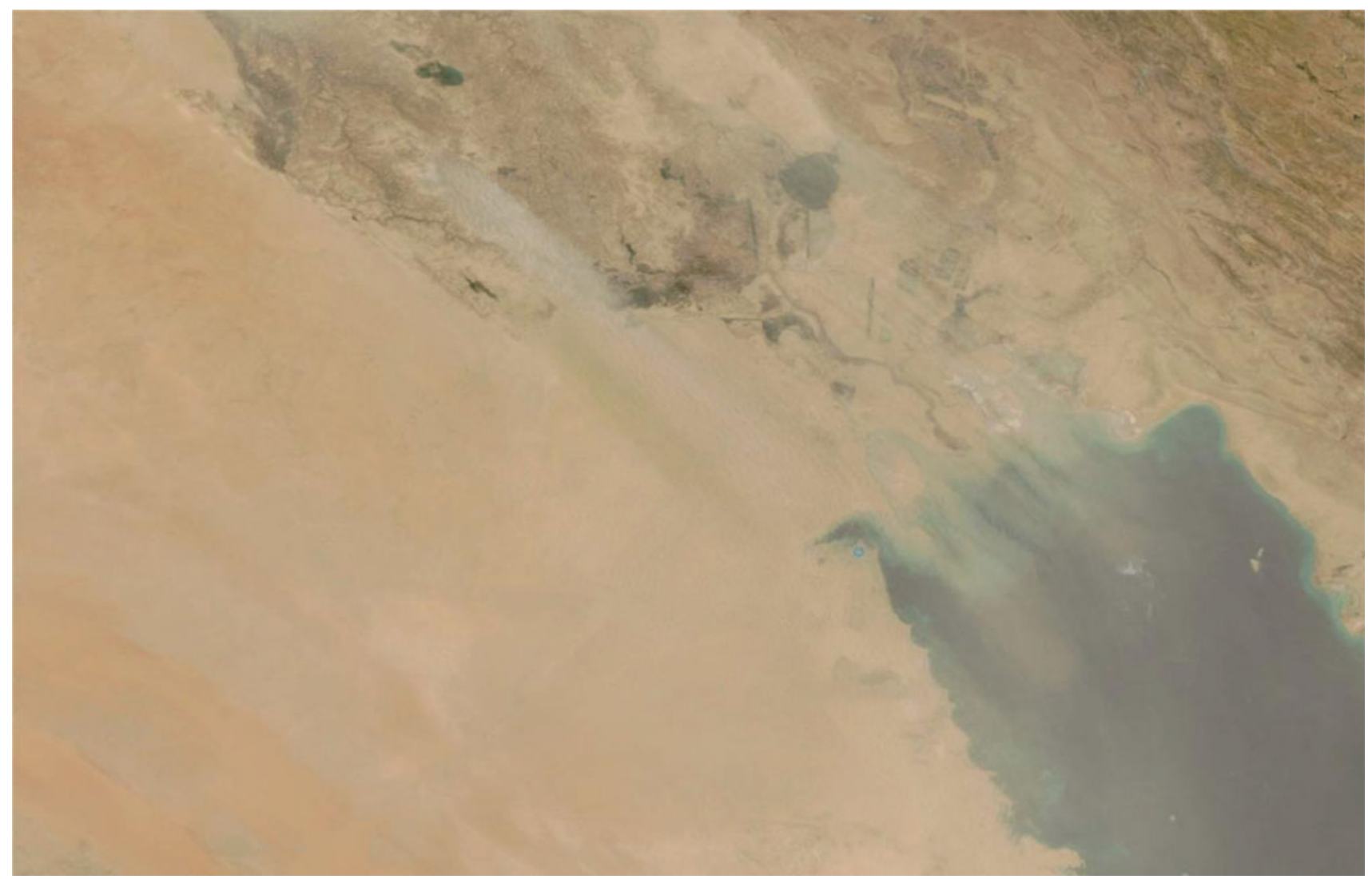

Fig. 1.22 MODIS image of dust storm that originated from the Western Desert of Iraq, covering southern Iraq, Kuwait, and the northern Arabian Gulf on 3rd July 2009

- The east and east-southeast wind directions represent $20.8 \%$ and $25.5 \%$, respectively, of the total hourly wind count for that day.

\section{Satellite Images}

A dust storm blew from the southeast toward Kuwait on 1st February 2010. The southeastern dust storm small trajectories usually blow in October and December, and occasionally in February. The wind passing over the Arabian Gulf becomes laden with water vapor, which causes the rapid deposition of dust. The fallen dust within southeastern trajectories is brighter in color, coarser in size fraction, with more sand particles, and contains more quartz and feldspars but fewer carbonates and clay minerals, with a lower particle surface area, and less content of iron and organic matter in comparison with trajectories from the north and northwest. On the other hand, the deposited dust from this trajectory is characterized by smaller particle size, less quartz, and contains more organic matter when compared with trajectories from the southwest. Weather data collected on 1st February 2010 were as follows (Fig. 1.28):

- Heavy cloud cover obscured the area of concern.

- Prevailing wind direction: east-southeast, southeast, south-southeast, south. The wind passing over the Arabian Gulf became laden with water vapor, which could explain the clouds.

\section{Satellite Images}

Coalescence of two wind directions from the southeast and southwest caused a dust storm blowing mainly from local sources within Kuwait on 3rd February 2010. This type of dust storm trajectory is a moderate form in which the area covered is less than $3000 \mathrm{~km}^{2}$. The southeasterly trajectories' fallen dust's physical and chemical properties are fully described in previous images from the same direction. The following weather data were recorded on 3rd February 2010 (Fig. 1.29): 


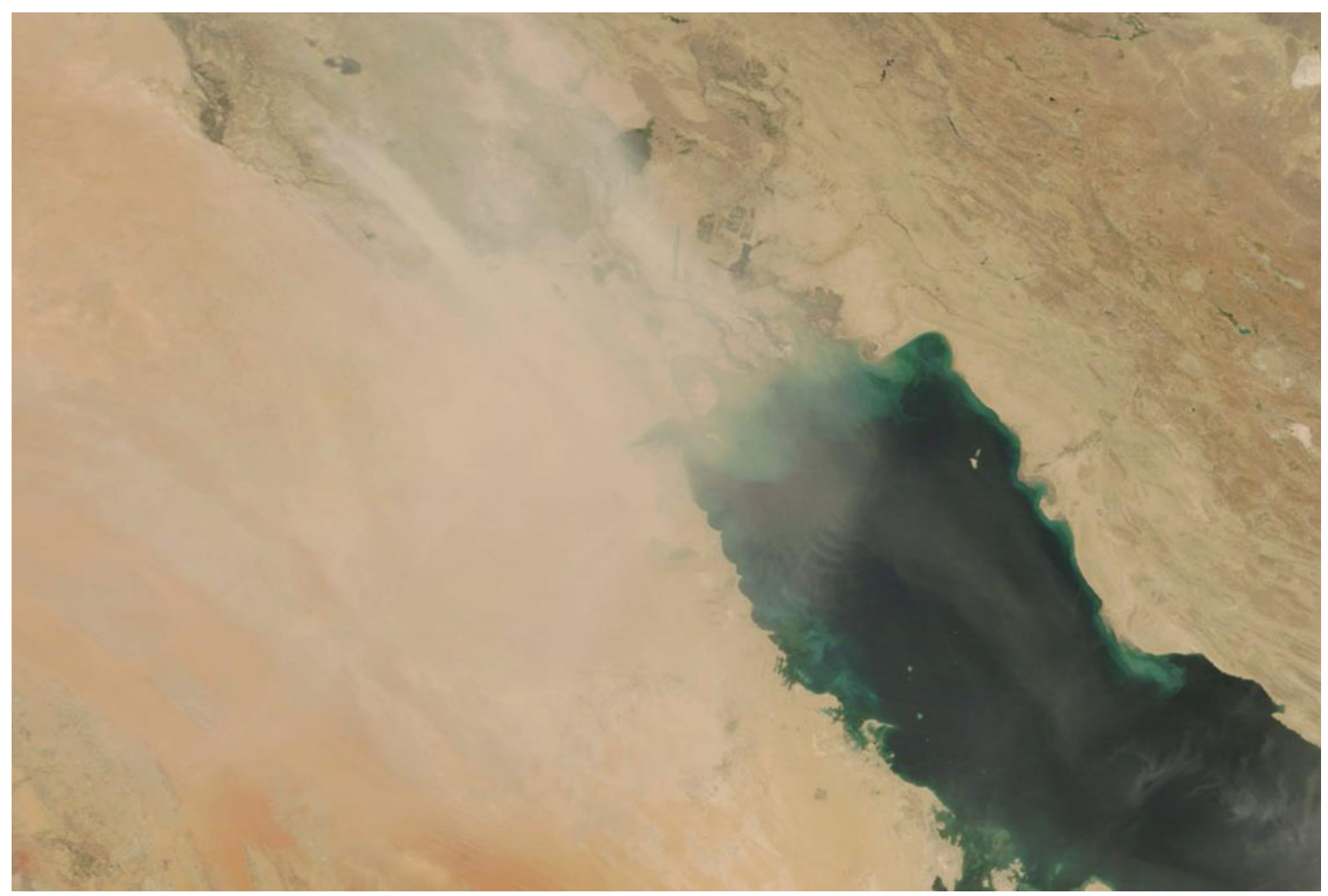

Fig. 1.23 MODIS image of dust storm that originated from the Western Desert of Iraq, covering southern Iraq, Kuwait, and the northern Arabian Gulf on 29th July 2009

- Heavy cloud cover obscured the area of concern.

- Prevailing wind direction: southeast, south-southeast. The wind passing over the Arabian Gulf became laden with water vapor, which explains the clouds.

- The southeast and south-southeast wind directions represent $25.5 \%$ and $22.9 \%$, respectively, of the total hourly wind count for that day.

\section{Satellite Images}

A two-wind direction from the southeast and west-northwest facing each other in northern Kuwait caused a small unidirectional dust storm blowing mainly from local and close regional sources toward Kuwait on 13th February 2010. This type of dust storm trajectory is a moderate form and lasts only for a short period. The southeasterly trajectory's fallen dust physical and chemical properties are fully described in previous images from the same direction. The following weather data were recorded on 13th February 2010 (Fig. 1.30):
- Cloud cover obscured the area of concern.

- Prevailing wind direction: east-southeast, southeast, south-southeast. The wind passing over the Arabian Sea became laden with water vapor, which explains the clouds.

- The east-southeast, southeast, and south-southeast wind directions represent $22.9 \%, 17.7 \%$, and $14.6 \%$, respectively, of the total hourly wind count for that day.

\section{Satellite Images}

A broad and unidirectional dust storm blew from northern Arabia and the Western Desert of Iraq toward Kuwait on 23rd February 2011. These types of dust storm trajectories take a wider form but have a low wind speed. Normally, the northwest trajectory has a high wind speed but, on this rare occasion, was only moderate, causing the movement of mud-sized particles. In this case, the dust contains more nutrients, organic matter, and pollen, and is characterized by a higher content of clay minerals and carbonates than 


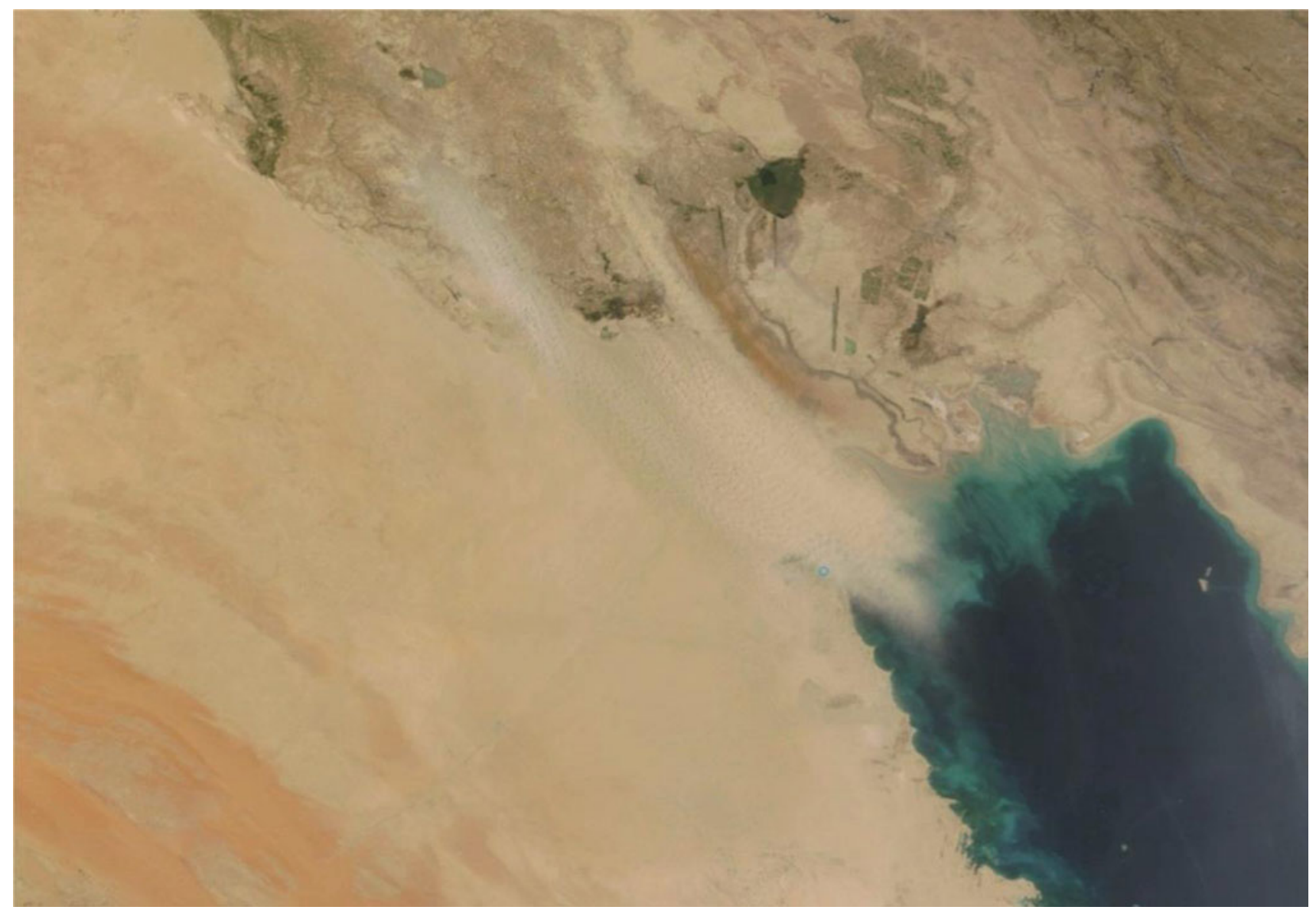

Fig. 1.24 Satellite image (MODIS) of dust storm on 15th August 2009 that blew from Diwaniyah and Ahwar in the Mesopotamian Floodplain in southern Iraq, passing through northern Kuwait toward the Arabian Gulf

normal. The following weather data were recorded on 23rd February 2010 (Fig. 1.31):

- Heavy cloud cover obscured the area of concern.

- Prevailing wind direction: north, north-northwest.

- The north and north-northwest wind directions represent $30.2 \%$ and $30.7 \%$, respectively, of the total hourly wind count for that day.

\section{Satellite Images}

A moderate, unidirectional dust storm blowing from northern Arabia and the Western Desert of Iraq toward Kuwait on 26th February 2010. This type of dust storm trajectory takes a small arrow shape form, in which the area covered by the trajectory is less than $3000 \mathrm{~km}^{2}$. These moderate, northwesterly large trajectories are familiar in March, but this one was at the end of February. The northwesterly trajectories' fallen dust contains more quartz and feldspars but fewer carbonates and clay minerals, with a lower particle surface area, and less iron and organic matter when compared with trajectories from the Mesopotamian Floodplain, but much more when compared with other trajectories. The following weather data were recorded on 26th February 2010 (Fig. 1.32):

- Heavy cloud cover obscured the area of concern.

- Prevailing wind direction: west, west-northwest, with south and east components.

- The west and west-northwest wind directions represent $15.6 \%$ each of the total hourly wind count for that day.

\section{Satellite Images}

Massive and strong unidirectional dust storm formed in northern Arabia and the Western Desert of Iraq blowing toward Kuwait on 4th March 2010. This type of dust storm trajectory took the wider form, in which the area covered is 


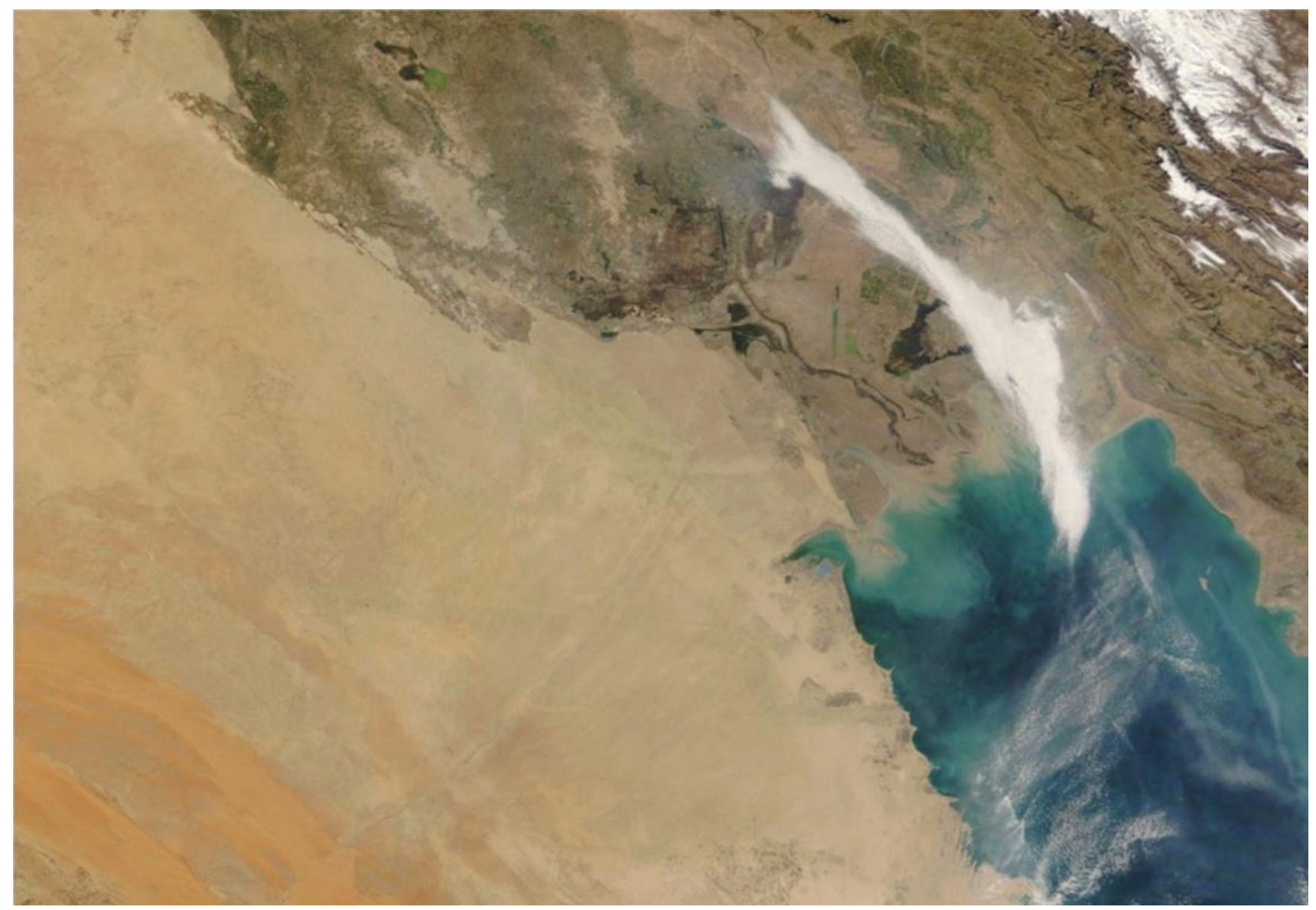

Fig. 1.25 MODIS image of dust storm that originated from the Western Desert of Iraq, covering southern Iraq, Kuwait, and the northern Arabian Gulf on 6th January 2010

more than $3000 \mathrm{~km}^{2}$. The northwestern large trajectories blow normally in January, February, March, April, June, September, and October. Fallen dust of the northwesterly trajectories is brighter in color, coarser in size fraction, with more sand particles, and contains more quartz and feldspars but fewer carbonates and clay minerals, with a lower particle surface area, and less iron and organic matter when compared with the trajectories from the Mesopotamian Floodplain, but is higher when compared with the other trajectories. The following weather data were recorded on 4th March 2010 (Fig. 1.33):

- The local prevailing wind direction (northwest, west-northwest) agrees with the outcome deduced from the image. Note there is a huge south-southeast wind component.

- The northwest and west-northwest wind directions represent $22.9 \%$ and $26.0 \%$, respectively, of the total hourly wind count for that day. The south-southeast component represents $17.2 \%$.

\section{Satellite Images}

A northwesterly unidirectional dust storm covering the northern part of the Arabian Gulf coming from the Western Desert of Iraq toward Kuwait on 5th March 2010. This type of dust storm trajectory takes the wider form. The northwestern dust storm has large trajectories that blow normally in January, February, March, April, June, September, and October. The fallen dust during these trajectories is brighter in color, coarser in size fraction, with more sand particles, contains more quartz and feldspars but fewer carbonates and clay minerals, with a lower particle surface area, and less iron and organic matter than trajectories from the Mesopotamian Floodplain but more than other trajectories. The following weather data were recorded on 5th March 2010 (Fig. 1.34):

- The local prevailing wind direction (northwest, west-northwest) agrees with that deduced from the image. 


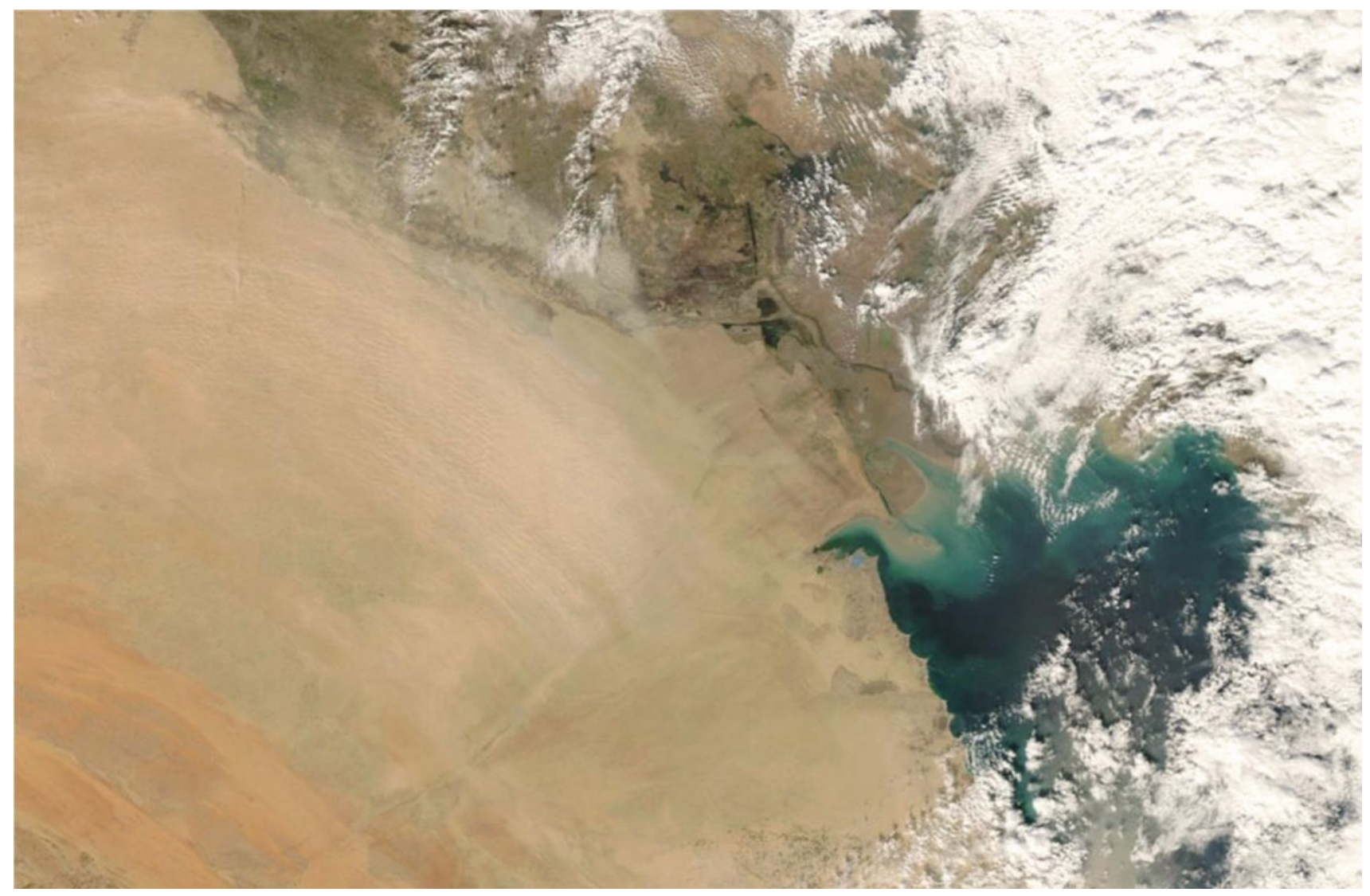

Fig. 1.26 MODIS image of dust storm that originated from the Western Desert of Iraq, covering southern Iraq, Kuwait, and the northern Arabian Gulf on 25th January 2010

- The northwest and west-northwest wind directions represent $36.5 \%$ and $41.7 \%$, respectively, of the total hourly wind count for that day.

\section{Satellite Images}

A unidirectional dust storm blowing with moderate wind speed from the northern Arabian Gulf toward Kuwait on 19th March 2010. The northwestern dust storm has large trajectories that blow normally in January, February, March, April, June, September, and October. The fallen dust of the trajectories is brighter in color, finer in size fraction, with very few sand particles, contains more carbonates and clay minerals but less quartz and feldspars, with higher particle surface area, and is high in iron content and organic matter when compared with all other trajectories. The following weather data were recorded on 19th March 2010 (Fig. 1.35):

- The local prevailing wind direction (northwest, north-northwest) agrees with that deduced from the image.
- The northwest and north-northwest wind directions represent $40.1 \%$ and $39.6 \%$, respectively, of the total hourly wind count for that day.

\section{Satellite Images}

A dust storm of about $250 \mathrm{~km}$ width blowing from the southeast toward the northern Arabian Gulf, Bahrain, Qatar, and Kuwait on 27th March 2010. The southwestern large trajectories' fallen dust is brighter in color, coarser in size fraction, and contains more quartz and feldspars but has fewer carbonates and clay minerals, with a lower particle surface area, and less iron and organic matter in comparison with trajectories from the north and northwest. The following weather data were recorded on 27th March 2010 (Fig. 1.36):

- The local prevailing wind direction: west, west-northwest. There was also a north component. This direction agrees with that deduced from the image over the area of Kuwait. 


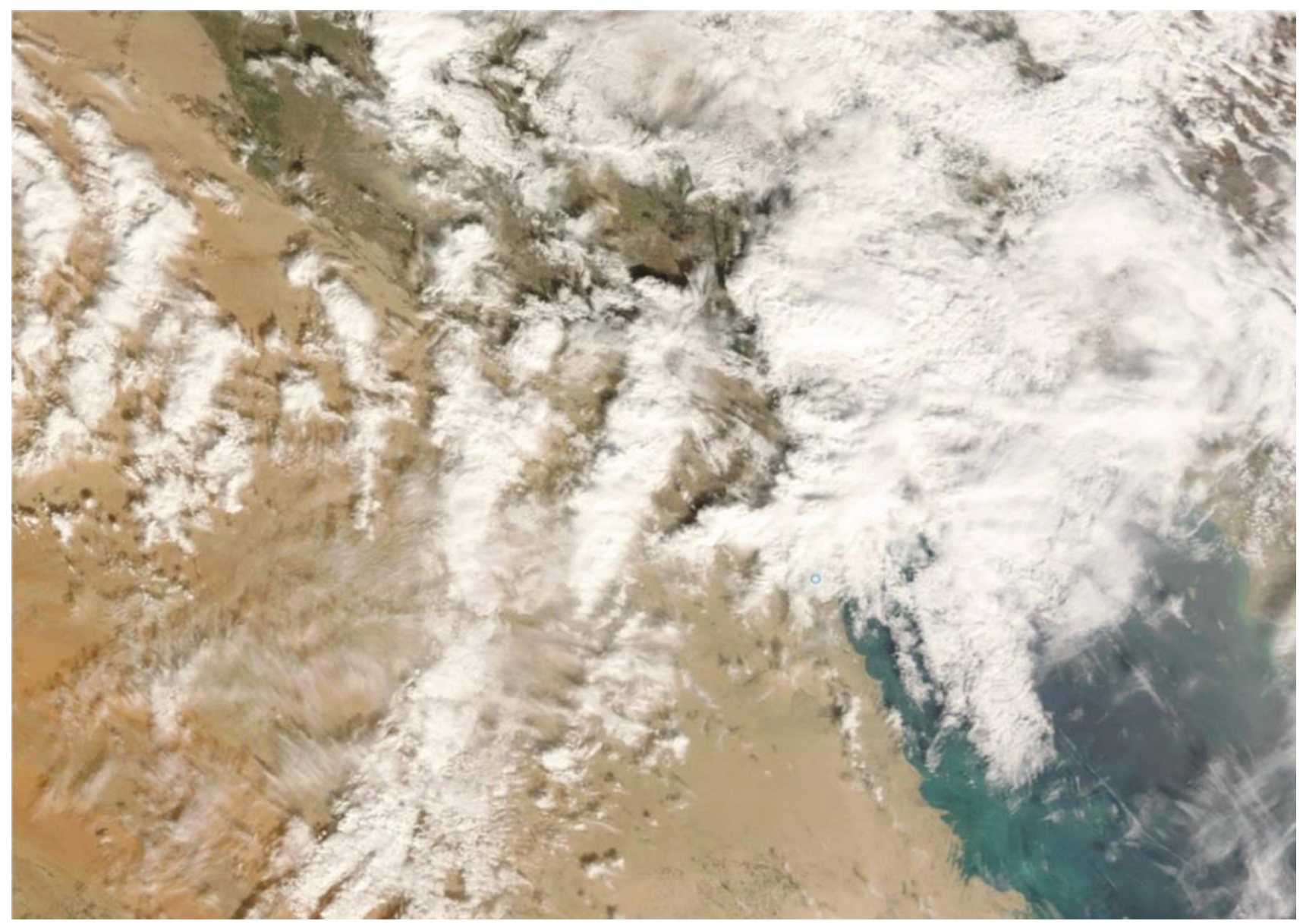

Fig. 1.27 MODIS image of dust storm that originated from the Western Desert of Iraq, covering southern Iraq, Kuwait, and the northern Arabian Gulf on 31 st January 2010

- The west-northwest and west wind directions represent $16.1 \%$ each of the total hourly wind count for that day.

\section{Satellite Images}

A substantial unidirectional dust storm blowing from the northern Mesopotamian Floodplain and the Western Desert of Iraq toward Kuwait on 7th June 2010. This type of dust storm trajectory takes the wider form, covering more than $3000 \mathrm{~km}^{2}$. The northwestern large trajectories blow normally in January, February, March, April, June, September, and October. The northwesterly trajectories' fallen dust is brighter in color, coarser in size fraction, with mud particles, contains more carbonates and clay but less quartz and feldspar minerals, has a higher particle surface area, and a high content of iron and organic matter compared with other trajectories toward Kuwait. The following weather data were recorded on 7th June 2010 (Fig. 1.37):
- The local prevailing wind direction (northwest, west-northwest) agrees with that deduced from the image over the area of the State of Kuwait.

- The northwest and west-northwest wind directions represent $35.9 \%$ and $32.2 \%$, respectively, of the total hourly wind count for that day.

\section{Satellite Images}

A unidirectional dust storm blowing from northern Arabia and the Western Desert of Iraq toward Kuwait on 20th June 2010. This type of dust storm trajectory takes the wider form, covering more than $3000 \mathrm{~km}^{2}$. The northwestern dust storm large trajectories blow normally in January, February, March, April, June, September, and October. Furthermore, moderate dust storm trajectories that cover an area of less than $3000 \mathrm{~km}^{2}$ are familiar in March, May, June, July, and August. The northwesterly trajectories' fallen dust is brighter 


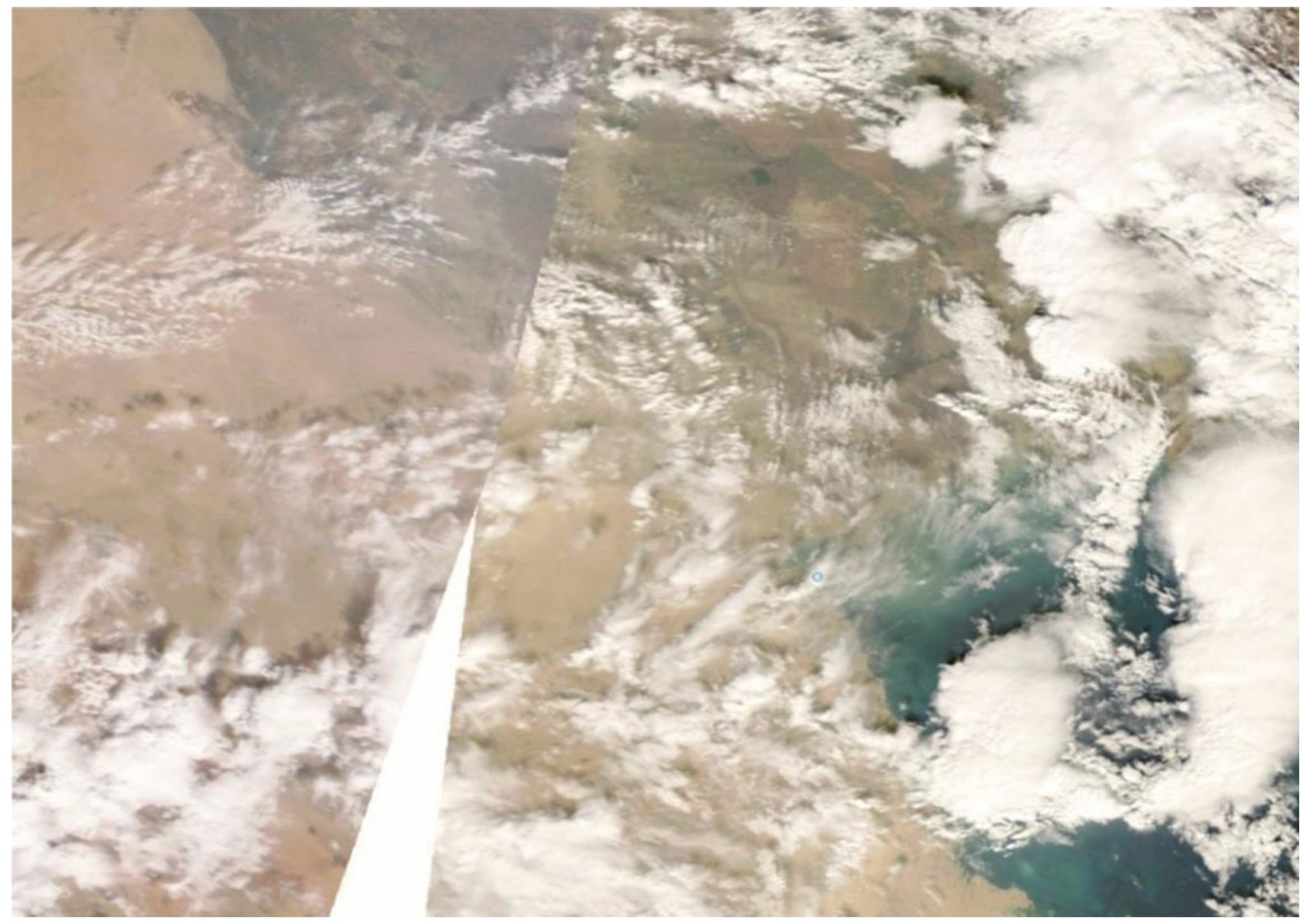

Fig. 1.28 MODIS image of dust storm that originated from the Western Desert of Iraq, covering southern Iraq, Kuwait, and the northern Arabian Gulf on 1st February 2010

in color, coarser in fraction size, with more sand particles, and contains more quartz and feldspars but fewer carbonates and clay minerals, has a lower particle surface area, and has less iron and organic matter compared with trajectories from the Mesopotamian Floodplain. The following weather data were recorded on 20th June 2010 (Fig. 1.38):

- Cloud cover obscured the area of concern.

- Prevailing wind direction: southeast-east, east, northeast-east.

- The southeast-east, east, and northeast-east wind directions represent $9.9 \%, 19.8 \%$, and $13.5 \%$, respectively, of the total hourly wind count for that day.

\section{Satellite Images}

A strong unidirectional dust storm blowing from northern Arabia and the Western Desert of Iraq toward Kuwait on 23rd July 2010. This type of dust storm trajectory takes the wider form, covering more than $3000 \mathrm{~km}^{2}$. The northwestern large trajectories blow normally in January, February, March, April, June, September, and October. Furthermore, moderate dust storm trajectories that cover an area of less than $3000 \mathrm{~km}^{2}$ are familiar in March, May, June, July, and August. The northwesterly trajectories' fallen dust is brighter in color, coarser in fraction size, with more sand particles, contains more quartz and feldspars but fewer carbonates and clay minerals, has a lower particle surface area and less iron and organic matter in comparison with trajectories from the Mesopotamian Floodplain. The following weather data were recorded on 28th July 2010 (Fig. 1.39):

- Local prevailing wind direction (west, southwest-west) agrees with that deduced from the image. Note that there is a north wind component too.

- The west and southwest-west wind directions represent $21.9 \%$ and $21.3 \%$, respectively, of the total hourly wind count for that day. The north component represents $9.9 \%$. 


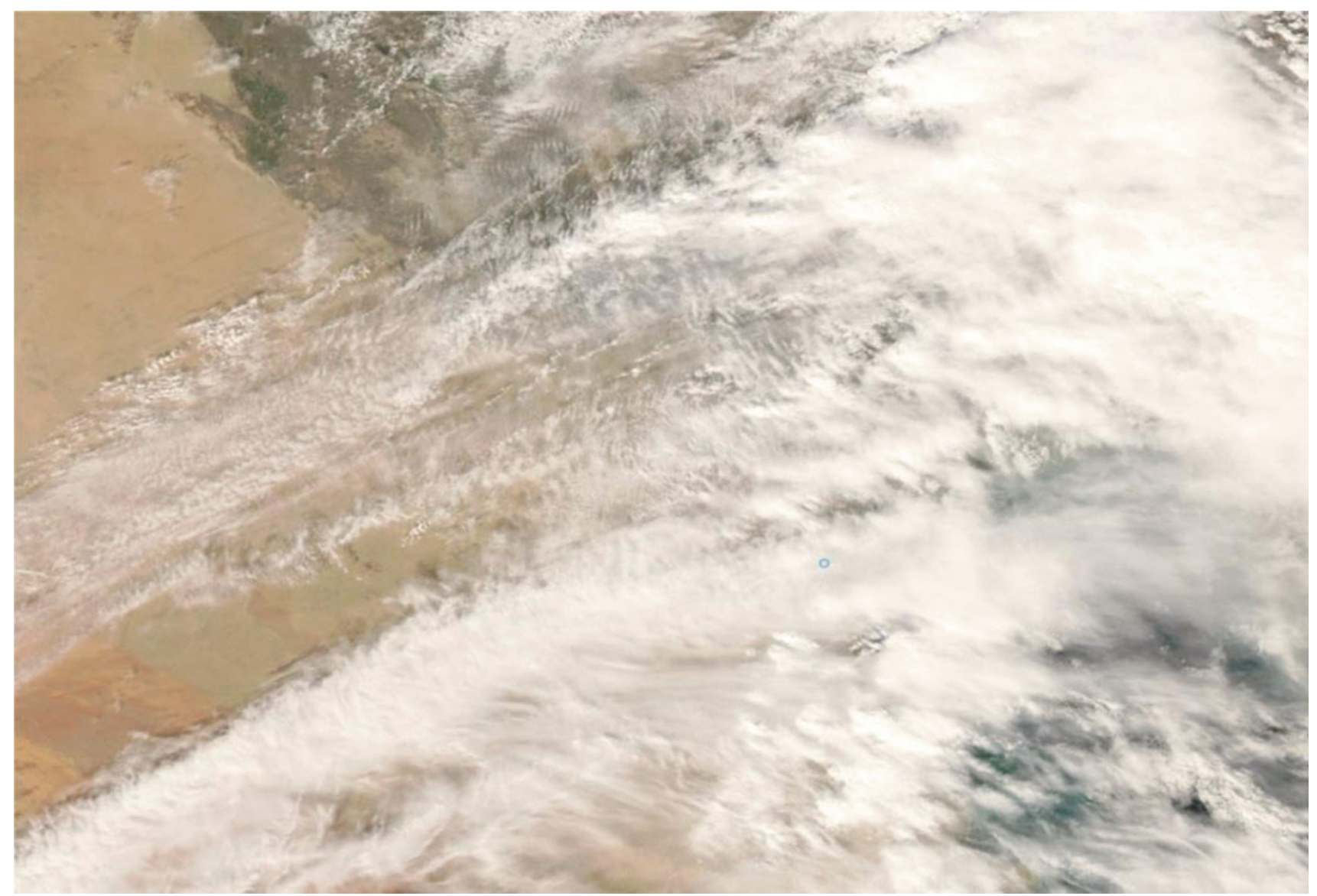

Fig. 1.29 MODIS image of dust storm that originated from the Western Desert of Iraq, covering southern Iraq, Kuwait, and the northern Arabian Gulf on 3rd February 2010

\section{Satellite Images}

A spiral multidirectional dust storm blowing from the southwest toward Kuwait on 29th July 2010. This type of dust storm trajectory is uncommon in the area. The trajectory takes the wider form, covering more than $3,000 \mathrm{~km}^{2}$ and normally blows in January, February, March, April, June, September, and October. The northwesterly trajectories' fallen dust is brighter in color, coarser in fraction size, with more sand particles (diameter more than $0.063 \mathrm{~mm}$ ), contains more quartz and feldspars but fewer carbonates and clay minerals, has a lower particle surface area, and less iron and organic matter when compared with trajectories from the Mesopotamian Floodplain. The following weather data were recorded on 29th July 2010 (Fig. 1.40):
- The local prevailing wind direction (south-southeast, southeast, east- southeast) agrees with that deduced from the image. Note that there is a huge west-southwest wind component.

- The south-southeast, southeast, and east-southeast wind directions represent $11.5 \%, 16.1 \%$, and $14.1 \%$, respectively, of the total hourly wind count for that day. The west-southwest component represents $14.6 \%$.

\section{Satellite Images}

A small, unidirectional dust storm on 10th August 2010 that originated in southeastern Kuwait. The storm has a smaller trajectory, covering the southern area of Kuwait, but 


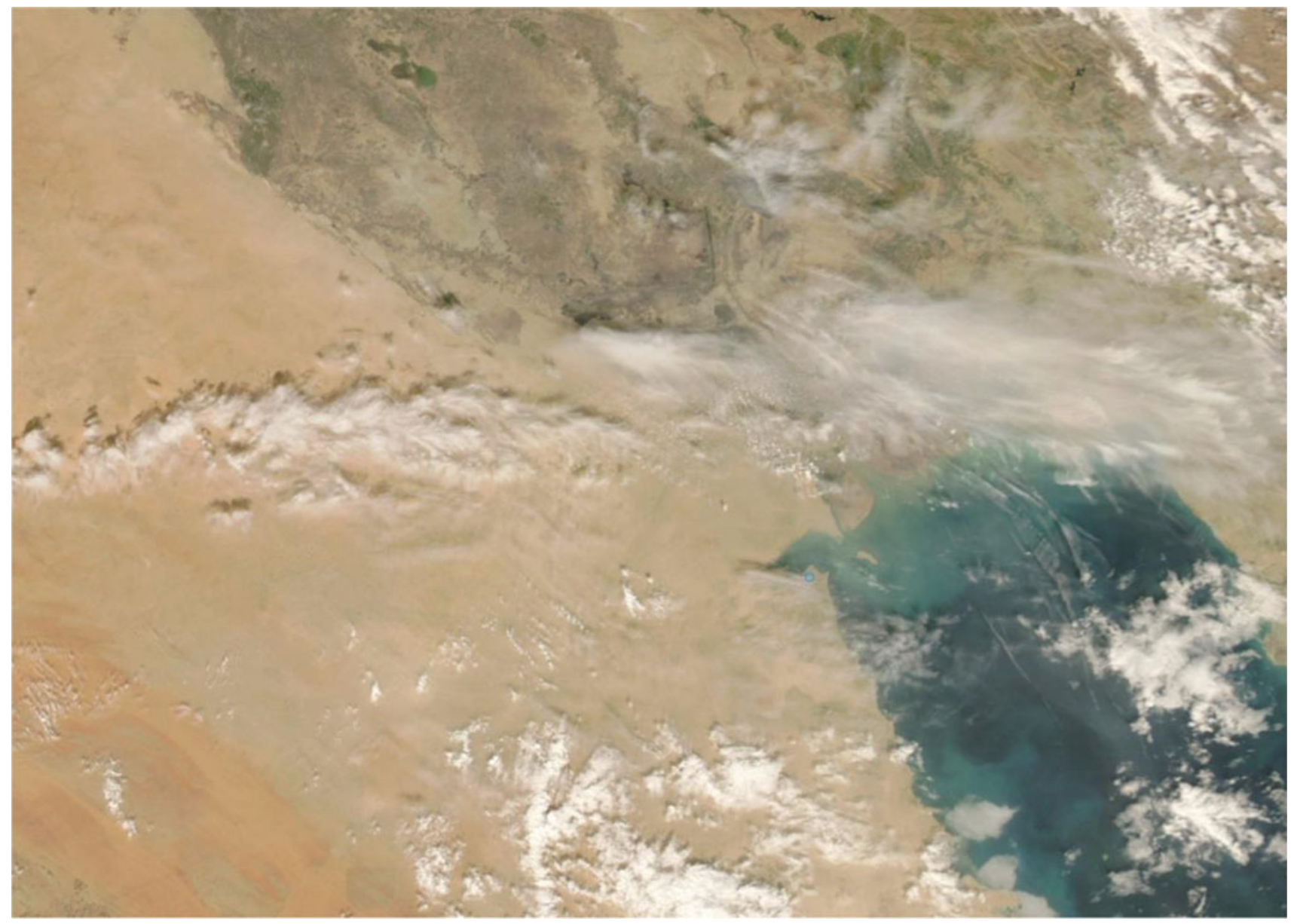

Fig. 1.30 MODIS image of dust storm that originated from the Western Desert of Iraq, covering southern Iraq, Kuwait, and the northern Arabian Gulf on 13th February 2010

contains the largest particles of dust, which have the highest quartz content and the smallest surface area compared with other trajectories. This type of trajectory is not in a straight line but is curved because of the wind from the sea. The settlement time is quick, as it contains large particles, mainly sand and coarse silt (Fig. 1.41).

The following weather data were recorded on 10th August 2010:

- The local prevailing wind direction: east, east-southeast, southeast. The skies reflect this direction (i.e., the wind is clear of sand), and this agrees with that deduced from the image. There is a northwest wind component.

- The southeast, east-southeast, east wind directions represent $13.0 \%, 13.0 \%$, and $10.4 \%$, respectively, of the total hourly wind count for that day. The northwest component represents $9.4 \%$.

\section{Satellite Images}

A small dust storm that originated from a regional but short distance and local source areas of dust. This type of dust is brighter in color, has coarse size particles that contain more quartz but fewer carbonates and a lower surface area than from dust storms from the north and northeast. The following weather data were recorded on 31st August 2010 (Fig. 1.42):

- The local prevailing wind direction: west-northwest, west. The dominant wind speed category is $3.6-5.7 \mathrm{~m} / \mathrm{s}$; hence, not much dust is evident in the image.

- The west-northwest and west wind directions represent $30.2 \%$ and $26.0 \%$, respectively, of the total hourly wind count for that day. 


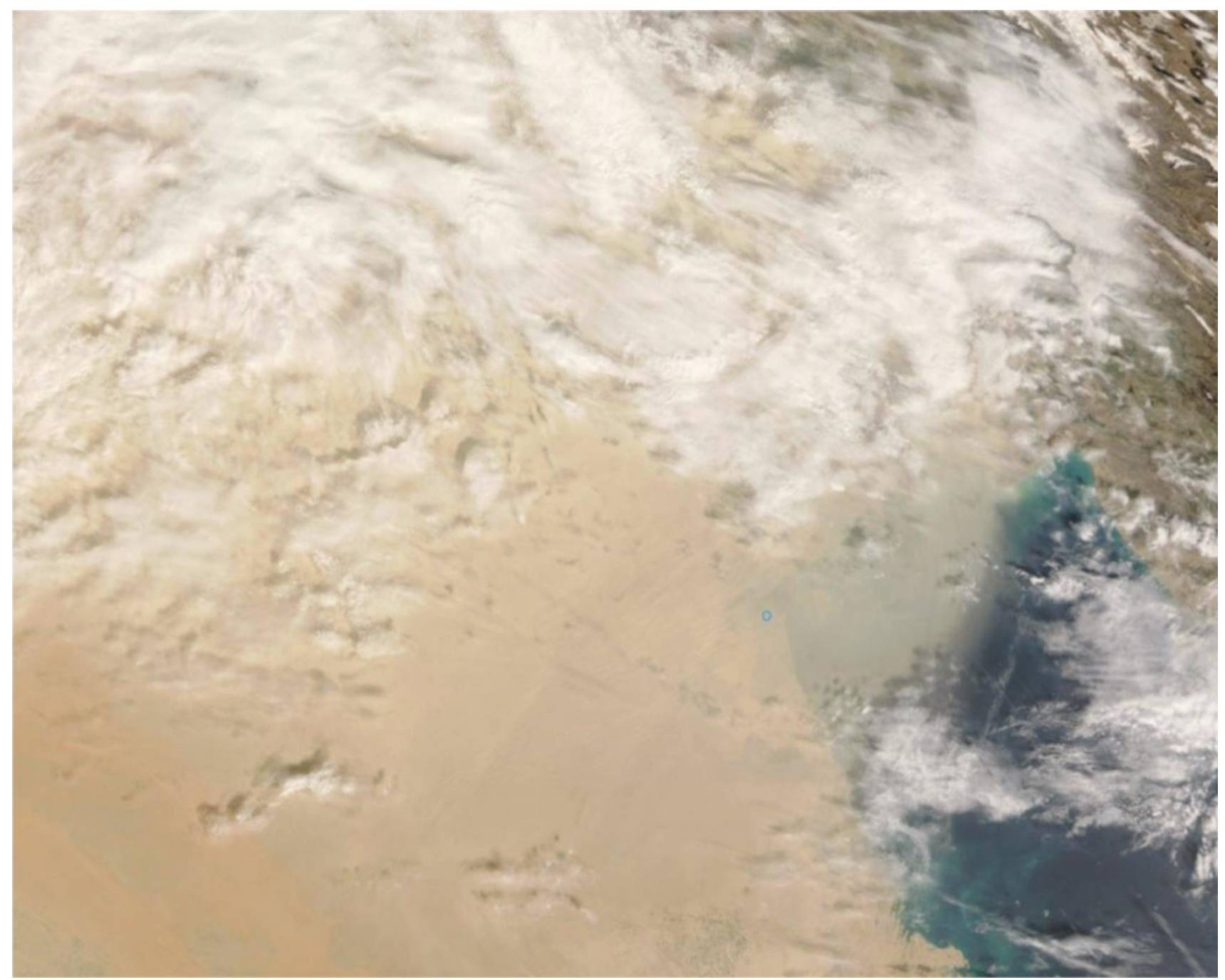

Fig. 1.31 MODIS image of dust storm that originated from the Western Desert of Iraq, covering southern Iraq, Kuwait, and the northern Arabian Gulf on 23rd February 2010

\section{Satellite Images}

A small dust storm blowing from the northwest, covering small areas less than $3000 \mathrm{~km}^{2}$. This type of dust storm forms commonly from intermediate regional and local source areas. This type of dust contains more quartz, fewer carbonates and heavy minerals, larger particles, has a smaller surface area and quicker settling time in comparison with broader scale dust storms from the same direction. The following weather data were recorded on 10th October 2010 (Fig. 1.43): 


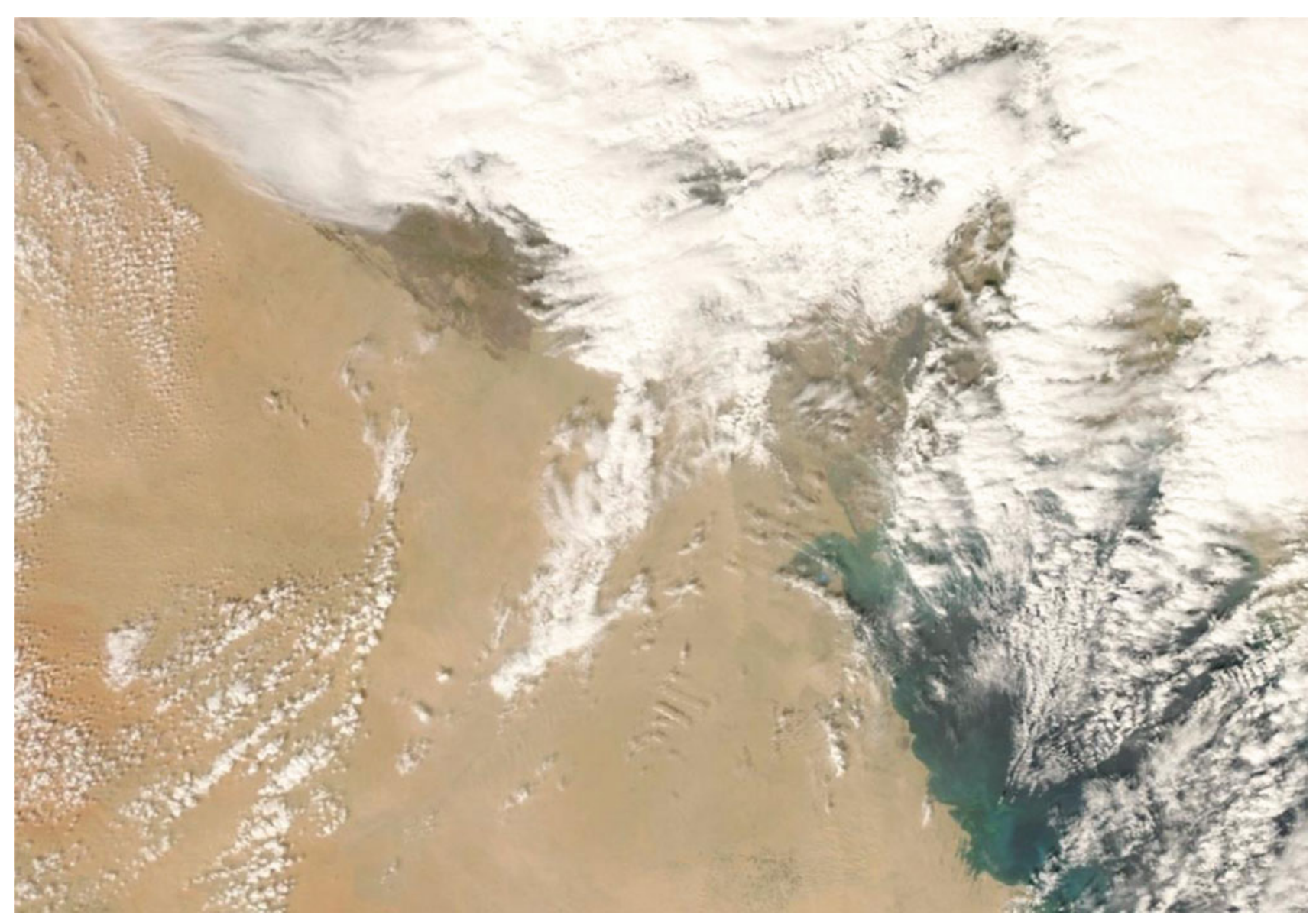

Fig. 1.32 MODIS image of dust storm that originated from the Western Desert of Iraq, covering southern Iraq, Kuwait, and the northern Arabian Gulf on 26th February 2010

- The local prevailing wind direction: northwest, north-northwest, north.

- The northwest, north-northwest, and north wind directions represent $19.3 \%, 22.9 \%$, and $21.4 \%$, respectively, of the total hourly wind count for that day.

\section{Satellite Images}

A strong unidirectional dust storm blowing from northern Arabia and the Western Desert of Iraq toward Kuwait and the Arabian Gulf on 13th December 2010. This type of dust storm trajectory takes the wider form, covering more than $3,000 \mathrm{~km}^{2}$ (Fig. 1.44).

The following weather data were recorded on 13th December 2010:

- The local prevailing wind direction (northwest, west-northwest) agrees with that deduced from the image. Note that there is a huge south-southeast wind component.

- The northwest and west-northwest wind directions represent $24.5 \%$ and $30.7 \%$, respectively, of the total hourly wind count for that day. The south-southeast component represents $17.7 \%$. 


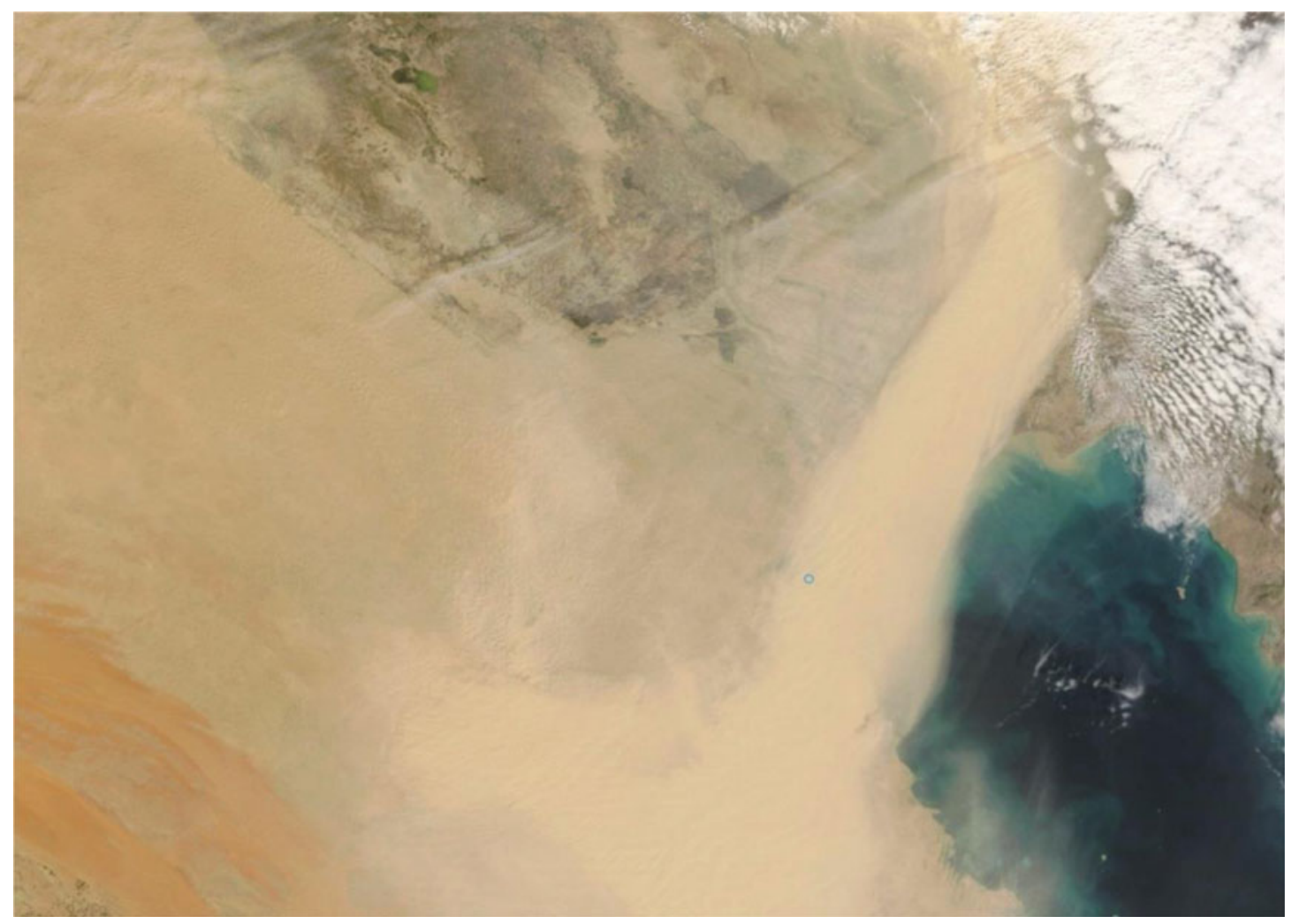

Fig. 1.33 MODIS image of dust storm that originated from the Western Desert of Iraq, covering southern Iraq, Kuwait, and the northern Arabian Gulf on 4th March 2010

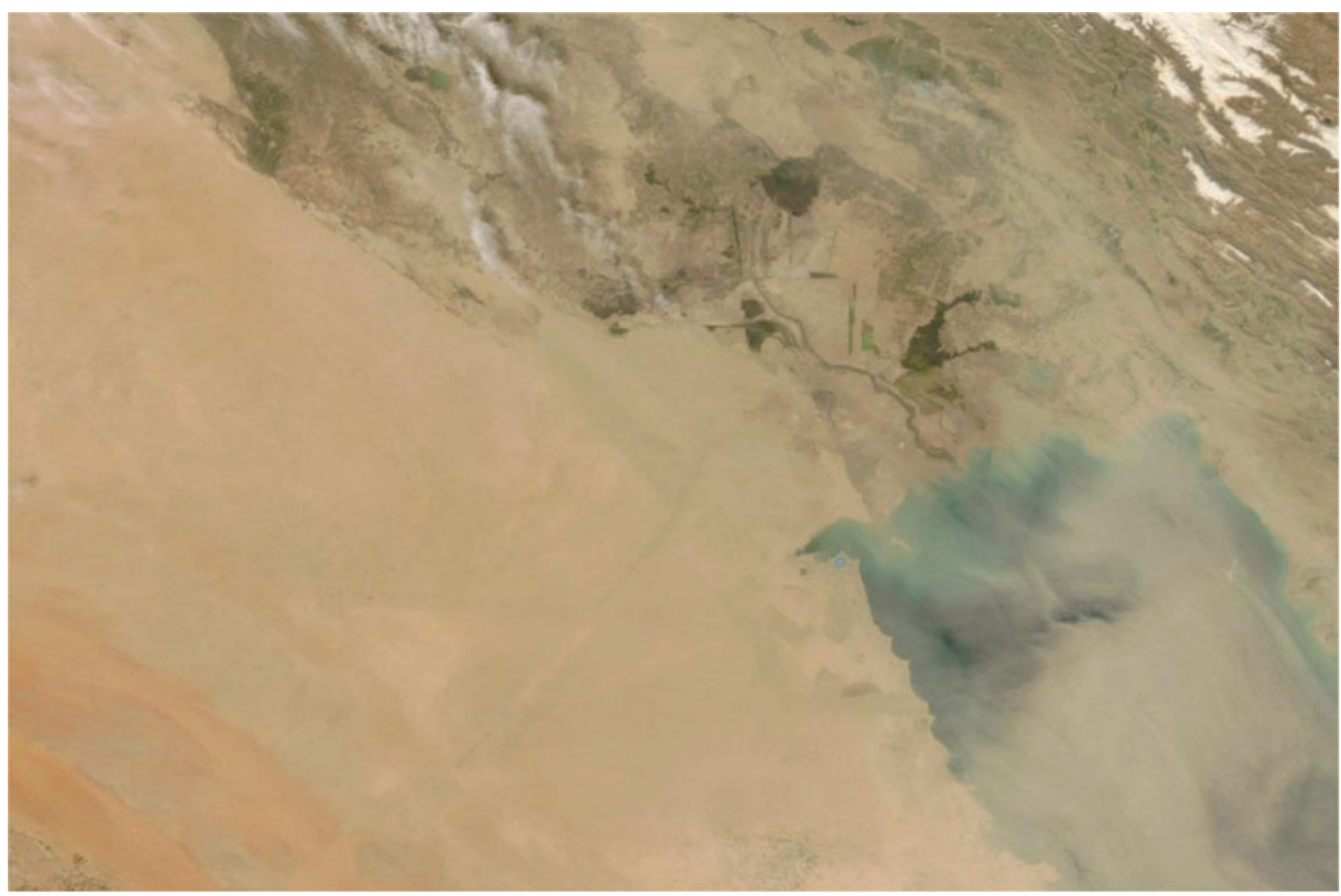

Fig. 1.34 MODIS image of dust storm that originated from the Western Desert of Iraq, covering southern Iraq, Kuwait, and the northern Arabian Gulf on 5th March 2010 


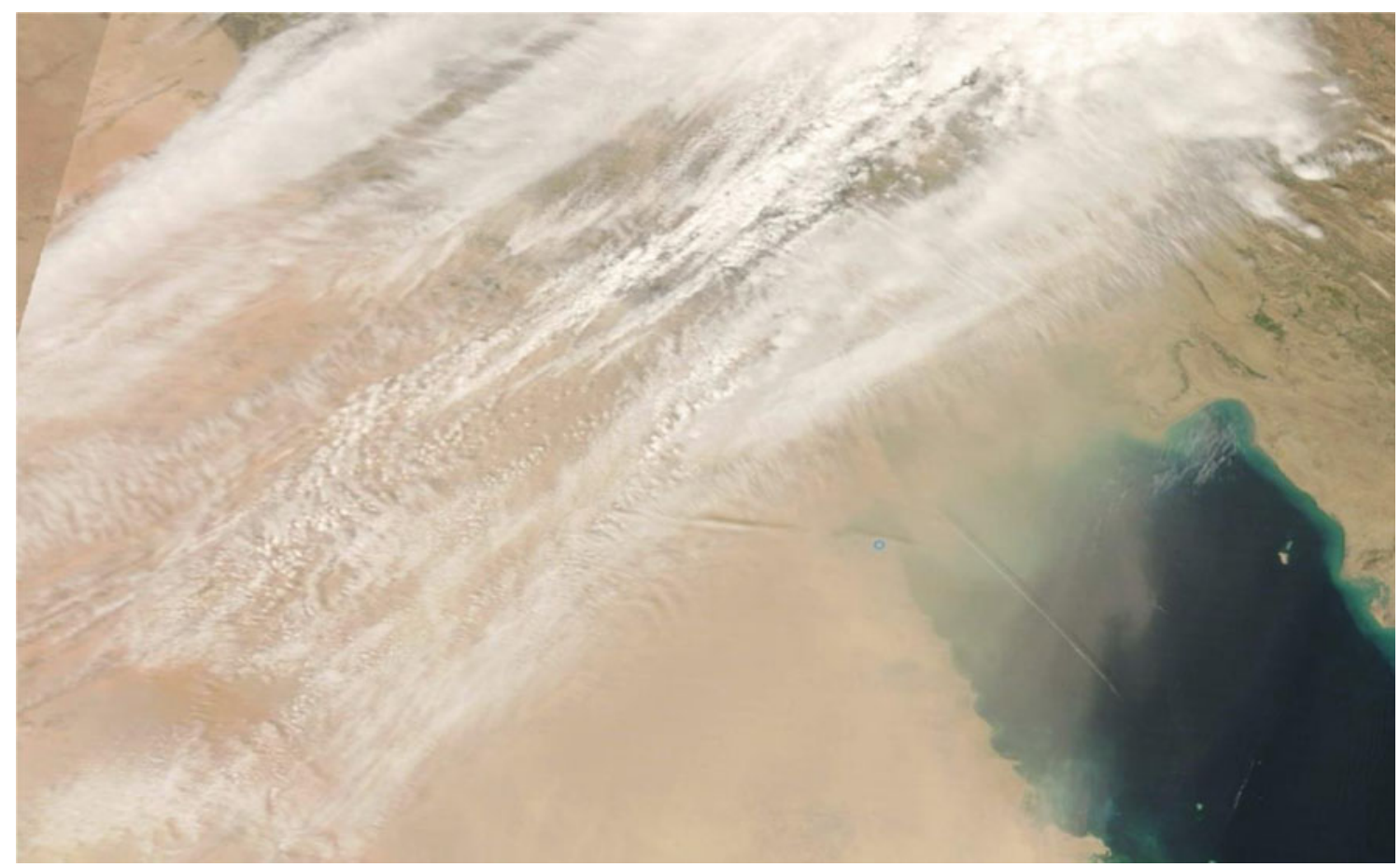

Fig. 1.35 MODIS image of dust storm that originated from the Western Desert of Iraq, covering southern Iraq, Kuwait, and the northern Arabian Gulf on 19th March 2010

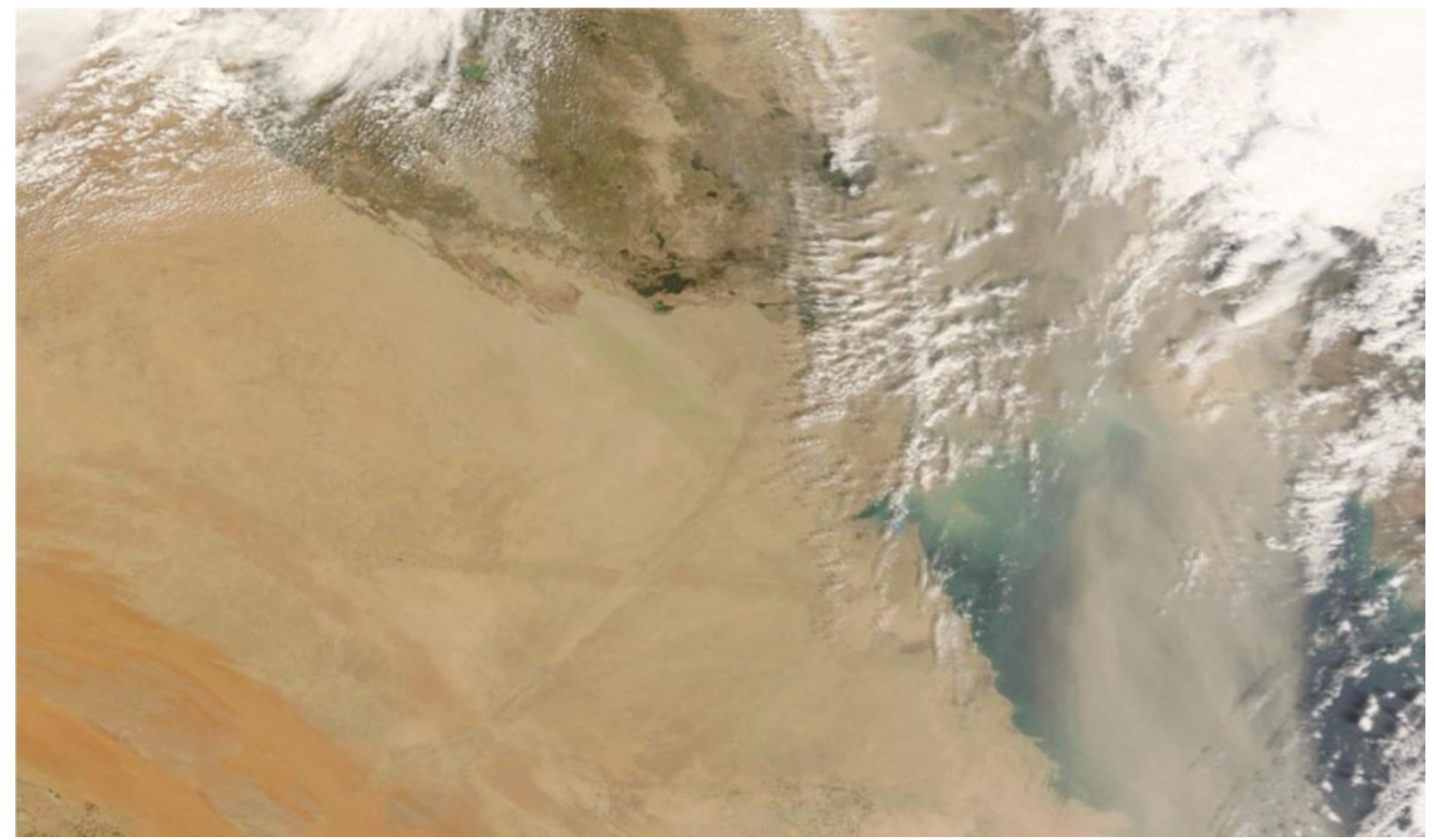

Fig. 1.36 MODIS image of dust storm that originated from the Western Desert of Iraq, covering southern Iraq, Kuwait, and the northern Arabian Gulf on 27th March 2010 


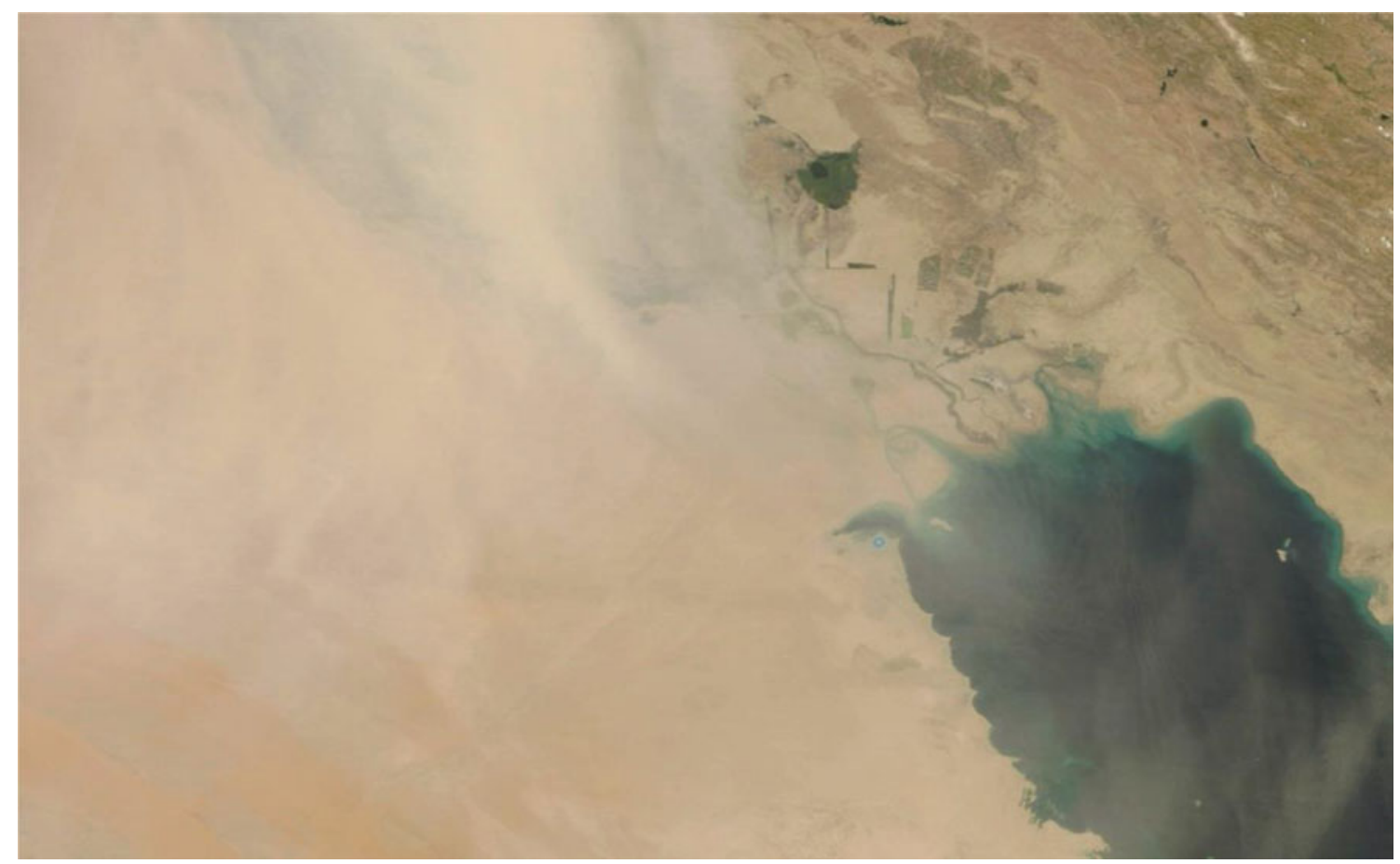

Fig. 1.37 MODIS image of dust storm that originated from the Western Desert of Iraq, covering southern Iraq, Kuwait, and the northern Arabian Gulf on 7th June 2010

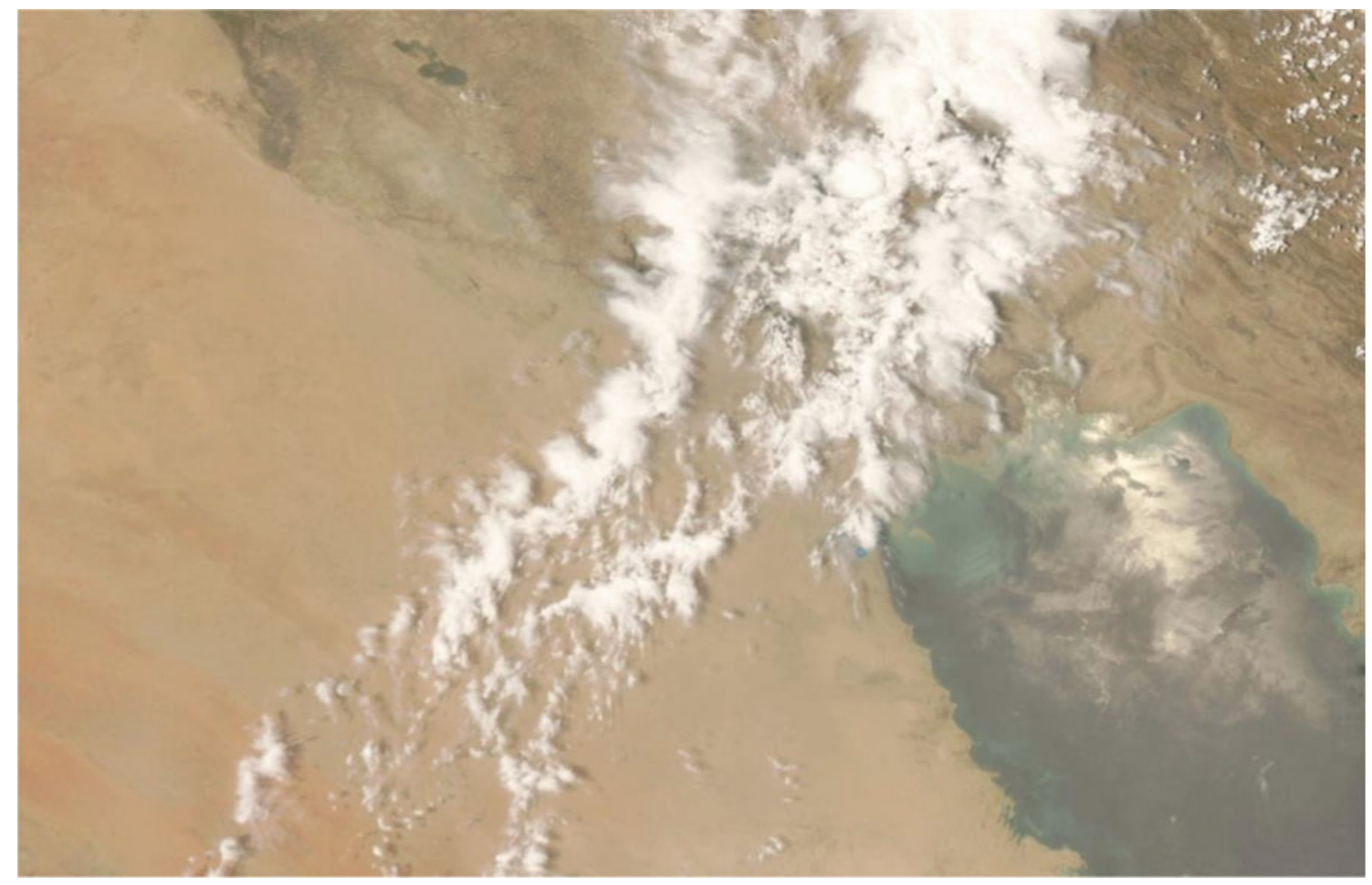

Fig. 1.38 MODIS image of dust storm that originated from the Western Desert of Iraq, covering southern Iraq, Kuwait, and the northern Arabian Gulf on 20th June 2010 


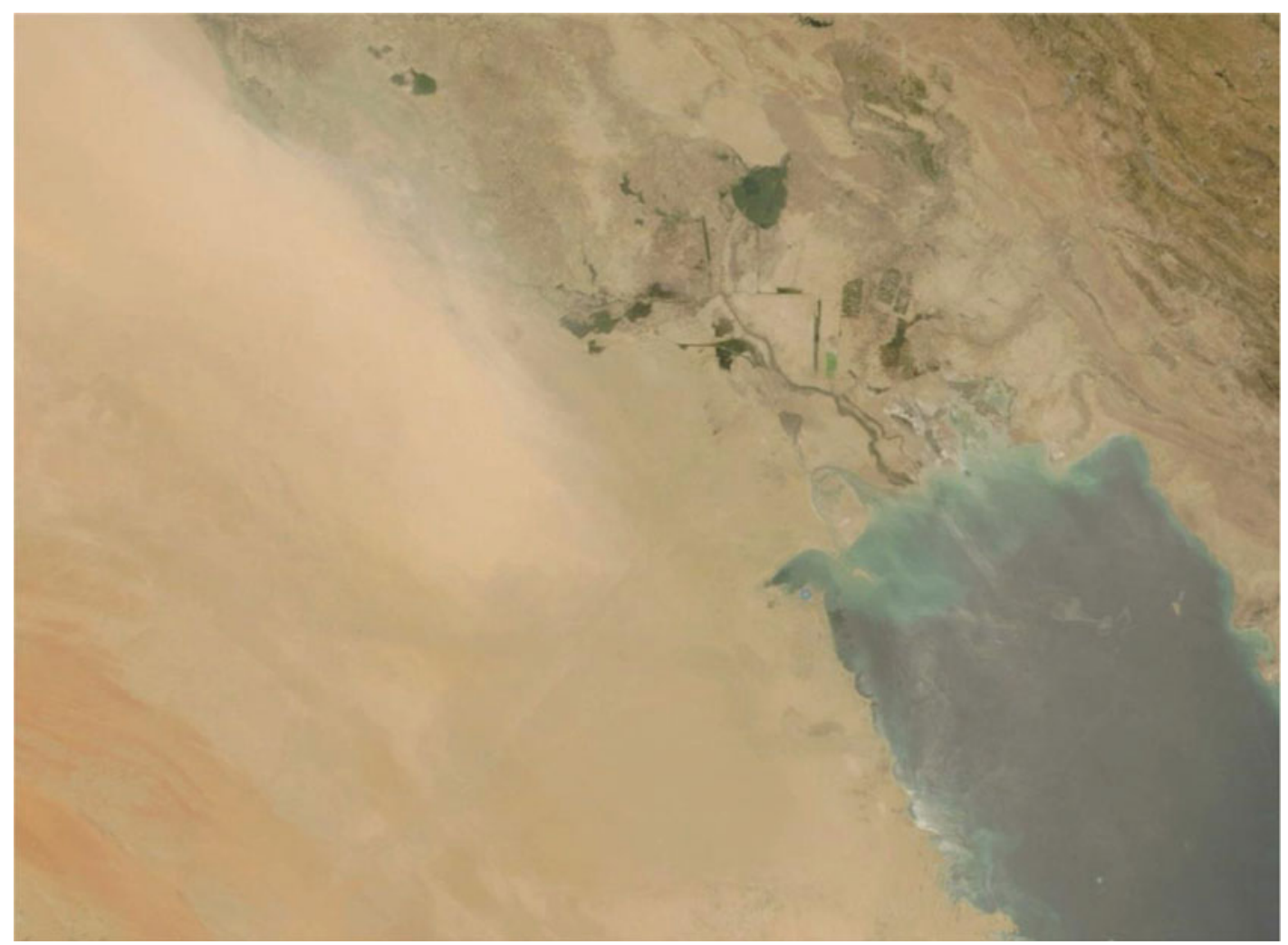

Fig. 1.39 MODIS image of dust storm that originated from the Western Desert of Iraq, covering southern Iraq, Kuwait, and the northern Arabian Gulf on 28th July 2010

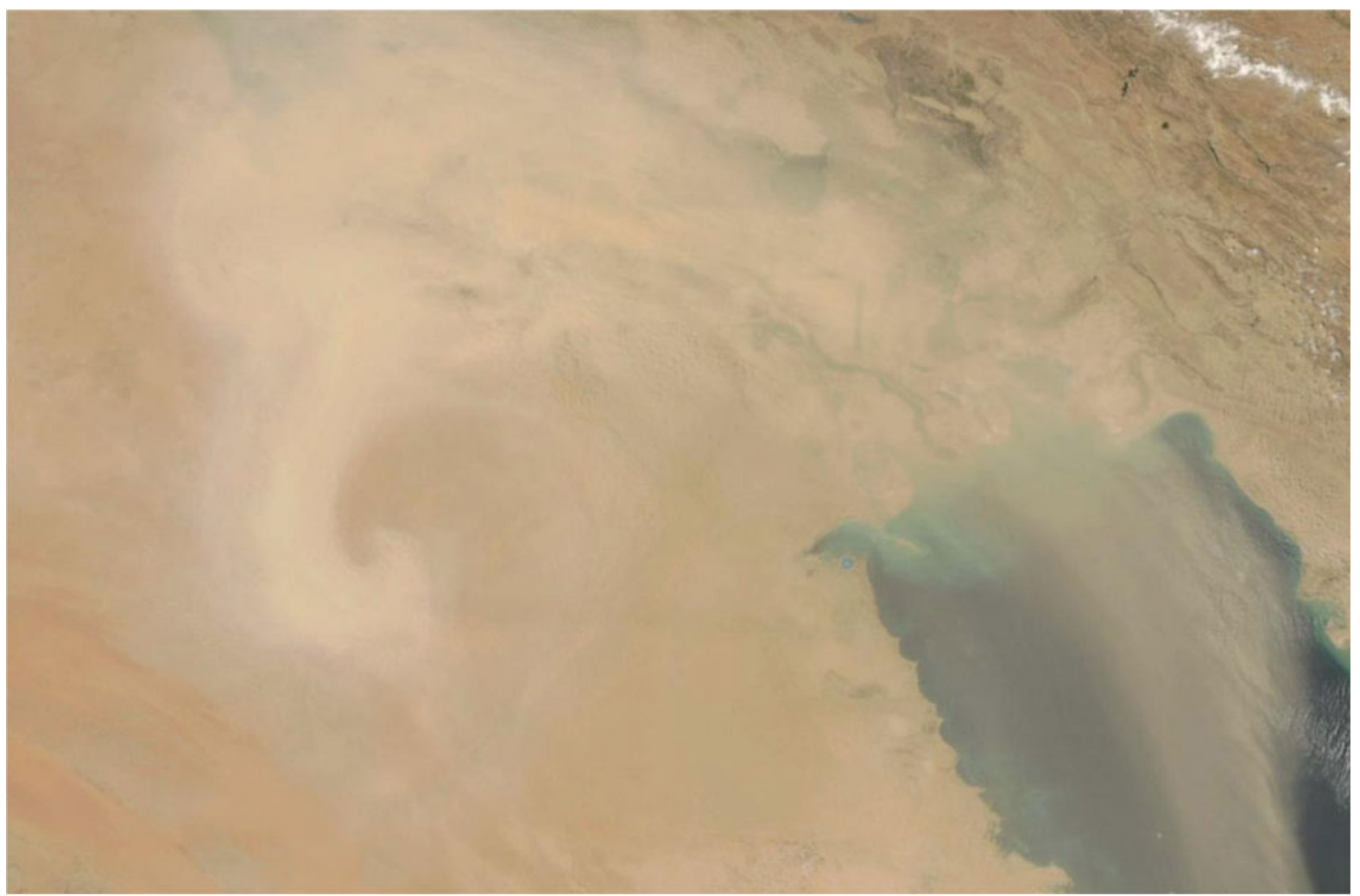

Fig. 1.40 MODIS image of dust storm that originated from the Western Desert of Iraq, covering southern Iraq, Kuwait, and the northern Arabian Gulf on 29th July 2010 


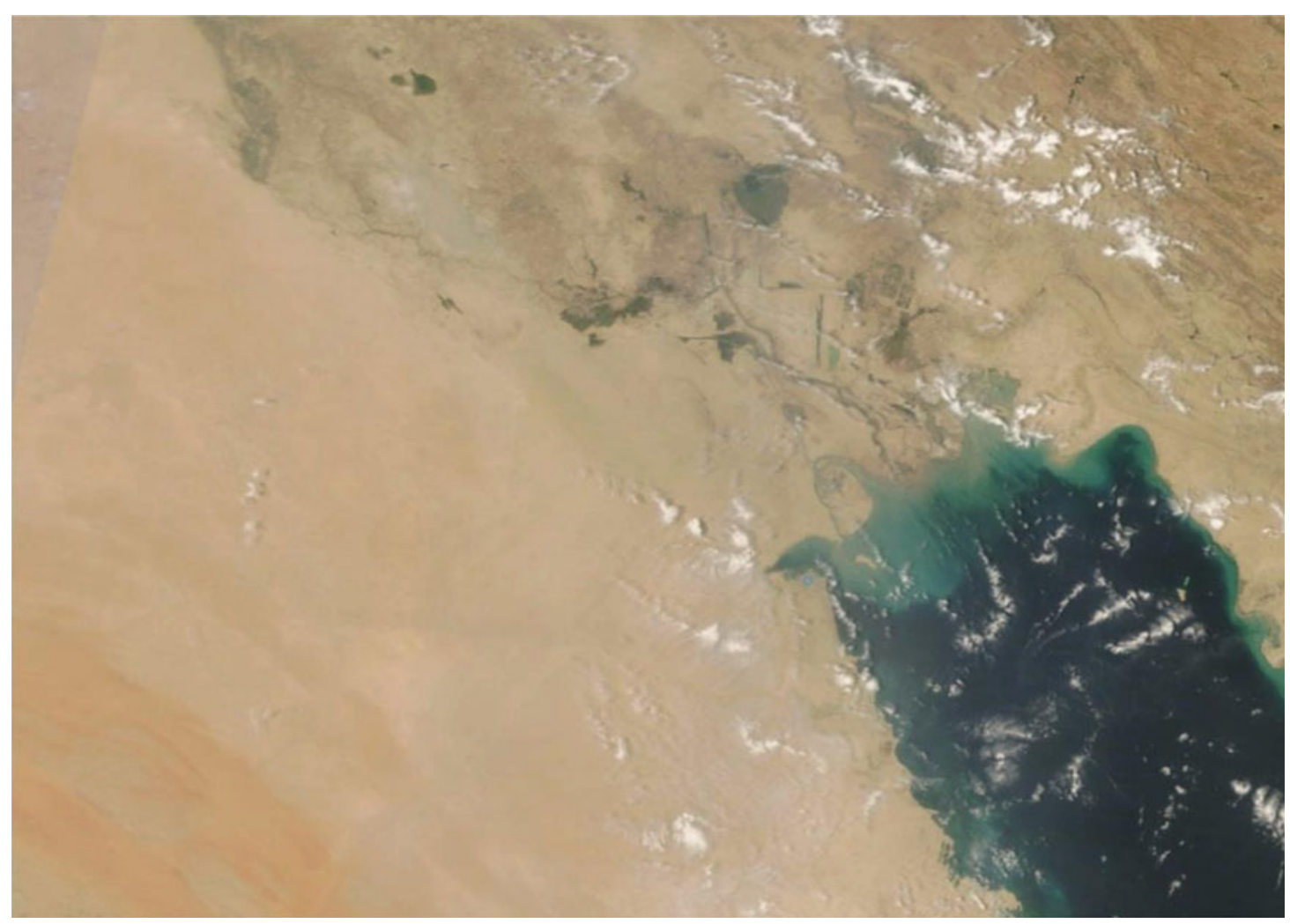

Fig. 1.41 Satellite image showing the State of Kuwait and surroundings - taken on 10th August 2010

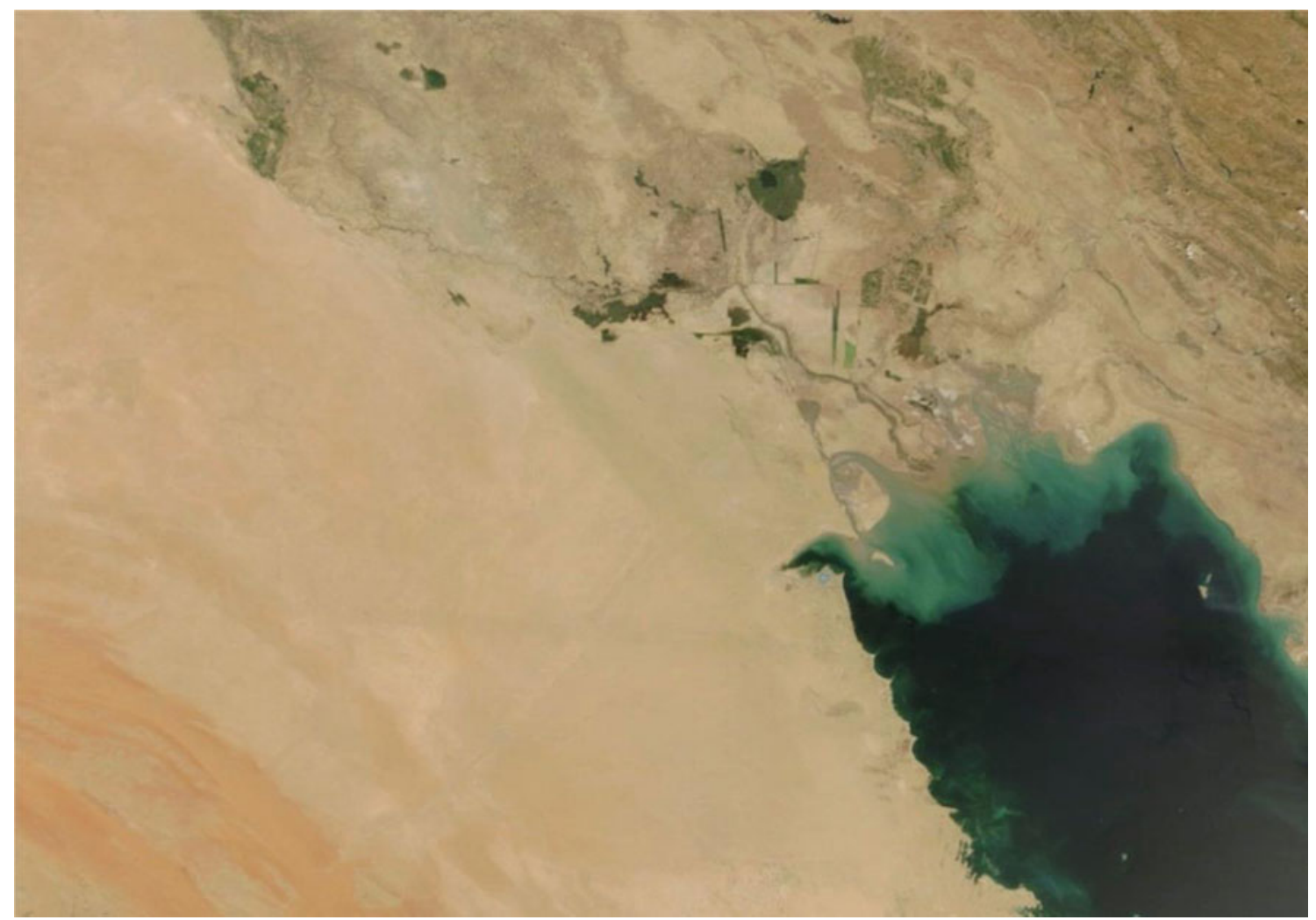

Fig. 1.42 Satellite image showing the State of Kuwait and surroundings - taken on 31st August 2010 


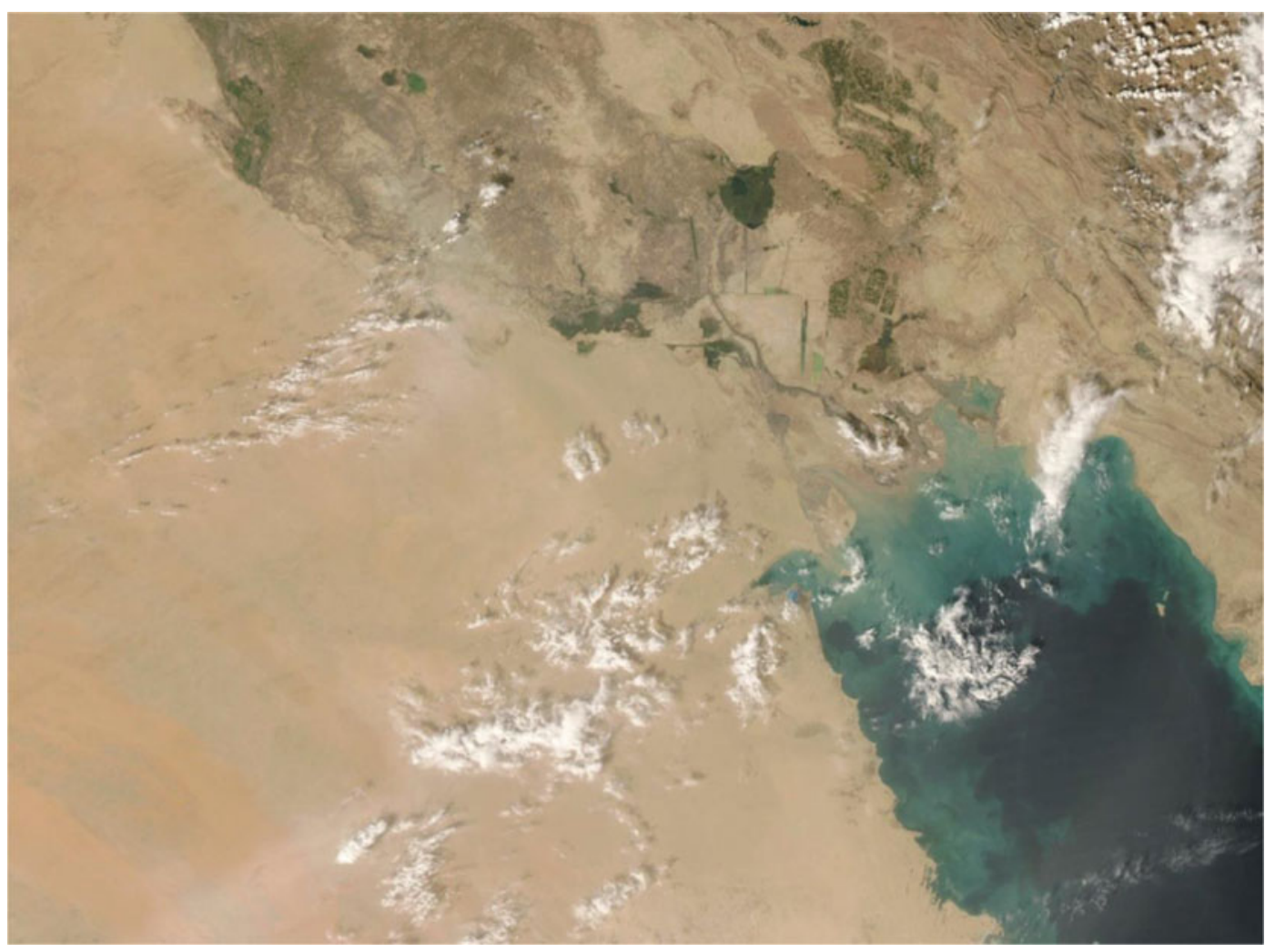

Fig. 1.43 Satellite image showing the State of Kuwait and surroundings - taken on 10th October 2010

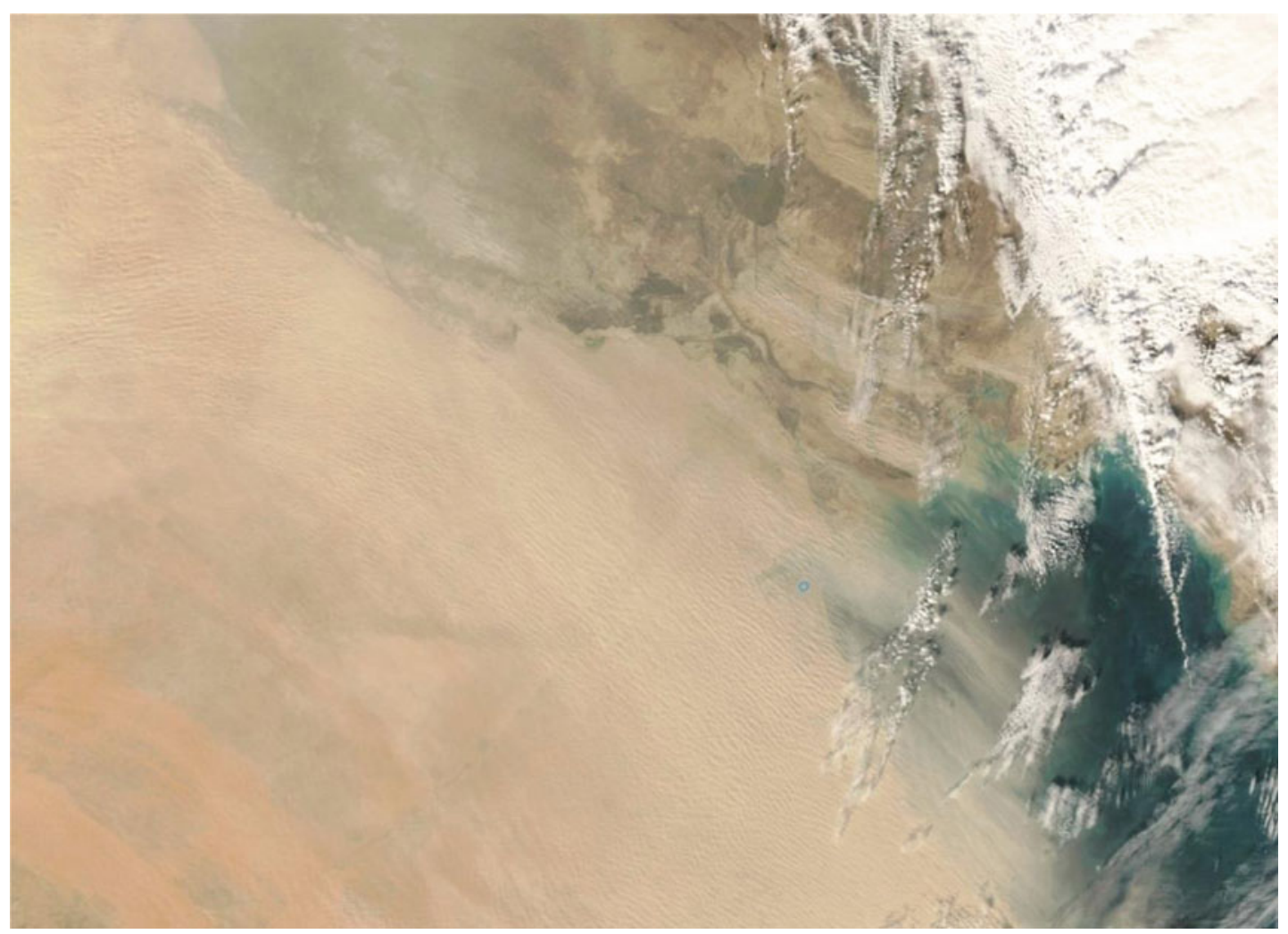

Fig. 1.44 Satellite image showing the State of Kuwait and surroundings - taken on 13th December 2010 


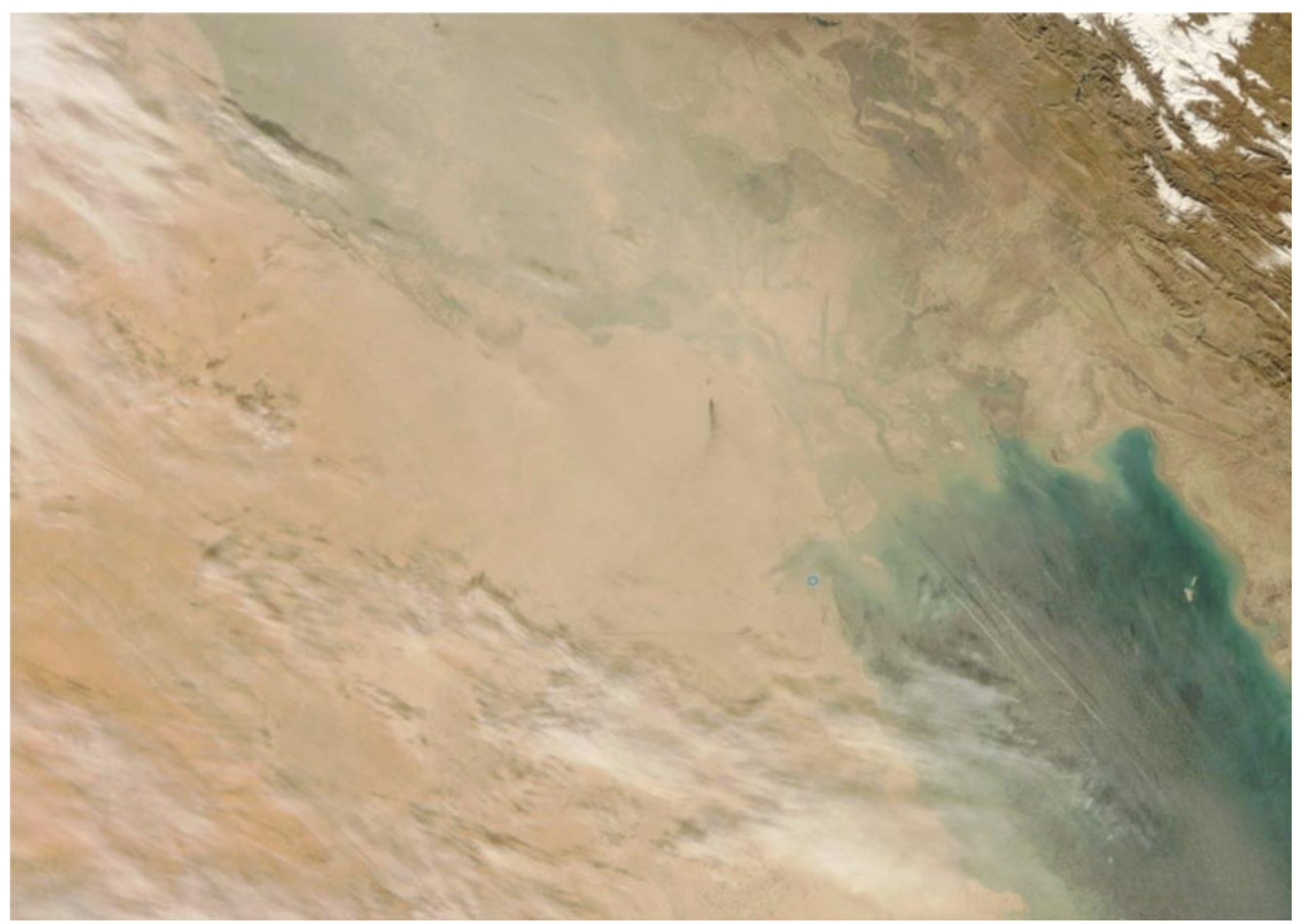

Fig. 1.45 Satellite image showing the State of Kuwait and surroundings - taken on 14th December 2010

\section{Satellite Images}

A unidirectional dust storm blowing from northern Arabia and the Western Desert of Iraq toward Kuwait on 14th December 2010. This dust storm trajectory takes the wider form and blows normally in January, February, March, April, June, September, and October. Additionally, moderate trajectories are common in March, May, June, July, and August. The dust in these trajectories is brighter in color, coarser in fraction size, with more sand particles, contains more quartz and feldspars but fewer carbonates and clay minerals, has a lower particle surface area, and less iron and organic matter when compared with trajectories from the Mesopotamian Floodplain. The following weather data were recorded on 14th December 2010 (Fig. 1.45):

- The local prevailing wind direction (west-northwest, northwest, north-northwest) agrees with that deduced from the image.

- The west-northwest, northwest, and north-northwest wind directions represent $29.7 \%, 29.2 \%$, and $19.8 \%$, respectively, of the total hourly wind count for that day.

\section{References}

Ahmed, M., \& Al-Dousari, A. (2013). Geomorphological characteristics of the Um-Rimam depression in northern Kuwait. Kuwait Journal of Science, 40(1), 165-178.

Al-Awadhi, J. (2005). Dust fallout characteristics in Kuwait: A case study. Kuwait Journal of Science and Engineering, 32(2), 135-152. ISSN: $1024-8684$.

Al-Awadhi, J. M., \& Al-Dousari, A. M. (2013). Morphological characteristics and development of coastal nabkhas, north-east Kuwait. International Journal of Earth Sciences, 102(3), 949-958. https://doi.org/10.1007/s00531-012-0833-9.

Al-Awadhi, J. M., Al-Dousari, A. M., \& Khalaf, F. I. (2014). Influence of land degradation on the local rate of dust fallout in Kuwait. Atmospheric and Climate Sciences, 4(03), 437-446. https://doi.org/ 10.4236/acs.2014.43042.

Al-Dabbas, M., Abbas, M. A., \& Al-Khafaji, R. (2011). The mineralogical and micro-organisms effects of regional dust storms over Middle East region. International Journal of Water Resources and Arid Environments 1.2 (2011), 129-141. ISSN 2079-7079

Al-Dousari, A. M., Al-Enezi, A., \& Al-Awadhi, J. M. (2008). Textural variations within different representative types of dunes in Kuwait. Arabian Journal of Geosciences, 1, 17-31. https://doi.org/10.1007/ s12517-008-0002-4.

Al-Dousari, A., \& Al-Hazza, A. (2013). Physical properties of aeolian sediments within major dune corridor in Kuwait. Arabian Journal of Geosciences, 6(2), 519-527. https://doi.org/10.1007/s12517-0110353-0. 
Al-Dousari, A., Doronzo, D., \& Ahmed, M. (2017). Types, indications and impact evaluation of sand and dust storms trajectories in the Arabian Gulf. Sustainability, 9(9), 1526. https://doi.org/10.3390/ su9091526.

Al-Dousari, A. M., Ahmed, N.-D., \& Al-Awadhi, S. (2018). Native plants in Kuwait: environmental and economic perspective. Journal of the Gulf and Arabian Peninsula Studies, 44(168), 277-310.

Al-Dousari, A. M., M. I. Ibrahim, Al-Dousari, N., Ahmed, M., \& Al-Awadhi, S. (2018b). Pollen in aeolian dust with relation to allergy and asthma in Kuwait. Aerobiologia, 1-12. https://doi.org/ 10.1007/s10453-018-9516-8.

Al-Dousari, A. M., \& Al-Awadhi, J. (2012). Dust fallout in northern Kuwait: Major sources and characteristics. Kuwait Journal of Science, 39, 171-187.

Al-Dousari, A. M. (2009). Section III: Recent studies on dust fallout within preserved and open areas in Kuwait. In N.R. Bhat, A.Y. Al-Nasser, \& S. Omar (Eds.), Desertification in Arid lands: Causes, consequences and mitigation (pp. 137-148). Kuwait: Kuwait Institute for Scientific Research.

Al-Ghadban, A. N., Uddin, S., Beg, M. U., Al-Dousari, A. M., Gevao, B., \& Al-Yamani, F. (2008). Ecological consequences of river manipulations and drainage of Mesopotamian marshes on the Arabian Gulf ecosystem: Investigations on changes in sedimentology and environmental quality, with special reference to Kuwait Bay. Kuwait Institute for Scientific Research (KISR), 9362, 1-141. https://doi.org/10.13140/RG.2.2.10969.62562.

Alpert, P., Kaufman, Y. J., El-Shay, Y., Tanre, D., da Silva, A., Schubert, S., \& Joseph, J. H. (1998). Quantification of dust-forced heating of the lower troposphere. Nature, 394, 367-370. https://doi. org/10.1038/26456.

Awadh, S. M. (2012). Geochemistry and mineralogical composition of the airborne particles of sand dunes and dust storms settled in Iraq and their environmental impacts. Environmental Earth Sciences, 66 (8), 2247-2256. https://doi.org/10.1007/s12665-011-1445-6.

Boucher, O., \& Haywood, J. (2001). On summing the components of radiative forcing of climate change. Climate Dynamics, 18, 297 302. https://doi.org/10.1007/s003820100185.

Boyles, R. P., \& Raman, S. (2003). Analysis of climate trends in North Carolina (1949-1998). Environment International, 29(2003), 263275. https://doi.org/10.1016/S0160-4120(02)00185-X.

Chi, K. H., Hsu, S. C., Wang, S. H., \& Chang, M. B. (2008). Increases in ambient PCDD/F and PCB concentrations in Northern Taiwan during an Asian dust storm episode. Science of the Total Environment, 401 (1-3), 100-108. https://doi.org/10.1016/j.scitotenv.2008.03.041.

Chrysikou, L. P., Gemenetzis, P. G., \& Samara, C. A. (2009). Wintertime size distribution of polycyclic aromatic hydrocarbons (PAHs), polychlorinated biphenyls (PCBs) and organochlorine pesticides (OCP) in the urban environment: Street-vs rooftop-level measurements. Environmental Pollution, 43, 290300. https://doi.org/10.1016/j.atmosenv.2008.09.048.

Di-lella, L., Protano, G., Loppi, S., \& Riccobono, F. (2006). Toxic trace elements and organic compounds in the ambient air of Kabul, Afghanistan. Atmospheric Environment, 40(2), 225-237. https:// doi.org/10.1016/j.atmosenv.2005.09.052.

Diner, D., Beckert, J., Reilly, T. H., Bruegge, C., Conel, J. E., Kahn, R. A., et al. (1998). Multi-angle Imaging SpectroRadiometer (MISR) Instrument Description and experiment overview. IEEE Transactions Geoscience Remote Sensing, 36, 1072-1087. https://doi.org/ 10.1109/36.700992.

Diner, D., Martonchik, J. J., Kahn, R. A., Verstraete, M., \& Pinty, B. (2002). Characterization of tropospheric aerosols: new insights from MISR on Terra. AGU fall meeting Abstracts.

Dockery, D. W., Pope, C. A., Xiping, X., Spengler, J. D., Ware, J. H., Fay, M. E., et al. (1993). An association between air pollution and mortality in six US cities. The New England Journal of Medicine, 329, 1753-1759. https://doi.org/10.1056/NEJM199312093292401.

Foda, M. A., Khalaf, F. I., \& Al-Kadi, A. S. (1985). Estimation of dust fallout rates in the northern Arabian Gulf. Sedimentology, 32, 595603. https://doi.org/10.1111/j.1365-3091.1985.tb00473.x.

Garrison, V. H., Foreman, W. T., Genualdi, S., Griffin, D. W., Kellogg, C. A., Majewski, M. S., et al. (2006). Sahara dust-A carrier of persistent organic pollutants, metals and microbes to the Caribbean. International Journal of Tropical Biology and Conservation, 54 (Supplement 3), 9-21. https://doi.org/10.15517/rbt.v54i3.26867.

Gevao, B., Al-Ghadban, A. N., Uddin, S., Jaward, F. M., Bahloul, M., \& Zafar, J. (2011). Polybrominated diphenyl ethers (PBDEs) in soils along a rural-urban-rural transect: Sources, concentration gradients, and profiles. Environmental Pollution, 159, 3666-3672. https://doi.org/10.1016/j.envpol.2011.07.021.

Goudie, A. S., \& Middleton, N. J. (2001). Saharan dust storms: Nature and consequences. Earth-Science Reviews, 56, 179-204. https://doi. org/10.1016/S0012-8252(01)00067-8.

Griffin, D. W. (2007). Atmospheric movement of microorganisms in clouds of desert dust and implications for human health. Clinical Microbiology Reviews, 20(3), 459-477. https://doi.org/10.1128/ CMR.00039-06.

Griffin, D. W., Kellogg, C. A., Garrison, V. H., \& Shinn, E. A. (2002). The global transport of dust. American Scientist, 90, 228-235. https://doi.org/10.1511/2002.3.228.

Hansen, J., Sato, M., Lacis, A., Ruedy, R., Tegen, I., \& Mathews, E. (1998). Climate forcings in the industrial era. Proceedings National Academy of Science, 95, 12753-12758. https://doi.org/10.1073/ pnas.95.22.12753.

Hu, D., Qiao, L., Chen, J., Ye, X., Yang, X., Cheng, T., \& Fang, W. (2010). Hygroscopicity of inorganic aerosols: Size and relative humidity effects on the growth factor. Aerosol and Air Quality Research, 10, 255-264. https://doi.org/10.4209/aaqr.2009.12.0076.

Hurtado, E., Vidal, A., \& Caselles, V. (1996). Comparison of two atmospheric correction methods for Landsat TM thermal band. International Journal of Remote Sensing, 17, 237-247. https://doi. org/10.1080/01431169608949002.

Kahn, R., \& Braverman, A. (1998). What shall we do with the data we are expecting from upcoming earth observation satellites? Journal of Computational and Graphical Statistics, 8. https://doi.org/10. 1080/10618600.1999.10474834.

Kahn, R. A., Gaitley, B. J., Martonchik, J. V., Diner, D. J., Crean, K. A., \& Holben, B. (2005a). MISR global aerosol optical depth validation based on two years of coincident Aeronet observations. Journal Geophysical Research, 110, D10S04. https://doi.org/10. 1029/2004JD004706.

Kahn, R., Banerjee, P., \& McDonald, D. (2001). The sensitivity of Multiangle Imaging to natural mixtures of aerosols over ocean. Journal Geophysical Research, 106, 18219-18238. https://doi.org/ 10.1029/2000JD900497.

Kahn, R., Banerjee, P., McDonald, D., \& Diner, D. (1998). Sensitivity of multiangle imaging to aerosol optical depth, and to pure-particle size distribution and composition over ocean. Journal of Geophysical Research, 103(D24), 32195-32213. https://doi.org/10.1029/ 98JD01752.

Kahn, R., Li, W.-H., Martonchik, J., Bruegge, C., Diner, D., Gaitley, B., et al. (2005). MISR low-light-level calibration, and implications for aerosol retrieval over dark water. Journal of Atmospheric Sciences, 62, 1032-1062. https://doi.org/10.1175/JAS3390.1.

Katz, M., \& Chan, C. (1980). Comparative distribution of eight polycyclic aromatic hydrocarbons in airborne particulates collected by conventional high-volume sampling and by size fractionation. Environmental Science and Technology, 14, 838-843. https://doi. org/10.1021/es60167a010. 
Kaufman, Y. J., Tanré, D., Remer, L., Vermote, E. F., Chu, A., \& Holben, B. N. (1997). Operational remote sensing of tropospheric aerosol over the land from EOS-MODIS. Journal of Geophysical Research, 102, 17051-17068. https://doi.org/10.1029/96JD03988.

King, M. D., Menzel, W. P., \& Tanré, D. (1992). Remote sensing of cloud, aerosol, and water vapor properties from the Moderate Resolution Imaging Spectrometer (MODIS). IEEE Transactions on Geoscience and Remote Sensing, 30, 2-27. https://doi.org/10.1109/36.124212.

King, M. D., Kaufman, Y. J., Tanré, D. A., \& Nakajima, T. (1999). Remote sensing of tropospheric aerosols from space: Past, present, and future. Bulletin of the American Meteorological Society, 80(11), 2229-2259. https://doi.org/10.1175/1520-0477(1999)080\%3c2229: RSOTAF\%3e2.0.CO;2.

Lewis, R. G., Fortune, C. R., Willis, R. D., Camann, D. E., \& Antley, J. T. (1999). Distribution of pesticides and polycyclic aromatic hydrocarbons in house dust as a function of particle size. Environmental Health Perspective, 107, 721-726. https://doi.org/ 10.1289/ehp.99107721.

Li, X., Maring, H., Savoie, D., Voss, K., \& Prospero, J. M. (1996). Dominance of mineral dust in aerosol light-scattering in the North Atlantic trade winds. Nature, 380, 416-419. https://doi.org/10. 1038/380416a0.

Liu, Y., Sarnat, J. Kilaru, V., Jacob, D., \& Koutrakis, P. (2005). Estimating ground-level PM2.5 in the eastern United States using satellite remote sensing. Environment Science and Technology, 39 (9), 3269-3278. https://doi.org/10.1021/es049352m.

Liu, Y., Kahn, R. A., Chaloulakou, A., \& Koutrakis, P. (2009). Analysis of the impact of the forest fires in August 2007 on air quality of Athens using multi-sensor aerosol remote sensing data, meteorology and surface observations. Atmospheric Environment, 43(21), 33103318. https://doi.org/10.1016/j.atmosenv.2009.04.010.

Liu, Y., Kahn, R., \& Koutrakis, P. (2007). Estimating PM2.5 component concentrations and size distributions using satellite retrieved fractional aerosol optical depth: Part I-Method development. Journal of the Air and Waste Management Association, 57 (11), 1351-1359. https://doi.org/10.3155/1047-3289.57.11.1351

Liu, Y., Park, R. J., Jacob, D. J., Li, Q. B., Kilaru, V., \& Sarnat, J. A. (2004). Mapping annual mean ground-level PM2.5 concentrations using Multiangle Imaging Spectroradiometer aerosol optical thickness over the contiguous United States. Journal of Geophysical Research: Atmospheres, 109(D22): Art. No. D22206. https://doi. org/10.1029/2004jd005025.

Martonchik, J., Diner, D., Kahn, R., Gaitley, B., \& Holben, B. (2004). Comparison of MISR and AERONET aerosol optical depths over desert sites. Geophysical Research Letters, 31(16): Art. No. L16. https://doi.org/10.1029/2004GL019807.

Meng and Lu. (2007). Dust events as a risk factor for daily hospitalization for respiratory and cardiovascular diseases in Minqin, China. Atmospheric Environment, 41, 7048-7058. https:// doi.org/10.1016/j.atmosenv.2007.05.006.

Miller, R. L., \& Tegen, I. (1998). Climate response to soil dust serosols. Journal of Climate, 11, 3247-3267. https://doi.org/10.1175/15200442(1998)011\%3C3247:CRTSDA\%3E2.0.CO;2.

Moulin, C., Lambert, C. E., Dulac, F., \& Dayan, U. (1997). Control of atmospheric export of dust by North Atlantic oscillation. Nature, 387, 691-694. https://doi.org/10.1038/42679.

Offenberg, J. H., \& Baker, J. E. (1999). Aerosol size distributions of polycyclic aromatic hydrocarbons in urban and over-water atmospheres. Environmental Science and Technology, 33, 3324-3331. https://doi.org/10.1021/es990089c.

Peterson, S. T., \& Junge, C. E. (1971). Sources of particulate matter in the atmosphere. In W. W. Kellog \& G. D. Robinson (Eds.), Man's Impact on the Climate (pp. 310-320). MIT Press.

Pierson, D. C., Markensten, H., \& Strömbeck, N. (2003). Long and short term variations in suspended particulate material: The influence on light available to the phytoplankton community. Hydrobiologia, 494, 299-304. https://doi.org/10.1023/A: 1025455424972.

Pope, C. A., III., \& Dockery, D. W. (2006). Health effects of fine particulate air pollution: Lines that connect. Journal of the Air and Waste Management Association, 56, 709-742. https://doi.org/10. 1080/10473289.2006.10464485.

Pope, C. A., Burnett, R. T., Thun, M. J., Calle, E. E., Krewski, D., Ito, K., \& Thurston, G. D. (2002). Lung cancer, cardiopulmonary mortality, and long-term exposure to fine particulate air pollution. Journal of the American Medical Association, 287, 1132-1141. https://doi.org/10.1001/jama.287.9.1132.

Prasad, A. K., \& Singh, R. P. (2007). Comparison of MISR-MODIS aerosol optical depth over the Indo-Gangetic basin during the winter and summer seasons (2000-2005). Remote Sensing of Environment, 107, 109-119. https://doi.org/10.1016/j.rse.2006.09.026.

Prospero, J. M., Ginoux, P., Torres, O., Sharon E. Nicholson, S. E., \& Gill, T. E. (2002). Environmental characteristics of global sources of atmospheric soil dust identified with the Nimbus 7 Total Ozone Mapping Spectrometer (TOMS) absorbing aerosol product. Reviews of Geophysics, 40, February 1, 2002. https://doi.org/10.1029/ 2000RG000095.

Ramanathan, V., Ramana, M. V., Roberts, G., Kim, D., Corrigan, C., Chung, C., \& Winker, D. (2007). Warming trends in Asia amplified by brown cloud solar absorption. Nature, 448, 575-578. https://doi. org/10.1038/nature06019.

Reynolds, K. A., \& Pepper, I. L. (2000). Microorganisms in the environment. San Diego, CA: Academic Press.

Ridgwell, A. J. (2002). Dust in Earth system: The biogeochemical linking of land, air and sea. Philosophical Transactions of Royal Society London, 360, 2905-2924. https://doi.org/10.1098/rsta.2002. 1096.

Safar, M. I. (1980). Frequency of dust in day-time summer in Kuwait. Kuwait: Directorate General of Civil Aviation.

Seinfeld, J. H., \& Pandis, S. N. (1998). Atmospheric chemistry and physics: From air pollution to global change. New York: Wiley.

Trenberth, K., \& Hurrell, J. W. (1994). Decadal atmosphere-ocean variations in the Pacific. Climate Dynamics., 9, 303-319. https:// doi.org/10.1007/BF00204745.

Venkataraman, C., Thomas, S., \& Kulkarni, P. (1999). Size distributions of polycyclic aromatic hydrocarbons gas/particle partitioning to urban aerosols. Journal of Aerosol Science, 30, 759-770. https:// doi.org/10.1016/S0021-8502(98)00761-7.

Walker, P. H., \& Costin, A. B. (1971). Atmospheric dust accession in south-eastern Australia. Australian Journal of Soil Research, 9, 1-5. https://doi.org/10.1071/SR9710001.

WHO. (2005). Air quality guidelines for particulate matter, ozone, nitrogen dioxide and sulfur dioxide. Global update 2005. World Health Organization, Geneva, Switzerland

Wilkerson, W. D. (1991). Dust and sand forecasting in Iraq and adjoining countries. USAF Environmental Technical Applications Center, $72 \mathrm{pp}$.

Williamson, K. E., Wommack, K. E., \& Radosevich, M. (2003). Sampling natural viral communities from soil for culture-independent analyses. Applied Environmental Microbiology, 69, 6628-6633. https://doi.org/10.1128/AEM.69.11.66286633.2003

Wu, S. P., Tao, S., \& Liu, W. X. (2006). Particle size distributions of polycyclic aromatic hydrocarbons in rural and urban atmosphere of Tianjin, China. Chemosphere, 62, 357-367. https://doi.org/10.1016/ j.chemosphere.2005.04.101.

Yates, M. V., \& Yates, S. R. (1988). Modeling microbial fate in the subsurface environment. CRC Critical Reviews in Environmental Control, 17, 307-344. https://doi.org/10.1080/10643388809388339 
Open Access This chapter is licensed under the terms of the Creative Commons Attribution 4.0 International License (http:// creativecommons.org/licenses/by/4.0/), which permits use, sharing, adaptation, distribution and reproduction in any medium or format, as long as you give appropriate credit to the original author(s) and the source, provide a link to the Creative Commons licence and indicate if changes were made.
The images or other third party material in this chapter are included in the chapter's Creative Commons licence, unless indicated otherwise in a credit line to the material. If material is not included in the chapter's Creative Commons licence and your intended use is not permitted by statutory regulation or exceeds the permitted use, you will need to obtain permission directly from the copyright holder. 